

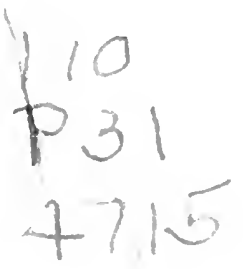

BOOK 170.P3 I c. 1

PEABODY \# MANUAL OF MORAL

PHILOSOPHY

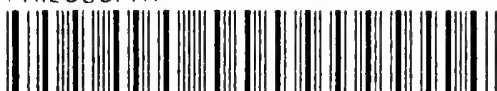

39153 0006дьट2 8 
This book may be kept out

\section{T W O WEEKS}

only and is subject to a fine of TWO CENTS

a day thereafter. It will be due on the day indicated below.

hisit b 1390

FE T 1929 


$$
\text { , }
$$





\section{A M A U A L}

n)

\section{MORAL PHILOSOPHY.}

DESIGNED FOR

COLLEGES AND HIGH SCHOOLS.

BY

\section{ANDREW P. PEABODY, D.D., LL.D.,}

PLCMMRR PROTZESOR OT CBRISTIAN MORALS IN BARTARD UNIVRESITY.

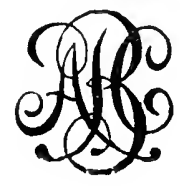

NEW YORK $\cdot: \cdot$ CINCINNATI $\cdot: \cdot$ CHICAGO

AMERICAN BOOK COMPANY 
Copyright, 1873 , by A. S. Bar Nes \& Co.

4. 2 


\section{PREFACE.}

THE author has endeavored in this treatise to comprehend all that is essential in a manual of ethics, with a view equally to precision and to conciseness. He has not thought it necessary to controvert views other than his own; for conflicting opinions are apt to bewilder rather than to enlighten those who are not adepts in the science, and it is better to supersede false theories by the clear statement of the truth than to enter into their formal refutation. Thus, for instance, as regards utilitarianism, instead of exposing the fallacies of its sereral types, the attempt has been made (in Chapter III.) to set them aside by assigning to expediency its legitimate secondary place as a principle of action.

Among the author's chief motives in the preparation of this manual has been his desire to gire emphasis to his view of the ground of Right, as consisting in intrinsic fitness, independent of any will or arbitrary law human or divine, and essential as furnishing the only standard by which we can attain a knowledge of the Divine attributes. The ground of Right is the basis of Moral Philosophy, and must of necessity determine the validity and worth of the system built upon it.

Next in importance to this is the classification of the virtues which constitute the Right. Here it is not sufficient to enumerate the prominent traits which enter in to a good character. 'I'he division should be exhaustive, and in this treatise the four cardinal virtues are so defined as to embrace the whole of human duty, and so 
divided, it is believed, as to give its due place to erery head of moral obligation.

Another prominent aim in this book has been to present the Christian religion and morality in their true relations, as at once mutually independent, and in the most intimate and helpful alliance, iuasmuch as Christianity creates some classes of obligations, reveals others, intensifies all, and furnishes the only motive power that can insure their fulfilment.

It is believed that such value as this book may have is enhanced by the chapters on the history of Moral Philosophy, especially as there is no compend of this history that is likely to fall into the hands of the student; while it is of no little importance that he should have some aequaintance with the principal ethical theories of the ancient world, and that such names as Cudworth, Clarke, Butler, Price, Paley and Bentham should not remain wholly unknown.

This book was originally prepared for the anthor's own classes, because, while acknowledging the great merits of other manuals. he found none that presented its range of subjects in what scemed to him their due perspective and relations, and because some of them, otherwise excellent, lacked conciseness and comprehensireness. His use of the manual as a text-book for sereral years, and assurances received from experienced teachers in schools and colleges who have made use of it, have given him a confidence in its teaching power which he dared not to express or to feel when it first silw the light.

C'AMBRIDGE, January 17, 1884. 


\section{CONTENTS.}

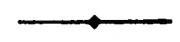

CHAPTER I.

\section{CHAPTER $\boldsymbol{\Pi}$.}

The Springs of Action $\cdot$. $\quad . \quad \cdot \quad \cdot \quad \cdot \quad \cdot \quad \cdot 10$

Section I. The Appetites . . . . . . 10

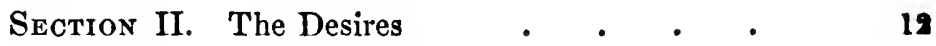

Section III. The Affections . $\quad . \quad$. $\quad$ • $\quad$, 22

CHAPTER III.

The Governing Principles of Action . . . . 30

\section{CHAPTER IV.}

Tre Right .

\section{CHAPTER V.}

Means and Sources of Krowledge as to Right and

Wrong. . . * . . . . . . . 41

Section I. Conscience . , . 4 . 41

Section II. Sources of Knowledge. 1. Ubservation, Experience, and Tradition . . . . . 46

Section III. Sources of Knowledge. 2. Law - 50

Section IV. Sources of Knowledge. 3. Christianity 55 
CHAPTER VI.

Rights and Obligations

61

CHAPTER VII.

Motive, Passion, and Habit . .

CHAPTER VIII

Virtue, and the Virtees

88

CHAPTER IX.

Prudence; or, Duties to One's Self . . . . 98

Section I. Self-Preservation . . . . . . 99

Section II. The Attainment of Knowiedge . . 102

Section III. Self-Control . • . . • 106

Section IV. Moral Self-Culture . . . . . 109

CHAPTER $\mathbf{X}$.

Justice; OR, Duties to ONe's Fellow-Beings . . . 113

Section I. Duties to God . . . . . . 113

Section II. Duties of the Family . . . . . 118

Section III. Veracity.$\quad \cdot \quad \cdot \quad \cdot \quad \cdot \quad \cdot 122$

Section IV. Honesty . • . . . . 134

Section V. Beneficence . . . . . 143

CHAPTER XI.

Fortitude; or, Duties witil reference to unatoidable

Erils and Stfferivgs . . . . . . . . 151

Section I. Patience . . . . . . . 152

Section II. Submission. . . . . . . 156

Section III. Courage $. \quad . \quad . \quad . \quad . \quad .158$ 


\section{CHAPTER XII.}

Order; or, DUties as to Objects under oUt owy Con-

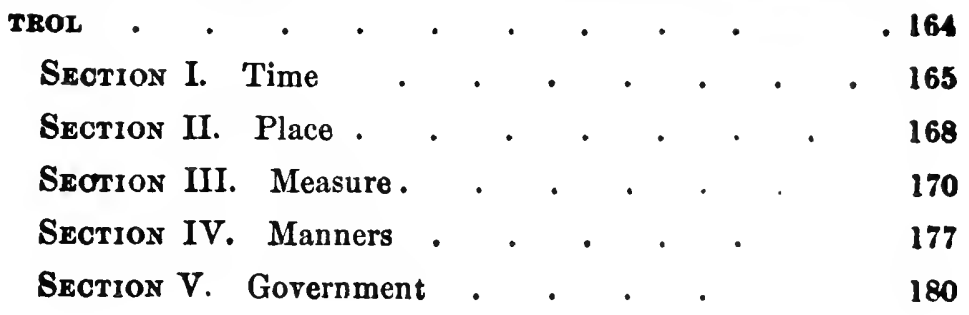

\section{CHAPTER XIII.}

Casuistry

\section{CHAPTER XIV.}

Ancient History of Moral Philosophy

CHAPTER XV.

Modern History of Moral Philosophy . . , 207 
. 


\section{A MANUAL}

\section{OF \\ MORAL PHILOSOPHY.}

CHAPTER 1 .

ACTION.

$\mathrm{A}^{\mathrm{N}}$ act or action is a voluntary exercise of any power of body or mind. The character of an action, whether good or bad, depends on the intention of the agent. Thus, if I mean to do my neighbor a kindness by any particular act, the action is kind, and tharefore good, on my part, even though he derive su benefit from it, or be injured by it. If I mean to do my neighbor an injury, the action is unkind, and therefore bad, though it do him no harm, or though it even result to his benefit. If I mean to perform an action, good or bad, and am prevented from performing it by some unforeseen hindrance, the ast is as truly mine as if I liad performed it. Words which have any meaning are actions. So are thoughts which we purposely call up, or retain in the mind.

On the other hand, the actions which we are compelled to perform against our wishes, and the thoughts which are forced upon our minds, without 
our own consent, are not our actions. This is obvlously true when our fellow-men forcibly compel us to do or to hear things which we do not wish to do or to hear. It is their action solely, and we have no more part in it than if we were brute beasts, or inanimate objects. It is, then, the intention that gives character to the action.

That we commonly do what we intend to do there can be no doubt. We do not act under immediate compulsion. We are, therefore, free agents, or actors. But are our intentions free? Is it in our power to will otherwise than we will? When we choose to perform an act that is just or kind, is it in our power to choose to perform an act of the opposite character? In other words, is the will free? If it be not so, then what we call our intentions are not ours, but are to be attributed to the superior will which has given direction to our wills. If Grod has so arranged the order of nature and the course of events as to force my will in certain direations, good or evil, then it is He that does the good or evil which I seem to do. On this supposition God is the only agent or actor in the universe. Evil, if it be wrought, is wrought by Him alone; and if we cannot admit that the Supreme Being does evil, the only alternative is to deny the existence of evil, and to maintain that what we call evil bears an essential part in the production of good. For instance, if the horrible enormities imputed to Nero were utterly bad, the evil that was in them is chargeable, not on Nero, but on God; or if it be 
Inaintained that God cannot do evil, then Nero was an instrument for the advancement of human happiness and well-being.

What reasons have we for believing that the human will is free?

1. We have the direct evidence of consciousness. We are distinctly conscious, not only of doing as we choose, but of exercising our free choice among different objects of desire, between immediate and future enjoyment, between good and evil. Now, though consciousness may sometimes deceive us, it is the strongest evidence that we can have; we are so constituted that we cannot refuse our credence to it ; and our belief in it lies at the basis of all evidence and of all knowledge.

2. We are clearly conscious of merit or demerit, of self-approval or self-condemnation, in consequence of our actions. If our wills were acted upon by a force beyond our control, we might congratulate or pity ourselves, but we could not praise or blame ourselves, for what we had done.

3. We praise or blame others for their good or evil actions; and in our conduct toward them we show that we believe them to have been not merely fortunate or unfortunate, but praiseworthy or blameworthy. So far as we suppose their wills to have been influenced by circumstances beyond their control, we regard them with diminished approval or censure. On the other hand, we give the highest praise to those who have chosen the good amidst 
strong temptations to evil, and bestow the severest censure on those who have done evil with virtuous surroundings and influences. Now our judgment of others must of necessity be derived from our own consciousness, and if we regard and treat them as freely willing beings, it can only be because we know that our ow $r$ wills are free.

These arguments, all derived from consciousness, can be directly met only by denying the validity of consciousness as a ground of belief. The opposing arguments are drawn from sources independent of consciousness.

1. The most obvious objection to the freedom of the human will is derived from the power of motives. It is said, We never act without a motive; we always yield to the strongest motive; and motives are not of our own creation or choice, but are brought to bear upon us independently of our own action. There has been, from the creation until now, an unbroken series of causes and effects, and we can trace every human volition to some anterior cause or causes belonging to this inevitable series, so that, in order for the volition to have been other than it was, some member of this series must have been displaced.

To this it may be answered :-

(a) We are capable of acting without a motwve, and we do so act in numberless instances. It was a common saying among the Schoolmen, that an ass, at equal distances from two equal bundles of hay, 
wculd starve to death for lack of a motive to choose either. But have we any motive whatever in the many cases in which we choose - sometimes after the vain endeavor to discover a ground of preference between two equally valuable, beautiful, or appetizing objects, between two equally pleasant routes to the same terminus, or between two equally agreeable modea of passing a leisure day or hour? Yet this choice, made without motive, may be a fruitful cause of motives that shall have a large influence in the future. Thus, on the route which one chooses without any assignable reason, he may encounter persons or events that shall modify his whole plan of life. The instances are by no means few, in which the most decisive results have ensued upon a choice thus made entirely without motive.

(b) Motives of equal strength act differently on different temperaments. The same motive, when it stands alone, with no opposing motive, has not the same effect on different minds. There is in the will of every human being a certain reluctance to action - in some greater, in others less - corresponding to the vis inertice in inanimate substances; and as the impulse which will move a wooden ball may not suffice to move a leaden ball, so the motive which will start into action a quick and sensitive temperament, may produce no effect on a person of more sluggish nature. Thus, among men utterly destitute of honesty, some are tempted by the most paltry opportunities for theft or fraud; others, not one whit more 
scrupulous, have their cupidity aroused only by tho prospect of some substantial gain. So, too, some sincerely benevolent persons are moved to charitable actions by the slightest needs and sufferings; others, equally kind and generous, have their sympathies excited only on grave occasions and by imperative claims. Motives, then, have not a determinate and calculable strength, but a power which varies with the previous character of the person to whom they are addressed. Moreover, the greater or less suscep. tibility to motives from without is not a difference produced by education or surroundings; for it may be traced in children from the earliest development of character. Nor can it be hereditary; for it may be found among children of the same parents, and not infrequently between twins nurtured under precisely the same care, instruction, and discipline.

(c) External motives are not the causes of action, but merely its occasions or opportunities. The cause of the action already exists in the character of the agent, before the motive presents itself. A purse of gold that may be stolen without detection is an irresistible motive to a thief, or to a person who, though not previously a thief, is covetous and unprincipled; but the same purse might lie in the way of an honest man every day for a month, and it would not make him a thief. If I recognize the presence of a motive, I must perform some action, whether exterior or internal; but whether that action will be in accordance with the motive, or in the opposite diren- 
tion, is determined by my previous character and habits of action.

(d) The objection which we are considering assumes, without sufficient reason, that the phenomena of human action are closely analogous to those of motion in the material world. The analogy fails in several particulars. No material object can act on itself and change its own nature, adaptations, or uses, without any external cause ; but the human mind can act upon itself without any external cause, as in repentance, serious reflection, religious purposes and aims. Then again, if two or more forces in different directions act upon a material object, its motion is not in the direction of either, or with the momentum derived from either, but in a direction and with a momentum resulting from the composition of these forces; whereas the human will, in the presence of two or more motives, pursues the direction and yields to the force of but one of those motives. We are not, then, authorized to reason about the power of motives from the action of material forces.

(e) Were the arguments against the freedom of the will logically sound and unanswerable, they would be of no avail against the testimony of consciousness. Axioms, intuitive beliefs, and truths of consciousness can be neither proved nor disproved by reasoning; and the reasoning by which they seem to be lisproved only evinces that they are beyond the range and reach of argument. Thus it may be main- 
tained with show of reason that motion is impossible; for an object cannot move where it is, and cannot move where it is not, - a dilemma which does not disprove the reality of motion, but simply indicates that the reality of motion, being an intuitive belief, neither needs nor admits logical proof.

2. It is urged against the freedom of the human will that it is inconsistent with God's foreknowledge of future events, and thus represents the Su preme Being as not omniscient, and in that particular finite and imperfect.

To this objection we reply:-

(a) If human freedom and the Divine foreknowledge of human acts are mutually incompatible, we must still retain the freedom of the will as a truth of consciousness; for if we discredit our own consciousness, we cannot trust even the act of the understanding by which we set it aside, which act we know by the testimony of consciousness alone.

(b) If the acts of a freely willing being cannot be foreknown, the ignorance of them does not detract from the perfectness of the Supreme Being. Omnipotence cannot make two and two five. Omnipotence cannot do what is intrinsically impossible. No more can Omniscience know what is intrinsically unknowable.

(c) If God's foreknowledge is entire, it must include his own acts, no less than those of men. If his foreknowledge of men's acts is incompatible with their freedom, then his foreknowledge of his 
own acts is incompatible with his own freedom. We have, therefore, on the theory of necessity, instead of a Supreme Will on the throne of the universe, mere fate or destiny. This is equivalent to the denial of a rersonal God.

(d) It cannot be proved that God's foreknowledge and man's free will are incompatible with each other. The most that we can say is that we do not fully see how they are to be reconciled, which is the case with many pairs of undoubted truths that might be named. But while a perfect explanation of the harmony of the Divine foreknowledge and human freedom is beyond the scope of our faculties, we may explain it in part, from our own experience. Human foreknowledge extends very far and with a great degree of certainty, without abridging the freedom of those to whom it relates. When we can foresee outward events, we can often foretell, with little danger of mistake, the courses of conduct to which they will give rise. In view of the extent and accuracy of human foresight, we cannot pronounce it impossible, that $\mathrm{He}$ who possesses antecedent knowledge of the native constitution of every human being, and of the shaping circumstances and influences to which each being is subjected, may foreknow men's acts, even though their wills be entirely free. 


\section{CHAP'TER II.}

\section{THE SPRINGS OF ACTION.}

THERE are certain elements of the human consti1 tution, in part natural, in part acquired, which always prompt and urge men to action, without reference to the good or evil there may be in the action, and without reference to its ultimate effect: on the actor's well-being. These are the Appetites, the Desires, and the Affections.

\section{SECTION 1.}

THE APPETITES.

The Appetites are cravings of the body, adapted, and undoubtedly designed, to secure the continued life of the individual and the preservation of the species. They are common to mian with the lower orders of animals, with this difference, that in man they may be controlled, directed, modified, in part suppressed, while in brutes they are uncontrollable, and always tend to the same modes of gratification.

Appetite is intermittent. When gratified, it ceases for a time, and is renewed for the same person nearly at the same intervals, and under similar circumstances. It is, while it lasts, an uneasy, even a painful sensation, and therefore demands prompt relief, and leads 
to action with a view to such relief. It is also a characteristic of appetite that its indulgence is attended, not merely by relief, but by positive pleasure.

The appetites are essential to the well-being of men, individually and collectively. Were it not for the pain of hunger and thirst, and the pleasure of gratifying them, both indoleuce and engrossing industry would draw off the attention of men from their bodily needs; nourishment would be taken irregu. larly, and with little reference to quality; and one would often become aware of his neglect only too late to arrest its consequences. A similar remark applies to the appetite designed to secure the preservation of the species. But for this, it may be doubted whether men would willingly take upon themselves the cares; labors, responsibilities, and contingent disappointments and sorrows involved in the rearing of children.

In a life conformed to nature, hunger and thirst recur only when the body actually needs the supply which they crave. But stimulating food, by the reaction that follows strong excitement of any portion of the nervous system, may create hunger when there is no need of food, and in like manner not only intoxicating, but highly stimulating liquids, may occasion an excessive, morbid, and injurious thirst.

Appetite is modified by habit. There is hardly any substance so offensive that it may not by use become agreeable, then an object of desire, and, at length, of intense craving. 
The craving for repose and that for muscular action, though not classed among the appetites, have all their characteristics, and serve similar ends in the eronomy of human life. After a certain period of activity, rest is felt as a bodily necessity, as food is, after long fasting; and in like manner, when the wearied muscles have bad their due repose, there is an irresistible tendency to their exercise, without reference to any special employment or recreation. It is by the alternation of these tendencies that the active and industrious are saved from the ruinous consequences of overtasked limbs or brain, and that the indolent are urged to the reluctant activity without which health and life itself would be sacrificed.

The appetites, being mere bodily impulses, and being all liable to excess or misdirection, need the control of the will, and of the principles of action by which the will is determined and regulated.

\section{SECTION $\Pi$.}

THE DESIRES.

The Desires are distinguished from the Appetites, first, in their not originating from the body ; secondly, in their not being necessarily intermittent; and thirdly, in their tendency to increase indefinitely, often through the whole of life, and to gain strength by the attainment of their specific objects. If classified by their objects, they might seem too numerous to be specified: but they may all be embraced under the 
titles of the Desire for Knowledge, for Society, for Esteem, for Power, and for Superiority. These all may be traced, in a more or less rudimentary form, in the $i$ iferior animals. Many of these animals show an active curiosity. Many are gregarious in their native state, and most of the domestic animals delight in the society of their kind; some take manifest pleasure in human society; and the instances are by no means rare, in which animals, by nature mutually hostile, bocome strongly attached to each other, and render to each other the most friendly serrices. The dog, the horse, and the cat evidently crave the esteem of human beings, and show tokens of genuine grief when they incur rebuke or discern tokens of disapproval. The dog maintains with watchful jealousy his own authority in his own peculiar domain; and in the chase or on the race-ground the dog and the horse are as emulous of success as their masters.

1. The Desire of Knowledge. This in the buman being is manifested with the earliest dawn of intelligence. The infant is busy with eye and hand throughout his waking hours; and that the desire of knowledge is innate, and has no reference to the use that is to be made of the things known, is manifest from the rapid growth of knowledge in the first years of life, before the child has any distinct conception of the uses of objects, or any corıscious capacity of employing them for his own benefit. It may be doukted whether in any subsequent year of life so much knowledge is acquired as during the first year. The 
child but a year old has learned the nature of the familiar objects of the house and the street, the faces and names of a large number of relatives, domestics, and acquaintances, the regular succession of seasons ana events in daily domestic life, and the meanings of most of the words that are addressed to him or employed concerning him and the objects around him. In more advanced life this desire grows by what it feeds on, and never ceases to be active. It assumes, indeed, different directions, in part determining, and in part determined by, condition, profession, or employment. Even in the most idle and frivolous, it is strong, often intense, though its objects be worthless. Such persons frequently are as sedulous in collecting the paltry gossip of society as the naturalist in acquiring the knowledge of new species of plants or insects, and as ingenious in their inferences from what they see and hear as the philosopher in his inductions from the facts of science.

Not only in infancy, but through life, knowledge is sought evidently for its own sake, and not merely for its uses. But a very sinall part of what one knows can be made of practical utility as to his own comfort or emolument. Many, indeed, voluntarily sacrifice ease, gain, position, in the pursuit of science or literature. Fame, if it accrues, is not unwelcome; but by the higher order of minds fame is not pursued as an end, and there are many departments of knowledge in which little or no reputation is to be attained. Then, too, it is not the learner, 
but the teacher, not the profound scholar, merely, but the able expositor, speaker, or writer, who can expect a distinguished name; while there are many who content themselves with acquiring knowledge, without attempting publicity. Nor yet can benevolence account for the love of knowledge. Many, indeed, make their attainments the property of others, and are zealous in diffusing their own scientific views, or in dispensing instruction in their own departments. But there are also many solitary, recluse students; and it may be doubted whether, if a man who is earnestly engaged in any intellectual pursuit were shut out entirely from human society, and left alone with his books or with nature, his diligence would be relaxed, or his ardor abated.

2. The Desire of Society. This, also, is man1fested so early as to show that it is an original, and not an acquired principle. Little children dread solitude, crave the presence of familiar faces, and evince pleasure in the company of children of their orrn age. A child, reared in comparative seclusion and silence, however tenderly, suffers often in health, always in mental vigor and elasticity; while in a large family, and in intimate association with companions of his own age, the individual child has the fullest and most rapid development of all his powers. There is, indeed, in the lives of many children, a period when the presence of strangers is unwelcome; but this state of feeling - seldom of long duration - can in most instances be traced to some sudden tright, harsh voice, or imagined neglect or unkindness. 
The natural course of human life proves that man is by the necessity of his nature a social being. The young of other animals are at a very early period e:uuncipated and forsaken by their parents, while the human child has many years of dependence, and is hardly prepared to dispense with the shelter and kind offices of his native home, when he is moved to create in new home of his own.

There is no pursuit in life in which a community of interest fails to give added zest and energy. There is no possible ground of association on which societies are not formed, and the trivial, fictitious, or imaginary pretences on which men thus combine, meet, and act in concert, are manifest proofs of a social proclivity so strong as to create reasons for its indulgence where such reasons do not already exist. Even in science and in the most abstruse forms of erudition, men of learning seek mutual countenance and encouragement, and readily suspend their solitary research and study for the opportunity of intercommunication on the subjects and objects of their pursuit. The cases in which society is voluntarily shunned or forsaken are as rare as the cases of congenital disease or deformity; and for every such instance there may generally be assigned some grave, if not sufficient, cause. Religious asceticism has, indeed, induced many persons, especially in the early Christian ages, to lead a solitary life; but the cœnobites have always vastly ontnumbered the hermits; monasteries (solitary abodes) have become convents (assemblages); and those who 
are shut out from the rest of the world find comfort in social devotion, in the common refectory, and in those seasons of recreation when the law of silence is suspended. For prisoners solitary confinement has been found deleterious both to body and mind, and this system, instituted with philanthropic purpose. and rommended on grounds that seemed intimatcly connected with the reformation of the guilty, is now generally repudiated as doing violence to human nature. Even for the insane, society, with judicious classification and restriction, is an essential part of curative treatment, and the success of asylums, as compared with the most skilful and humane private treatment, is due in great part to the social element.

It cannot be maintained that the desire of society results from fear, and from the felt need of mutual protection; for it exists in full at the most fearless periods of life, and among those who are the least timid, and is equally manifest in the strong and the weak, in those who can proffer and in those who might crave protection.

3. The Desire of Esteem. It is almost superfluous to say that this is a native and indestructible element of the human constitution. Its first manifestations bear even date with the earliest displays of intelligence and affection. To the infant, approval is reward ; rebuke, even by look, is punishment. The hope of esteem is the most healthful and effective stimulant in the difficult tasks of childhood and of school-life, Under the discipline of parents both 
wise and good, it is among the most important and salutary means of moral discipline. It is seldon deficient in young persons. Their chict danger lies in its excess ; for when it is too strongly developed, it inclines them to seek at all bizards the approval of their associates for the time being. Hence the chief danger from vicious or unscrupulous associates. The first steps in vice are oftener prompted, no doubt, by the desire for the complacent regard of one's companions than by an antecedent disposition to evil. Indeed, the confession is often made, that these steps were taken with compunction and horror, solely from the fear of ridicule and from the desire to win the approval and faror of older transgressors.

On the other hand, the desire of the esteem of good men is one of the strongest auxiliary motives to virtue; while a yearning for the Divine approval forms an essential part of true piety towards God.

4. The Desire of Power. This is manifested in every period of life, and in the exercise of every faculty, bodily, mental, and moral. It is this which gives us pleasure in solitary exercises of physical strength. in climbing mountains, swimming, lifting heavy weights, performing difficult gymnastic feats. It is this, more than deliberate cruelty, that induces boys to torture animals, or to oppress and torment their weaker or more timid companions.

In intellectual pursuits, the love of power leads to many exercises and efforts that have no ulterior result. The mathematician will turn aside from his 
course of study to master a problem, which involves no new principle, but is mere $y$ difficult and perplexing. The reading of books obscurely written, or in languages that task the utmost power of analysis, frequently has no other result, and probably no other object, than the trial of strength. What can be at. tained only by strenuous mental labor, is for that very reason sought, even if it promise no utility.

In the affairs of practical life, every man desires to make his influence felt. With persons of the highest character, the love of power is manifest in connection with the aim to be useful. Even the most modest. men, while they may spurn flattery, are gladdened by knowing that they are acting upon the wills and shaping the characters of those around them.

The love of property belongs in great part under this head. Money is power, preëminently so at the present day. Property confers influence, and puts at one's command resources that may be tue means of extended and growing power alike over inanimate nature and the wills of men. Avarice, or the desire of money for its own sake, is not an original desire. Few or none are avaricious in very early life. But money, first sought for the power it confers, from being a means becomes an end, to such a degree that, in order to possess it, the miser will iorego the very uses for which he at the outset learned to value it.

5. The Desire of Superiority. This is so nearly universal in all conditions of society, and at all periods 
of life, that it must be regarded as an original element of human nature. Without it there would be little progress. In every department of life, men stimulate one another toward a higher standard of endeavor, attainment, or excellence. What each does, his neighbor would fain outdo; what each becomes, his neighbor would fain surpass. It is only by perversion that this desire tends to evil. It finds its proper satisfaction, not in crushing, depressing, or injuring a rival, but barely in overtaking and excelling him; and the higher his point of attainment, the greater is the complacency experienced in reaching and transcending it. On the race-ground, I do not want to compete with a slow rumner, nor will it afford me the slightest satisfaction to win the race by trip ping up my competitor; what I want is to match myself with the best runner on a fair field, and to show myself his equal or superior. The object striven for is the individual's own ideal, and those whom he successively passes on his course mark but successive stages on his progress toward that ideal. Thus, in the pursuit of moral excellence, it is only a mean and a bad man who can imagine that he gains anything by detracting from the merit of others; but he who is sincerely contending for a high place among virtuous men, rejoices in the signal examples of goodness of every kind which it is his privilege to emulate, and rejoices most of all that the ideal of perfect excellence - once only actualized in human form - is so pure and lofty that it may be his life-work to approach it without reaching it. 
Emulation is not envy, nor need it lead to enry. Among those who strive for superiority there need be no collision. The natural desire is to be, not to seem, superior; to have the consciousness, not the mere outward semblance, of high attainment; and of attainment, not by a conventional, but by an absolute standard; and this aim excludes none, - there may be as many first places as there are deserving candidates for them. Then, too, there is so wide a diversity of ideals, both in degree and in kind, there are so many different ruling aims, and so many different routes by which these aims are pursued, that there need be little danger of mutual interference. Even as regards external rewards, so far as they depend on the bounty of nature, the constitution of society, or the general esteem and good will of men, the success of one does not preclude the equal success of many; but, on the other hand, the merited prosperity and honor of the individual cannot fail to be of benefit to the whole community. It is only in offices contingent on election or appointment that the aspirant incurs a heavy risk of failure; but when we consider how meanly men are often compelled to creep into office and to grovel in it, it can hardly be supposed that a genuine desire of superiority holds a prominent place among the motives of those who are willingly dependent on patronage or on popular suffrage.

These desires, according as one or another has the ascendency, prompt to action, without reference to 
the good or the evil there may be in the action; and they therefore need the control of reason, and of the principles which reason recognizes in the government of conduct

\section{SECTION III.}

THE AFFECTIONS.

The Affections are distinguished from the Desires, mainly in these two particulars: first, that the Desires are for impersonal objects, the Affections, for persons; and secondly, that the Desires prompt to actions that have a direct reference to one's self; the Affections, to actions that have a direct reference to others.

The Affections are benevolent or malevolent.

1. The benevolent affections are Love, Reverence, Gratitude, Kindness, Pity, and Sympathy.

Love needs no definition, and admits of none. It probably never exists uncaused; though it survives all real or imagined ground for it, and in some cases seems rendered only the more intense by the admitted unworthiness of its object. When it is not the reason for marriage, it can hardly fail to grow from the conjugal relation between one man and one woman, if the mutual duties belonging to that relation be held sacred. It is inconceivable that a mother should not love her child, inevitably cast upon her protec:tion from the first moment of his being; the father who extends a father's care over his children finds in that care a constant source of love ; and the children, 
waking into conscious life under the ministries of parental benignity and kindness, have no emotion so early, and no early emotion so strong, as filial love. It may be doubted whether there is among the members of the same family a natural affection, independent of relations practically recognized in domestic life. It is very certain that at both extremities of the social scale family affection is liable to be impaired, on the one hand, by the delegation of parental duties to hirelings, and, on the other, by the inability to render them constantly and efficiently. We may observe also a difference in family affection, traceablo indirectly to the influence of climate. Out-of-door life is unfavorable to the intimate union of families; while domestic love is manifestly the strongest in those countries where the shelter and hearth of the common home are necessary for a large portion of the year.

Friendship is but another name for love between persons unconnected by domestic relations, actual or prospective.

Love for the Supreme Being, or piety, differs not in kind from the child's love for the parent; but it rightfully transcends all other love, inasmuch as the benetits received from God include and surpass all other benefits. To awake. then, to a consciousness of our actual relation to God, is " to love Him with all the beart, and with all the understanding, and all the soul, and all the strength."

Reverence is the sentiment inspired by advanced 
superiority in such traits of mind and character as we regard with complacency in ourselves, or with esteem in our equals. Qualities which we do not esteem we may behold with admiration (that is, wonder), but not with reverence. Our reverence for age is not for advanced years alone, but for the valuable experience which they are supposed to have given, and especially for the maturity of excellence which belongs to the old age of good men, of which their features generally bear the impress, and which, in the absence of knowledge, we are prone to ascribe to a venerable mien and aspect. A foolish or wicked old man com. mands no reverence by his years.

God, as possessing in infinite fulness all the proper ties which we revere in man, must ever be the worthy object of supreme reverence.

Gratitude, though it can hardly be disjoined from love, is seldom cherished for the same person in the same degree with love. We love our beneficiaries more than our benefactors. We love those dependent upon us more than those on whom we depend. The mother's love for her child is the strongest of human affections, and undoubtedly exceeds that even of the child for the mother to whom he owes every benefit and blessing under heaven. We may be fervently grateful to persons whom we have never seen; but there cannot be much vividness in nur love for them. Love to God, whom we have not seen, needs to be kindled, renewed, and sustained by gratitude for the incessant flow of benefits from Him, and by the 
promise - contingent on character - of blessings immeasurable and everlasting.

Kindness is benevolence for one's kind, - a delight in their happiness and well-being, a readiness to perform friendly offices whenever and however they may be needed. In its lower forms it is designated as good nature; when intense and universal, it is termed philanthropy. It befits the individual man as a member of a race of kindred, and is deemed so essential an attribute of the human character, that he who utterly lacks it is branded as inhuman, while its active exercise in the relief of want and suffering is emphatically termed humanity.

Pity is the emotion occasioned by the sight or knowledge of distress or pain. While without it there can be no genuine kindness, it may exist without kindness. There are persons tenderly sensitive to every form of suffering, who yet feel only for the sufferer, not with him, and who would regard and treat nim coldly or harshly, if he were not a sufferer. In such cases, pity would seem to be a selfish feeling; and there can be no doubt that some men relieve distress and poverty, as they would remove weeds from a flower-bed, because they are offensive to the sight.

Sympathy is feeling, not for, but with others. ${ }^{1}$ It has for its objects successes and joys, no less than sufferings and sorrows; and probably is as real and intense in the case of the former as of the latter,

1 Compasmon ought from its derivation to have the same meaning with maspathy; but in common usage it is synonymons with pity. 
though its necessity is less felt and its offices are less prized in happy than in sad experiences. Kindness alone cannot produce sympathy. In order to feel with another, we must either have passed through similar experiences, or must have an imagination sufficiently vivid to make them distinctly present to our thought. This latter power is by no means necessary to create even the highest degree of kindness or of pity; and among the most active and persevering in works of practical beneficence, there are many who feel intensely for, yet but faintly with, the objects of their charity. On the other hand, sympathy sometimes finds its chief exercise in sensational literature, and there are persons, profoundly moved by fictitious representations of distress, who yet remain inactive and indifferent as regards the real needs and sufferings around them that crave relief.

2. The malevolent affections are Anger, Resentment, Envy, Revenge, and Hatred.

Anger is the sense of indignation occasioned by real or imagined wrong. When excited by actual wrong-doing, and when contained within reasonable bounds, it is not only innocent, but salutary. It intensifies the virtuous feeling which gives it birth; and its due expression is among the safeguards of society against corruption and evil. But when indulged without sufficient cau:e, or suffered to become excessive or to outliast its occasion, it is in itself evil, and it may lead to any and every form of social injustice, and of outrage against the rights of man and the law of God. 
Resentment is the feeling excited by injury done to ourselves. This also is innocent and natural, when its occasion is sufficient, and its limits reasonable. It may prevent the repetition of injury, and the spontaneous tendency to it, which is almost universal, is an efficient defence against insult, indignity, and encroachment on the rights of individuals. But, indulged or prolonged beyond the necessity of selfdefence, it is prone to reverse the parties, and to make the injured person himself the wrong-doer.

Both anger and resentment are painful emotions, and on this account are self-limited in a well-ordered mind. He who makes happiness his aim will, if wise, give these disturbing forces the least possible hold upon him, whether in intensity or in duration.

Envy has been defined as the excess of emulation. It seems rather to be a deficiency in tle genuine principle of emulation. The instinctive desire of superiority leads us, as we have seen, to aim at absolutely high attainments, and to measure ourselves less by what others are, than by our own ideal. It is only those of lower aims, who seek to supplant others on their vareer. Envy is the attempt, not to rise or exsel, but to stand comparatively high by subverting those who luold or serk a higher position. No just man voted for the banislument of Aristides because he was always called the Just; but his ostracism was the decree of those who knew that they could obtain nn reputation for justice till he were put out of their way. 
Revenge is the desire to inflict evil for evil. In principle it is always wrong; for the evil-doer, though he may merit transient anger and resentment, is not therefore placed beyond our benevolence, but is rather commended to our charity as one who may wo reformed and may become worthy of our esteem. In practice, revenge can scarce ever be just. Our selflove so exaggerates our estimate of the wrong we receive, that we could hardly fail to retaliate by greater wrong, and thus to provoke a renewal of the injury. There are, no doubt, cases in which self-defence may authorize the immediate chastisement or disabling of the wrong-doer, and in an unsettled state of society, where there is no legal protection, it may be the right of individuals to punish depredation or personal outrage; but acts of this kind are to be justified on the plea of necessity, not of revenge.

Hatred is the result of either of the malevolent affections above named, when carried to excess, or suffered to become permanent. It precludes the exercise of all the benevolent affections. No man can rightfully be the object of hatred; for there is no man who has not within him some element or possibility of good, none who has not rights that should be respected, none who is not entitled to pity for his sufferings, and, still more, for his sins.

The affections, benevolent and malevolent, are common to man with lower animals. Love and hatred are manifested by all of them whose habits are 
open to our inspection; anger, by not a few ; gratitude, kindness, pity, sympathy, resentment, and revenge, by the more intelligent; envy, by those most completely domesticated; reverence, perhaps, by the dog towards his master.

The affections all prompt to action, and do not discriminate the qualities of actions. Hence they need the control and guidance of reason, and can safely be indulged only in accordance with the principles which reason recognizes as supreme in the conduct of life. 


\section{CHAPTER III.}

THE GOVERNING PRINCIPLES OF ACTION.

THE appetites, desires, and affections constitute the impelling force in all action. Were we not possessed of them, we should not act. There is no act of any kind, good or bad, noble or base, mental or bodily, of which one or another of them is not the proximate cause. They are also imperative in their demands. They crave immediate action, - the appetites, in procuring or using the means of bodily gratification ; the desires, in the increase of their objects; the affections, in seeking or bestowing their appropriate tokens or expressions, whether good or evil. Were there no check, the specific appetite, desire, or affection to which circumstances gave the ascendency for the time being, would act in its appropriate direction, until counteracted by another, brought into supremacy by a new series of crrcumstances. This is the case with brutes, so far as we can observe their nodes of action. Here, in man, reason intervenes, and takes cognizance of the tendencies and the qualities of actions.

Reason vonsiders actions under two points of view, - interest and obligation, - expediency and right. The questions which we inwardly ask concerning 
actions all resolve themselves into one of these, - Is the act useful or desirable for me? or, Is it my right or my duty? He who is wont to ask the former of these questions is called a prudent man; he who habitually asks the latter is termed a virtuous or good man. He who asks neither of them yields himself, after the manner of the brutes, to the promptings of appetite, desire, and affection, and thus far omits to exercise the reason which distinguishes him from the brutes.

There can be no doubt that expediency and right coincide. Under the government of Supreme Benevolence, it is impossible that what ought to be done should not conduce to the welfare of him who does it. But its beneficent results may be too remote for him to trace them, nay, may belong to a life beyond death, to which human cognizance does not reach: while what ought not to be done may promise substantial benefit so far as man's foresight extends. Then, too, it is at least supposable that there may be cases, in which, were they solitary cases. expediency might diverge from right, yet in which, because they belong to a class, it is for the interest of society and of every individual member of society that general laws should be obeyed. It is obvious also, that there are many cases, in which the calculation of expediency involves details too numerous and too complicated to be fully understood by a mind of ordinary discernment, while the same mind car clearly perceive what course of conduct is in accordance with the 
strict rule of right. Still farther, in a question of conduct in which appetite, desire, or affection is con cerned, we cannot take as calm and dispassionate a view of our true interest, as we should of the interest of another person in like case. The impelling force may be so strong, that for the time being we sincerely regard it as expedient - though we know that it is not right - to yield to it.

For these reasons there is an apparent conflict between the useful and the right. Though a perfectly wise and dispassionate man might give precisely the same answer in every instance to the question of interest and that of duty, men, limited and influenced as they are, can hardly fail in many instances to answer these questions differently. The man who makes his own imagined good his ruling aim does many things which he would not defend on the ground of right; the man who determines always to do right sometimes performs acts of reputed and conscious selfdenial and self-sacrifice.

Nor yet can more general considerations of expediency, reference to the good of others, to the greatest good of the greatest number, serve as a guide to the right or a test of the right. We have less foresight as regards others than as regards ourselves; the details involved in the true interest of any community, society, or number of persons, are necessarily more numerous and complicated than those involved in our own well-being; and, if not appetite or desire, the benevolent or malevolent affertions are fully as apt to 
warp our judgment and to misdirect our conduct in the case of others as in our own case.

We perceive then that expediency, whether with reference to ourselves or to others, is not a trustworthy rule of conduct. Yet while it cannot hold the first place, it occupies an important place; for there are many cases in which the question before us is not what we ought to do, but what it is best for us to do. Thus, if there be several acts, all equally right, only one of which can be performed, we are evidently entitled to perform the act which will be most pleasing or useful to ourselves. If there be an end which it is our right or duty to attain, and there be several equally innocent modes of attaining it, the question for us is, by which of these modes we may find the least difficulty or gain the highest enjoyment or advantage. If there be several duties incumbent upon us at the same time and place, all of which have equal intrinsic claims, yet one of which must necessarily take precedence of the rest, the question which shall have precedence is a question of expediency, that by which we may do the most good being the foremost duty.

Expediency is not a characteristic of actions. An act is not in itself expedient or inexpedient, but is made one or the other by varying circum. stances alone; while there are acts in themselves good which no possible circumstances could make bad, and there are acts in themselves bad which no possible circumstances conld make good. If, therefore, 
there be a science which has for its province the intrinsic qualities of actions, questions of expediency have no place in such a science.

Moral Philosophy or Ethics (synonymous terms), is the science which treats of human actions. The term morals is often applied to external actions; but always with reference to the intentions from which they proceed. We can conceive of the treatment of actions under various aspects, as wise or unwise, agreeable or disagreeable, spontaneous or deliberate; but by the common consent of mankind, at least of the civilized and enlightened portion of mankind, the distinction of actions as right or wrong is regarded as of an importance so far transcending all other distinctions, as to render them of comparatively little moment. Therefore Moral Philosophy confines itself to this single distinction, and takes cognizance of others, only as they modify this, or are modified by it. The questions which Moral Philosophy asks and answers are these:- What constitutes the right? How is it to be ascertained? Wherein lies the obligation to the right? What are the motives to right action? What specific actions, or classes of actions are right, and why? What specific actions, or classes of actions are wrong, and why? 


\section{CHAPTER IV.}

THE RIGHT.

W Ver object, by virtue of its existence, has its
appropriate place, purpose, uses, and relations. At every moment, each specific object is either in or out of its place, fulfilling or not fulfilling its purpose, subservient to or alienated from its uses, in accordance or out of harmony with its relations, and therefore in a state of fitness or unfitness as regards other objects. Every object is at every moment under the control of the intelligent will of the Supreme Being, or of some finite being, and is by that will maintained either in or out of its place, purpose, uses, or relations, and thus in a state of fitness or unfitness with regard to other objects. Every intelligent being, by virtue of his existence, bears certain definite relations to outward objects, to his fellow-beings, and to his Creatcr. At every moment, each intelligent being is either faithful or unfaithful to these relations, and thus in a state of fitness or unfitness as regards outward objects and other beings. Thus fitness or unfitness may be affirmed, at every moment, of every object in existence, of the volition by which each object is controlled, and of every intelligent being, with regard to the exercise of his will toward or upon outward 
objects or his fellow-beings. Fitness and unfitness are the ultimate ideas that are involved in the terms right and wrong. These last are metaphorical terms, - right (Latin, rectus), straight, upright, according to rule, and therefore fit; wrong, wrung, distortied, deflected, twisted out of place, contrary to rule, and therefore unfit. We are so constituted that we cannot help regarding fitness with complacency and esteem ; unfitness, with disesteem and disapproval, even though we ourselves create it or impersonate it.

Fitness is the only standard by which we regard our own actions or the actions of others as good or evil, - by which we justify or condemn ourselves or others. Duty has fitness for its only aim and end. To whatever object comes under our control, its fit place, purpose, uses, and relations are due ; and our perception of what is thus due constitutes our duty, and awakens in us a sense of obligation. To ourselves, and to other beings and objects, our fidelity to our relations has in it an intrinsic fitness; that fitness is $d u e$ to them and to ourselves; and our perception of what is thus due constitutes our duty, and awakens in as a sense of obligation.

Right and wrong are not contingent on the knowledge of the moral agent. Unfitness, misuse, abuse, is none the less intrinsically wrong, because it is the result of ignorance. It is out of harmony with the fitness of things. It deprives an object of its due use. It perverts to pernicious results what is salutary in its purpose. It lessens for the agent his 
aggregate of good and of happiness, and increases for him his aggregate of evil and of misery. In this sense - far more significant than that of arbitrary infliction - the well-known maxim of jurisprudence, "Ignorance of the law excuses no one,"1 is a fundamental law of nature.

There is, however, an important distinction between absolute and relative right. In action, the absolute right is conduct in entire conformity with beings and objects as they are; the relative right is conduct in accordance with beings and objects as, with the best means of knowledge within our reach, we believe them to be. The Omniscient Being alone can have perfect knowledge of all beings and things as they are. This knowledge is possessed by men in different degrees, corresponding to their respective measures of intelligence, sagacity, culture, and personal or traditional experience. In the ruder conditions of society, acts that seem to us atrociously wrong, often proceed from honest and inevitable misapprehension, are right in their intention, and are therefore proper objects of moral approbation. In an advanced condition of in. telligence, and especially under high religious culture, though the realm of things unknown far exceeds that of things known, there is a sufficiently clear understanding of the objects and relations of ordinary life to secure men against sins of ignorance, and to leave in their wrong-doing no semblance or vestige of right. The distinction between absolute and relative right 1 "Ignorantia .egis neminem excusat." 
enables us to reconcile two statements that may have seemed inconsistent with each other, namely, that " the character of an action, whether good or bad, depends on the intention of the agent," and "that unfitness, misuse, abuse, is none the less wrong because the result of ignorance." Both these propositions are true. The same act may be in intent right and good, and yet, through defect of knowledge, wrong and evil; and it may, in virtue of its good intent, be attended and followed by beneficent results, while at the same time the evil that there is in it may be attended or followed by injurious consequences. We may best illustrate this double character of actions by a case so simple that we can see through it at a single glance. I will suppose that I carry to a sick person a potion which I believe to be an efficient remedy, but which, by a mistake for which I am not accountable, proves to be a deadly poison. My act, by the standard of absolute right, is an unfitting and therefore a wrong act, and it has its inevitable result in killing the patient. But because my intention was right, I have not placed myself in any wrong relation to God or man. Nay, if I procured what I supposed to be a healing potion with care, cost, and trouble, and for one whose suffering and need were his only claim upon me, I have by my labor of love brought myself into an even more intimate relation, filial and fraternal, with God and man, the result of which musi be my enhanced usefulness and happiness. If on the other hand I had meant to poison the man, but had by 
mistake given him a healing potion, my act would have been absolutely right, because conformed to the fitness of things, but relatively wrong, because in its intention and purpose opposed to the fitness of things; and as in itself fitting, it would have done the sick inan good, while, as in its purpose unfitting, it would have thrown me out of the relations in which $I$ ought to stand both with God and man.

Mistakes as to specific acts of duty bear the closest possible analogy to the case of the poison given for medicine. The savage, who sincerely means to express reverence, kindness, loyalty, fidelity, may perform, in the expression of those sentiments, acts that are utterly unfitting, and therefore utterly wrong; and if so, each of these acts produces its due consequences, it may be, baleful and lamentable. Yet because he did the best he knew in the expression of these sentiments, he has not sunk, but risen in his character as a moral being, - has become better and more capable of good.

Ignorance of the right, however, is innocent, only when inevitable. At the moment of action, indeed, what seems to me fitting is relatively right, and were I to do otherwise, even though my act were absolutely right, it would be relatively wrong. But if I have had and neglected the means of knowing the right, 1 have violated the fitnesses of my own nature by not employing my cognitive powers on subjects of vital importance to my well-being. In this case, though 
what are called the sins of ignorance may be mistakes and not sins, the ignorance itself has all the characteristics that attach themselves to the term sin, and must be attended with proportionally harmful consequences to the offender. 


\section{CHAPTER V.}

MEANS AND SOURCES OF KNOWLEDGE AS TO RIGHT AND WRONG.

\section{SEC'TION I.}

\section{CONSCIENCE.}

YONSCIENCE is a means, not a source, of knowledge. It is analogous to sight and hearing. It is the power of perceiving fitness and unfitness. Yet more, it is consciousness, - a sense of our own per sonal relation to the fitting and the unfitting, of our power of actualizing them in intention, will, and conduct. It is in this last particular that man differs from the lower animals. They have an instinctive perception of fitness, and an instinctive impulse to acts befitting their nature. But no brute says to himself, "I am acting in accordance with the fitness of things;" while man virtually says to himself, in every act, "I am doing what it is fit for me to do," or, "I am doing what it is unfitting for me to do."

Conscience is a judicial faculty. Its decisions are based upon such knowledge as the individual has, whether real or imagined, and from whatever source derived. It judges according to such law and evidence as are placed before it. Its verdict is always 
relatively right, a genuine verdict (verum dictum), though, by the absolute standard of right, it may be wrong, through defect of knowledgre, - precisely as in a court of law an infallibly wise and incorruptibly just judge may pronounce an utterly erroneous or unjust decision, if he have before him a false statement of facts, or if the law which he is compelled to administer be unrighteous.

We may illustrate the function of conscience by reference to a question now agitated in our community, - the question as to the moral fitness of the moderate use of fermented liquors. In civilized society, intoxication is universally known to be opposed to the fitnesses of body and mind, an abuse of alcoholic liquors, and an abuse of the drinker's own personality ; and it is therefore condemned by all consciences, by none more heartily than by those of its victims. But there still remains open the question whether entire abstinence from fermented liquors be a duty, and this is a question of fact. Says one party, "Alcohol, in every form, and in the least quantity, is a virulent poison, and therefore unfit for body and mind." Says the other party, "Wine, moderately used, is healthful, salutary, restorative, and therefore fitted to body and mind." Change the opinion of the latter party, their consciences would at once take the other side; and if they retained in precept and practice their present position, they would retain it. self-condemned. Change the opinion of the former party, their consciences would assume the 
ground which they now assail. Demonstrate to the whole community - as it is to be hoped physiology will do at no distant day - the precise truth in this matter, there would remain no difference of conscientious judgment, whatever difference of practice might still continue.

Conscience, like all the perceptive faculties, prompts to action in accordance with its perceptions. In this respect it differs not in the least from sight, hearing, taste. Our natural proclivity is to direct our movements with reference to the objects within the field of our vision, to govern our conduct by what we hear, to take into our mouths only substances that are pleasing to the taste. Yet fright, temerity, or courage may impel us to incur dangers which we clearly see; opiniativeness or obstinacy may make us inwardly deaf to counsels or warnings which we hear ; and motives of health may induce us to swallow the most nauseous drugs. In like manner, our inevitable tendency is to govern our conduct by the fitness of things when clearly perceived; but intense and unrestrained appetite, desire, or affection may lead us to violate that fitness, though distinctly seen and acknowledged.

Men act in opposition to conscience only under immediate and strong temptation. The great majority of the acts of bad men are conscientious, but not therefore meritorious; for merit consists not in doing right when there is no temptation to evil, but in resisting temptation. But, as has been said, it is 
as natural, when there is no inducement to the contrary, to act in accordance with the fitness of things, as it is to act in accordance with what we see and bear. It is the tendency so to act, that alone renders human society possible, in the absence of high moral principle. In order to live, a man must so act with reference to outward nature; still more must he so act in order to possess human fellowship, physical comfort, transient enjoyment, of however low a type ; and the most depraved wretch that walks the earth purchases his continued being and whaterer pleasure he derives from it by a thousand acts in accordance with the fitness of things to one in which he violates that fitness.

Conscience, like all the perceptive faculties, is educated by use. The watchmaker's or the botanist's eye acquires an almost microscopic keenness of vision. The blind man's hearing is so trained as to supply, in great part, the lack of sight. The epicure's taste can discriminate flavors whose differences are imperceptible to an ordinary palate. In like manner, the conscience that is constantly and carefully exercised in judging of the fit and the unfitting, the right and the wrong, becomes prompt, keen, searching, sensitive, comprehensive, microscopic. On the other hand, conscience, like the senses, if seldom called into exercise, becomes sluggish, inert, incapable of minute discrimination, or of vigilance over the ordinary conduct of life. Yet it is never extinct, and is never perverted. When roused to action, even in the most obdurate, it 
resumes its judicial severity, and records its verdict in remorseful agony.

Conscience is commonly said to be educated by the increase of knowledge as to the relations of beings and objects, as to the moral laws of the universe, and as to religious verities. This, however, is not true. Knowledge does not necessarily quicken the activity of conscience, or enhance its discriminating power. Conscience often is intense and vivid in the most ignorant, inactive and torpid in persons whose cognitive powers have had the most generous culture. Knowledge, indeed, brings the decisions of conscience into closer and more constant conformity with the absolute right, but it does not render its decisions more certainly in accordance with the relative right, that is, with what the individual, from his point of view, ought to will and do. It has the same effect upon conscience that accurate testimony has upon the clearminded and uncorrupt judge, whose mind is not made thereby the more active or discriminating, nor his decision brought into closer accordance with the facts as they are presented to him. Knowledge is indeed an indispensable auxiliary to conscience; but this cannot be affirmed exclusively of any specific department of knowledge. It is true of all knowledge ; for there is no fact or law in the universe that may not in some contingency become the subjectmatter or the occasion for the action of conscience. Nothing could seem more remote from the ordinary field of conscience than the theory of planetary mo- 
tion; yet it was this that gave Galileo the one grand opportunity of his life for testing the supremacy of conscience, - it may be, the sole occasion on which his conscience uttered itself strongly against his seeming interest, and one on which obedience to conscience would have averted the only cloud that ever rested on his fame.

\section{SECTION ח.}

SOURCES OF KNOWLEDGE. 1. OBSERVATION, EXPERIENCE, AND TRADITION.

Except so far as there may have been direct communications from the Supreme Being, all man's knowledge of persons, objects, and relations is derived, in the last resort, from observation. Experience is merely remembered self-observation. Tradition, oral and written, is accumulated and condensed observation; and by means of this each new generation can avail itself of the experience of preceding generations, can thus find time to explore fresh departments of knowledge, and so transmit its own traditions to the generations that shall follow. Now what we observe in objects is chiefly their properties, or, what is the same thing, their fitnesses; for a property is that which fits an object for a specific place or use. What we observe in persons is their relations to other beings and objects, with the fitnesses that belong to those relations. What we experience all resolves itself into the fitness or unfitness of persons and objects to one 
another or to ourselves. What is transmitted in history and in science is the record of fitnesses or unfitnesses that have been ascertained by observation, or tested by experience. The progress of knowledge is simply an enlarged acquaintance with the fitnesses of persons and things. He knows the most, who most fully comprehends the relations in which the beings and objects in the universe stand, have stood, and ought to stand toward one another. Moreover, as when we see a fitness within our sphere of action, we perceive intuitively that it is right to respect it, wrong to violate it, our knowledge of right and wrong is coextensive with our knowledge of persons and things. The more enlightened and cultivated a nation is, then, the more does it know as to right and wrong, whatever may be its standard of practical morality.

For instance, in the most savage condition, men know, with reference to certain articles of food and drink, that they are adapted to relieve the cravings of hunger and thirst, and they know nothing more about them. They are not acquainted with the laws of health, whether of body or of mind. They therefore eat and drink whatever comes to hand, without imagining the possibility of wrong-doing in this matter. But, with the progress of civilization, they learn that various kinds of food and drink impair the health, cloud the brain, enfeeble the working power, and therefore are unfit for human use ; and no sooner is this known, than the distinction of right and wrong begins to be recognized, as to what men eat and 
drink. The more thorough is the knowledge of the human body and of the action of various substances on its organs and tissues, the more minute and discriminating will be the perception of fitness or unfit ness as to the objects that tempt the appetites, and the keener will be the sense of right or wrong in their use.

For another illustration of the same principle, we may take the relation between parents and children. In the ruder stages of society, and especially among a nomadic or migratory people, there is not a sufficient knowledge of the resources of nature or the possibilities of art, to render even healthy and vigorous life more than tolerable; while for the infirm and feeble, life is but a protracted burden and weariness. At the same time, there is no apprehension of the intellectual and moral worth of human life, still less, of the value even of its most painful experiences as a discipline of everlasting benefit. In fine, life is little more than a mere struggle for existence. What won. der then, that in some tribes filial piety has been wont to relieve superannuated parents from an existence devoid equally of joy and of hope; and that in others narental love may have even dictated the exposure - with a view to their perishing - of feebie, sickly, and deformed children, incapable of being nurtured into self-sustaining and self-depending life? But increased conversance with nature and art constantly reveals new capacities of comfort and happiness in life, and that, not for the strong alone, but for 
the feeb!e, the suffering, the helpless, so that there are none to whom humanity knows not how to render continued life desirable. At the same time, a higher culture has made it manifest that the frailest body may be the seat of the loftiest mental activity, moral excellence, and spiritual aspiration, and that in such a body there is often only a surer and more finished education for a higher state of being. Filial piety and parental love, therefore, do all in their power to prolong the flickering existence of the age-worn and decrepit, and to cherish with tender care the life which seems born but to die. There is, then, to the limited view of the savage, an apparent fitness in practices which in their first aspect seem crimes against nature; while increased knowledge develops a real and essential fituess in all the refinements and endearments of the most persevering and skilful love.

These examples, which might be multiplied indefinitely, show the dependence of conscience on knowledge, not for relatively right decisions, but for verdicts in accordance with the absolute right. There is no subject that can be presented for the action of conscience, on which, upon precisely the same principles, divergent and often opposite courses of conduct may not be dictated by more or less accurate knowledge of the subject and its relations.

It will be seen, also, that with the growth of knowledge, conscience has a constantly wider scope of action. The number of indifferent acts is thus diminished; the number of positively right or 
wrong acts, increased. An indifferent act is one for the performance of wlich, rather than its opposite, no reason, involving a question of right or wrong, can be given. Thus, if the performance or the omission of a specific act be equally fitted to the time, place, circumstances, and persons concerned, the act is an indifferent one; or, if two or more ways of accomplishing a desired end be equally fitted to time, place, circumstances, and persons, the choice between these ways is, morally speaking, a matter of indifference. But with a knowledge both more extensive and more minute of the nature, relations, and fitnesses of beings and objects, we find an increasing number of in stances in which acts that seemed indifferent have a clearly perceptible fitness or unfitness, and thus acquire a distinct moral character as right or wrong.

\section{SECTION III.}

SOURCES OF KNOWLEDGE. 2. LAW.

Law is the result of the collective experience, iu part, of particular communities, in part, of the human race as a whole. It encourages, protects, or at least permits whatever acts or modes of conduct have been found or believed to be fitting, in accordance with the nature of things and the well-being of men, and therefore right; it forbids and punishes such acts or modes of conduct as have been found or believed to be unfitting, opposed to nature and to human well- 
being, and therefore wrong. It is far from perfect; it is below the standard of the most advanced minds; but it represents the average knowledge or belief of the community to which it belongs. The laws of any particular state cannot rise far abcre this average; for laws unsustained by general opinion could not be executed, and if existing in the statutebook, they would not have the nature and force of law, and would remain on record simply because they had lapsed out of notice. Nor can they fall far below this average; for no government can sustain itself while its legislation fails to meet the demands of the people.

While law thus expresses the average knowledge or belief, it tends to perpetuate its own moral standard. The notions of right which it embodies form a part of the general education. The specific crimes, vices, and wrongs which the law marks out for punishment are regarded by young persons, from their earliest years, as worthy of the most emphatic censure and condemnation; while those which the law leaves unpunished are looked upon as comparatively slight and venial. Not only so, the degree of detestation in which a community learns to look on specific crimes and offences is not in proportion to their actual heinousness, but to the stress of overt ignominy attached to them by legal penalties. Instances of this effect of law on opinion will be readily called to mind. Thus a common thief loses, and can hardly regain his position in society; while the man who by dishonest 
bankruptcy commits a hundred thefts in one, can hold his place unchallenged, even in the Christian church, while it is known to every one that he is living - it may be in luxury - on the money he bas stolen. The obvious reason is that from time immemorial simple theft has been punished with due, when not with undue, severity, while the comparatively recent crime of fraudulent bankruptcy has as yet been brought very imperfectly within the grasp of penal law. Again, no man of clear moral discernment can doubt that he who consciously and willingly imbrutes himself by intoxication is more blameworthy than he who sells alcoholic liquors without knowing whether they are to be used internally or externally, moderately or immoderately, for medicine or for luxury. Yet because the latter makes himself liable to fine and imprisonment, while the former — unless he belong to the unprivileged classes - has legal protection, instead of the disgraceful punishment he de. serves, there is a popular prejudice against the vender of strong drink, and a strange tenderness toward the intemperate ccnsumer. Yet another instance. There are crimes worse than murder. There are modes of moral corruption and ruin, whose victims it were mercy to kill. But while the murderer, if he escape the gallows, is an outcast and an object of universal abhorrence, no social ban rests upon him whose crime has been the death of innocence and purity, yet, if reached at all by law, can be compounded by the payment of monev 
But though law is in many respects an imperfect moral teacher, and its deficiencies are to be regretted, its educational power is strongly felt for good, especially in communities where the administration of justice is strict and impartial. It is of no little worth that a child grows up with some fixed beliefs as to the turpitude of certain forms of evil, especially as the positive enactments of the penal law almost always coincide with the wisest judgments of the best men in the community. Moreover, law is progressive in every civilized community, and in proportion as it approaches the standard of absolute right, it tends to bring the moral beliefs of the people into closer conformity with the same standard. It is, then, a partial and narrow view of law to regard it only or chiefly as the instrument of society for the detection and punishment, or even for the direct prevention of crime. Its far more important function is so to train the greater part of each rising generation. that certain forms and modes of evil-doing shall neves enter into their plans or purposes.

The civil, no less than the criminal law is a source of knowledge as to the right. The law does not create, but merely defines the rights appertaining to persons and property. The laws of different nations are, indeed, widely different; but there may be that in their respective histories which makes a difference in the actual rights of citizens, or their civil codes may present different stages of approach toward the right. Thus the laws as to the conveyance and inheritance 
of property are in some respects unlike in France, England, and the United States, and vary considerably in the several States of our Union; but there generally exist historical reasons for this variation, and it would be found that the ends of justice are best served, and the reasonable expectations of the people best met in each community, by its own methods of procedure. By the law of the land, then, we may learn civil rights and obligations, which we have not the means of ascertaining by our own independent research.

It remains for us to speak of the factitious rights and wrongs, supposed to be created by law. Of these there are many. Thus one mode of transacting a sale or transfer is in itself as good as another; and it might be plausibly maintained that, if the business be fairly and honorably conducted, it matters not whether the legally prescribed forms-sometimes burdensome and costly - be complied with or omitted. The law, it may he said, here creates an obligation for which there is no ground in nature or the fitness of things. This we deny. It is intrinsically fitting that all transactions which are liable to dispute or question should be performed in ways in which they can be attested; and this cannot be effected except by the establishment of uniform methods. He who departs from them performs not only an illegal, but an immoral act; and the legal provisions of the kind under discussion have an educational value in enlarging the knowledge of the individual as to the 
conditions and means of security, order, and good understanding in human society.

Similar considerations apply to the crimes created by law. Smuggling may serve as an instance. Undoubtedly there are smugglers who would not steal; and their apology is that they are but exercising the rights of ownership upon their own property. But the public must have property, else its community is dissolved; goverument must be able to avail itself of that property, else its functions are suspended. Men need to be taught that the rights of the state are inseparable from those of individuals, and no less sacred, and the laws that protect the revenue are among the most efficient means of teaching this lesson. Their only defect is that they attach less ignominy to frauds upon the revenue than to other modes of theft, and thus fail to declare the whole truth, that there is no moral difference between him who robs the public and him who robs any one of its individual members.

\section{SECTION IV.}

SOURCES OF KNOWLEDGE. 3. CHRISTIANITY.

Religion, in its relation to ethics, may be regarded both as a source of knowledge, and as supplying motives for the performance of duty. We are now concerned with it in the former aspect; and it will be sufficient for our present purpose to ascertain how much Christianity adds to our knowledge of the fit- 
nesses that underlie all questions of right and duty We by no means undervalue the beneficent ministry of natural religion in the department of ethics; but the most sceptical admit that Christianity includes all of natural religion, while its disciples claim that it not only teaches natural religion with a certainty, precision, and authority which else were wanting, but imparts a larger and profounder knowledge of God and the universe than is within the scope of man's unaided reason.

Christianity covers the entire field of human duty, and reveals many fitnesses, recognized whon seen, but discovered by few or none independently of the teachings and example of its Founder; while it gives the emphasis and sanction of a Divine revelation to many other fitnesses, easily discoverable, but liable to be overlooked and neglected.

In defining the relations of the individual human soul to God, Christianity opens to our view a department of duty paramount to all others in importance and interest. His fatherly love and care, his moral government and discipline, his retributive providence, define with unmistakable distinctness certain corresponding modes, in part, of outward action, and in still greater part, of action in that inward realm of thought whence the outward life receives its direction and impulse.

The brotherhood of the whole human race, also, reveals obligations which would exist on no other ground; and for the clear and self-eridencing state 
ment of this truth we are indebted solely to Christianity. The visible differences of race, color, culture, religion, and customs, are in themselves dissociating influences. Universal charity is impossible while these differences occupy the foreground. Slavery was a natural and congenial institution under Pagan auspices; nor have we in all ancient extra-Christian literature, unless it be in Seneca (in whom such sen. timents may have had indirectly ${ }^{1}$ a Christian origin), a single expression of a fellowship broad enough to embrace all diversities of condition, much less, of race. But the Christian, so far as he consents to receive the obvious and undoubted import of Christ's mission and teachings, must regard all men as, in nature, in the paternal care of the Divine Providence, in religious privileges, rights, and capacities, on an equal footing. With this view, he cannot but perceive the fitness, and therefore the obligation, of many forms of social duty, of enlarged beneficence, of unlimited philanthropy, which on any restricted theory of human brotherhood would be neither fitting nor reasonable.

The immortality of the soul, in the next place, casts a light at once broad and penetrating upon and into every department of duty; for it is obvious, without detailed statement, that the fitnesses, needs, and obligations of a terrestrial being of brief duration, and those of a being in the nursery and first

1 The theory that Seneca was squainted with St. Paul, or had any direct intercours. with Christians in Rome or elsewhere, has no historical evidence, and res : un ascumptions that are contradicted by known facts. 
stage of an endless existence, are very wide apar, that the latter may find it fitting, and therefore may deem it right, to do, seek, shum, omit, endure, resign, many things which to the former are very properly matters of indifference. Immortality was, in a cer. tain sense, believed before the advent of Christ, but not with sufficient definiteness and assurance to occupy a prominent place in any ethical system, or to furnish the point of view from which all things in the earthly life were to be regarded. Indeed, some of the most virtuous of the ancients, among others Epictetus, than whom there was no better man, expressly denied the life after death, and, of course, could have had no conception of the aspects of human and earthly affairs as seen in the light of eternity.

Christianity makes yet another contribution to ethical knowledge in the person and character of its Founder, exhibiting in him the very fitnesses it prescribes, showing us, as it could not in mere precept, the proportions and harmonies of the virtues, and manifesting the unapproached beauty and majesty of the gentler virtues, ${ }^{1}$ which in pre-Christian ages were sometimes made secondary, sometimes repudiated with contempt and derision. We cannot overestimate the importance of this teaching by example. The instances are very numerous, in which the fitness of a specific mode of conduct can be tested only by experiment; and Jesus Christ tried successfully several experiments in morals that had not been tried before within the 
memory of man, and evinced, in his own person and by the success of his religion, the superior worth and efficacy of qualities which had not previously borne the name of virtues.

Christianity still further enlarges our ethical knowl. edge by declaring the universality of moral laws. There are many cases, in which it might seem to us not only expedient, but even right, to set aside some principle acknowledged to be valid in the greater number of instances, to violate justice or truth for some urgent claim of charity, or to consent to the performance of a little evil for the accomplishment of a great good. But in all such cases Christianity interposes its peremptory precepts, assuring us on anthority which the Christian regards as supreme and infallible, that there are no exceptions or qualifications to any rule of right; that the moral law, in all its parts, is of inalienable obligation, and that the greatest good cannot but be the ultimate result of inflexible obedience.

That Christianity gives a fuller knowledge of the right than can be attained independently of its teachings, is shown by the review of all extra-Christian ethical systems. There is not one of these which does not confessedly omit essential portions of the right, and lardly one which does not sanction dispositions and modes of conduct confessedly wrong and evil; while even those who disclaim Christianity as a Divine revelation, fail to detect like omissions and blemishes in the ethics of the New Testament. Thus, though there is rardly a precept of Jesus Christ, 
the like of which cannot be found in the ethical writings of Greece, China, India, or Persia, the faultlessness and completeness of his teachings give them a position by themselves, and are among the strongest internal evidences of their divinity. They are also distinguished from the ethical systems of other teachers by their positiveness. Others say, "Thou shalt not;" Jesus Christ says, "Thou shalt." They forbid and prohibit; He commands. They prescribe abstinence from evil; $\mathrm{He}$, a constant approach to perfection. Buddhism is, in our time, often referred to as occupying a higher plane than Christianity; but its precepts are all negative, its virtues are negative, and its disciple is deemed most nearly perfect, when in body, mind, and soul he has made himself utterly quiescent and inert. Christianity, on the other hand, enjoins the unresting activity of all the powers and faculties in pursuit of the highest ends. 


\section{CHAPTER VI.}

\section{RIGHT'S AND OBLIGATIONS.}

$\mathrm{O}$ the things that are fitting and right, there are some which, though they may be described in general terms, cannot be defined and limited with entire accuracy; there are others which are so obvious and manifest, or so easily ascertained, that, in precise form and measure, they may be claimed by those to whom they are due, and required of those from whom they are due. These last are rights, and the duties which result from them are obligations. Thus it is right that a poor man should be relieved; and it is my duty, so far as I can, to relieve the poor. But this or that individual poor man cannot claim that it is my duty rather than that of my neighbor to minister to his needs, or that I am bound to give him what I might otherwise give to his equally needy neighbor. He has no specific right to any portion of my money or goods; I have no specific obligation to give him anything. But if a man has lent me money, he has a right to as much of my money or goods as will repay him with interest; and I am mucler an obligation thus to repay him. Again, it is right that in the public inghway there should be, among those who make it their thoroughfare, mutual 
accommodation, courtesy, and kindness; but no one man can prescribe the precise distance within which he shall not be approached, or the precise amount of pressure which may be allowable to his abutters in a crowd. Nor yet can the individual citizen occupy the street in such a way as to obstruct those who make use of it. He has no exclusive rights in the street; nor are others under obligation to yield to him any peculiar privileges. But he has a right to exclude whom he will from his own garden, and to occupy it in whatever way may please him best; and his fellowcitizens are under obligation to keep their feet from his alleys and flower-beds, their hands from his fruit, and to abstain from all acts that may annoy or injure him in the use and enjoyment of his garden.

Rights - with the corresponding obligations might be divided into natural and legal. But the division is nominal rather than real; for, in the first place, there are no natural rights, capable of being defined, which are not in civilized countries under the sanction and protection of law; secondly, it is an open question whether some generally recognized rights - as, for instance, that of property - exist independently of law; and, thirdly, it may be maintained, on the other hand, that law is powerless to rreate, competent only to declare rights.

One chief agency of law as to rights is exercised in limiting natural rights. Considered simply in his relation to outward nature, a man has a manifest right to whatever he can make tributary to his enjoy. 
ment or well-being. But his fellow-men have the same right. If, then, there be a restricted supply of what he and they may claim by equal right, the alternative is, on the one hand, usurpation or perpetual strife, or, on the other, an adjustment by which each shall yield a part of what he might claim were there no fellow-claimant, and thus each shall have his prir portion of what belongs equally to all. To make this adjustment equitably is the province of law. The problem which it attempts to solve is, How may each individual citizen secure the fullest amount of liberty and of material well-being, consistent with the admitted or established rights of others? Under repub. lican institutions, this problem presents itself in the simplest form, society being in principle an equal partnership, in which no one man can claim a larger dividend than another. But where birth or condition confers certain peculiar rights, the problem must be so modified, that the rights conceded to the common citizens shall not interfere with these inherited or vested rights. In either case, the rights of each member of the community are bounded only by the conterminous rights of others. Obligations correspond to rights. Each member of the community is under obligation, always to refrain from encroachment on the rights of others, and in many cases to aid in securing or defending those rights, he on like occasions and in similar ways having his own rights protected by others.

IVe will consider separately rights appertaining to the person, to property, and to reputation. 
1. Rights appertaining to the person. The most essential of these is the right to life, on which of course all else that can be enjoyed is contingent. This right is invaded, not only by direct violence, but by whatever may impair or endanger health. The corresponding obligation of the individual member of society is to refrain from all acts, employments, or recreations that may imperil life or health, and of society collectively, to furnish a police-force adequate to the protection of its members, to forbid and punish all crimes of violence, to enact and maintain proper sanitary regulations, and to suppress such nuisances as may be not only annoying, but harmful.

But the citizen is entitled to protection, only so long as he refrains from acts by which he puts other lives in peril. If he assault another man with a deadly weapon, and his own life be taken in the encounter, the slayer has violated no right, nay, so far as moral considerations are concerned, he is not even the slayer; for the man who wrongfully puts himself in a position in which another life can be protected only at the peril of his own, if his own be forfeited, has virtually committed suicide. Nor is the case materially altered, if a man in performing an unlawful act puts himself in a position in which he may be reasonably supposed to intend violence. Thus, while roth law and conscience would condemn me if I killed a thief in broad daylight, in order to protect iny property, - if a burglar enter my house by night with no intention of violence, and yet in the surprise 
and darkness of the hour I have reason to suppose my life and the lives of my family in danger from him, the law regards my slaying of such a person as justifiable homicide; and my conscience would acquit $\mathbf{n}, 0$ in defending the right to life appertaining to my family and myself, against one whose intention or willingness to commit violence was to be reasonably inferred from his own unlawful act.

Society, through the agency of law, in some cases and directions limits the right of the individual citizen to life, and this to the contingent beneflt of each, - to the absolute benefit of all. So long as men are less than perfect in character and condition, there must of necessity be some sacrifice of life; but this sacrifice may be reduced to its mini mum by judicious legislation. Now, if without such legislation the percentage of deaths would be numerically much higher than under well-framed laws, the lives sacrificed under these laws are simply cases in which the right of the individual is made to yield to the paramount rights of the community. Thus, there can be no doubt, that contagious disease of the most malignant type could, in many cases, be more successfully treated at the homes of the patients than in public hospitals. But if by the removal of patients to hospitals the number of cases may be greatly aminshed, and the contagion speedily arrested, this removal is the right of the community, - yet not under circumstances of needless privation and hardship, not without the best appliances of comfort, care, and skill 
which money can procure; for the public can be justified in the exercise of such a riglit, only by the extension of the most generous offices of lumanity to those who are imperilled for the public guod.

It is only on similar grounds that the death-penalty for murder can be justified. The life of the very worst of men should be sacrificed only for the preservation of life; for if it be unsafe to leave them at liberty, they may be kept under restraint and duress, without being wholly cut off from the means of enjoyment and improvement. The primeval custom of the earlier nations required the nearest kinsman of the murdered man to kill the murderer with his own hand, and in so doing to shed his blood, which was believed to have a mysterious efficacy in expiating the crime. This form of revenge was greatly checked and restricted by the institutions of Moses; it fell into disuse among the Jews, with their growth in civilization; and was certainly included in the entire repeal of the law of retaliation by Jesus Christ 1

1 The duty of society to inflict capital punishment on the murderer has been maintained on the ground of the Divine command to that effect, said m have been given to Noah, and thus to be binding on all his posterity. (Genesis ix. 5.) My own belief - founded on a careful examination of the Hebrew text - is, that the human murderer is not referred to in this precept, but that it simply requires the slaying of the beast that should cause the death of a man, - a precaution which was liable to be neglected in a rude state of society, anc was among the special enactments of the Mosaic law. (Exudas xxi. 28.) If, however, the common interpretation be retained, the precept recirires the shedding of the murderer's blood by the brother or ocarest kinsman of the murdered man, and is not obeyed by giving up the marderes to the gallows and the public executioner. Moreover, the same 
But if with the dangerous classes of men the dread of capital punishment is a dissuasive from crimes of violence, so that the number of murders is less, and the lives of peaceable citizens are safer, than were murder liable to some milder penalty, then it is the undoubted right of the public to confiscate the mur. derer's right to life, and thus to sacrifice the smaller number of comparatively worthless lives for the security of the larger number of lives that may be valuable to the community. Or again if, by the profligate use of the pardoning power, the murderer sentenced to perpetual imprisonment will probably be let loose upon society unreformed, and with passions which may lead to the repetition of his crime, it is immeasurably more fitting that he be killed, than that he be preserved to do farther mischief. Yet again, if there be in the death-penalty for murder an educational force, - if by means of it each new generation is trained in the greater reverence for human life, and the greater detestation and horror of the crime by which it is destroyed, - then is capital punishment to be retained as a means of preserving an incalculably greater number of lives than it sacrifices. On these grounds, though in opposition to early and strong conviction, we are constrained to express the

shres of precepts prescribes an abstinence from the natural juices of anıma :on. which would require an entire revolution in our shambles, kitchens, and tables. If these precepts were Divine commandments for men of all times, they should be obeyed in full; but there is the grossest inconsistency and absurdity in holding only a portion of one of them sacred, and ignor ino all the rest. 
belief that, in our time and country; the capital pun. ishment of the murderer is needed for the security of the public, and is justified as a life-saving measure.

In enforced military service, also, legal authcrity exposes the lives of a portion of the citizens for the security of the greater number. It is an unquestionable truth that, in its moral affinities, war is generated by evil, is allied to numberless forms of evil, and has a countless progeny of evil. But it is equally true that war will recur at not unfrequent intervals, so long as the moral evils from which it springs remain unreformed. Such are the complications of international affairs, that the most righteous and pacific policy may not always shield a people from hostile aggressions; while insurrection, sedition, and civil war may result not only from governmental oppression, but from the most salutary measures of reform and progress. In such cases, self-defence on the part of the nation or the government assailed, is a right and an obligation, due even in the interest of human life, and still more, in behalf of interests more precious than life. Moreover, even in a war of unprovoked aggression, the aggressive nation does not forfeit the right of self-defence by the unprincipled ambition of its rulers, and, war once declared, its vigorous pursuit may be the only mode of averting lisaster or ruin. Thus war, though always involving atrocious wrong on the part of its promoters and abettors, becomes to the nations involved in it a necessity for which they are compelled to provide. 
This provision may, in some cases, be made by voluntary enlistment; but in most civilized countries, it has been found necessary to fill and recruit the army by conscription, thus forcibly endangering the lives of a portion of the citizens, in order to a ert from the soil and the homes of the people at large the worse calamities of invasion, devastation, and conquest. So far as this is necessary, it is undoubtedly right, and the lives thus sacrificed are justly due to the safety and well-being of the whole people. But in making this admission, we would say, without abatement or qualification, that war is essentially inhuman, barbarous, and opposed to and by the principles and spirit of Christianity, and that should the world ever be thoroughly Christianized, the ages when war was possible, will be looked back upon with the same horror with which we now regard cannibalism.

Associated with the right to life, and essential to its full enjoyment, is the right to liberty. This includes the right to direct one's own employments and recreations, to divide and use his time as may seem to him good, to go where he pleases, to bestow his vote or his influence in public affairs as he thinks best, and to express his own opinions orally, in writing, or through the press, without hindrance or molestation. These several rights belong equally to all ; but as they cannot be exercised in full without mutual interference and annoyance, the common sense of mankind, uttering itself through law, permits each individual to enjoy them oniy so far as he can consistently with 
the freedom, comfort, and well-being of his fellowcitizens.

Slavery is so nearly extirpated from Christendom, that it is superfluous to enter into the controversy, which a few years ago no treatise on Mural Philos. ophy could have evaded. It was defended only by pictent sophistry, and its advocates argued from the fact to the right, inventing the latter to sustain the former.

Personal liberty is legally and rightfully rostricted in the case of minors, on the ground of their immature judgment and discretion, of their natural state of dependence on parents, and of their usual abode under the parental roof. The age of mature discretion varies very widely, not only in different races, but among different individuals of the same race, as does also the period of emancipation from the controlling influence of parents, and of an independent and self-sustaining condition in life. But, as it is impossible for government to institute special inquiries in the case of each individual, and as, were this possible, there would be indefinite room for favoritism and invidious distinctions, there is an intrinsic fitness in fixing an average age at which parental or quasi-parental tutelage shall cease, and after which the man shall have full and sole responsibility for his own acts. It is perfectly obvious that the liberty of the insane and feeble-minded ought to be restricted so far as is necessary for their own safety and for that of others. There is, also. in most communi- 
ties, a provision by which notorious spendthrifts may be put under guardianship, and thus restrained in what might be claimed as their rightful disposal of their own property. This may be justified on the ground that, by persistent wastefulness, they may throw upon the public the charge of their own support and that of their families.

Imprisonment is, on the part of society, a measare, not of revenge, but of self-defence. The design of this mode of punishment is, first, to prevent the speedy repetition of the crime on the part of the person punished; secondly, so to work, either upon his moral nature by confinement, labor, and instruction, or at the worst, on his fears, by the dread of repeated and longer restraint, that he may abstain from crime in future ; and lastly, to deter those who might otherwise be tempted to crime from exposing themselves to its penal consequences. As regards the prisoner, he has justly forfeited the right to liberty, by employing it in aggression on the rights of others.

As regards acts not in themselves wrong, the freedom of the individual is rightfully restrained, when it would interfere with the health, comfort, or lawful pursuits of his neighbors. Thus no man has the right, either legal or moral, to establish, in an inhabited vicinage, a trade or manufacture which confessedly poisons the air or the water in his neighbore hood; nor has one a moral right (even if there are technical difficulties in the way of declaring his calling a nuisance), to annoy his neighbors by an avoea 
tion grossly offensive or intolerably noisy. It is on this ground alone that legislation with reference to the Lord's day can be justified. Christians have nn right to impose upon Jews, Pagans, or infidels, entire cessation of labor, business, or recreation on Sunday, and the attempt at coercive measures of this kind can only react to the damage of the cause in which they are instituted. But if the majority of the people believe it their duty to observe the first day of the week as a day of rest and devotion, they have a right to be protected in its observance by the suppression of such kinds, degrees, and displays of labor and recreation as would essentially interfere with their employment of the day for its sacred uses.

2. The right to property is an ineritable corollary from the right to liberty; for this implies freedom to labor at one's will, and to what purpose can a man labor, unless he can make the fruit of his labor his own? All property, except land, has been created by labor. Except where slavery is legalized, it is admitted that the laborer owns the value he creates. If it be an article made or produced wholly by himself, it is his to keep, to use, to give, or to sell. If his labor be bestowed on materials not his own, or if he be one of a body of workmen, he is entitled to a fair equivalent for the labor he contributes.

Property in land, no doult, originated in labor. A man was deemed the proprietor of so much ground as he tilled. In a sparse population there could have been no danger of mutual interference; and in every 
country, governments must have been instituted before there was a sufficiently close occupation of the soil to occasion collisions and conflicts among the ocsupants. The governments of the early ages, in general, confirmed the titles founded in productive occupancy, and treated the unoccupied land as the property of the state, either to be held in common, to be ceded to individual owners in reward of loyalty or services, or to be sold on the public account.

It is manifest that the security of property is essential to civilization and progress. Men would labor only for the needs of the day, if they could not retain and enjoy the fruits of their labor; nor would they be at pains to invent or actualize industrial improvements of any kind, if they had no permanent interest in the results of such improvements. Then, too, if there were no protection for property, there could be no accumulation of capital, and without capital there could be no enterprise, no combined industries, no expenditure in faith of a remote, yet certain profit. Nor yet can the ends of a progressive civilization be answered by a community of goods and gains. Wherever this experiment has been tried, it has been attended by a decline of industrial enrrgy and capacity; and where there has not been absolute failure, there have been apathy, stupidity, and s decreasing standard of intelligence. In fine, there is in man's bodily and mental powers a certain vis inertice, which can be efficiently aroused only by the stimulus of personal interest in the results of indus. try, ingenuity, and prudence. 
'I'he right of property implies the right of the owner, while he lives, to hold, enjoy, or dispose of his possessions in such way as may please him. But his ownership necessarily ceases at death; and what was his becomes rightfully the property of the public. Yet in all civilized countries, it has been deemed fitting that the owner should have the liberty - with certain restrictions - of dictating the disposal of his property after his death, and also that, unless alienated by his will (and in some countries his will notwithstanding), his property should pass to his family or his nearest kindred. It is believed that it would discourage industry and enfeeble enterprise were their earnings to be treated as public property on the death of the owner; and that, on the other hand, men are most surely trained to and preserved in habits of diligence and thrift, either by the power of directing the disposal of their property after death, or by the certainty that they can thereby benefit those whom they hold in the dearest regard. Laws with reference to wills and to the succession of estates are not, then, limitations of the rights of private property, but a directory as to what is deemed the best mole of disposing of such property as from time to time acerues to the public.

The law limits the right of property by appropriating to public uses such portions of it as are needed for the maintenance, convenience, and wellbeing of the body politic. This is done, in the first place, by taxation, which - in order to be just - 
must be equitable in its mode of assessment, and not excessive in amount. As to the modes of assessment, it is obrious that a system which lightens the burden upon the rich, and thus presses the more heavily on the poor (as would be the case were a revenue raised on the necessaries of life, while luxuries were left free), cannot be justified. On the other hand, it may be maintained that the rate of taxation might fairly increase with the amount of property; for a very large proportion of the machinery of government is designed for the protection of property, and the more property an individual has, the less capable is he of protecting his various interests by his own personal care, and the more is he in need of well-devised and faithfully executed laws. Taxation excessive in amount is simply legalized theft. Sinecures, supernumerary offices, needless and costly formalities in the transaction of public business, journeys and festivities at the public charge, buildings designed for ostentation rather than for use, have been so long tolerated in the municipal, state, and national administrations, that they may seem inseparable from our system of government; but they imply gross dishonesty on the part of large numbers of our public servants, and guilty complicity in it on the part of many more. Under a system of direct taxation, assess. ments can be more equitably made, and their expen. diture will be more carefully watched, than in the case of indirect taxation; while the latter method is more likely to find faror with those who hold or seek pub- 
lic office, as encouraging a larger freedom of expenditure, and supporting a larger number of needless functionaries at the public cost.

The law, also, authorizes the appropriation of specific portions of property to public uses, as for streets, roads, aqueducts, and public grounds, and even in aid of private enterprises in which the community has a beneficial interest, as of canals, bridges, and railways. This is necessary, and therefore right. It is obvious that, but for this, the most essential facilities and improvements might be prevented, or burdened with unreasonable costs, by the obstinacy or cupidity of individuals. The conditions under which such use of private property is justified are, that the improvement proposed be for the general good, that a fair compensation be given for the property taken, and that as to both these points, in case of a difference of opinion, the ultimate appeal shall be to an impartial tribunal or arbitration.

3. The right to reputation. Every man has a right to the reputation he deserves, and is under obligation to respect that right in every other man. This obligation is violated, not only by the fabrication of slander, but equally by its repetition, unless the person who repeats it knows it to be true, and alsc by silence and seeming acquiescence in an injurious report, if one knows or believes it to be false. But has a man a right to a better reputation than ho deserves? Certainly not, in a moral point of view; 
and if men could be generally known to be what they are, few would fail to become what they would wish to seem. Yet the law admits the truth of a slanderous charge in justification of the slanderer, only when it can be shown that the knowledge of the truth is for the public benefit. There are good reasons for this attitude of the law, without reference to any supposed rights of the justly accused party. There is, in many instances, room for a reasonable doubt as to evil reports that seem authentic, and in many more instances there may be extenuating circumstances which form a part of the case, though almost never, of the report. Then, too, the family and kindred of the person defamed may incur, through true, yet useless reports to his discredit, shame, annoyance, and damage, which they do not merit. Evil reports, also, even if true, disturb the peace of the community, and often provoke violent retaliation. The wanton circulation of them, therefore, if a luxury to him who gives them currency, is a luxury indulged at the expense of the public, and he ought to be held liable for all that it may cost. Finally, and above all, tho slanderer becomes a nuisance to the community, not only by his reports of real or imagined wrong and evil, but by the degradation of his own character, which can hardly remain above the level of his social intercourse.

By the law, defamation and libel are, very justly, liable both to criminal prosecution, as offences against 
the public, and to action for damages by civil process, on the obvious ground that the injury of a man's character tends to impair his success in business, his pecuniary credit, and his comfortable enjoyment of his property. 


\section{CHAPTER VII.}

\section{MOTIVE, PASSION, AND HABIT.}

THE appetites, desires, and affections are, as has 1 been said, the proximate motives of action. The perception of expediency and the sense of right act, not independently of these motives, but upon them and through them, checking some, stimulating others. Thus they, both, restrain the appetites, the former, so far as prudence requires; the latter, in subserviency to the more noble elements of character. The former directs the desires toward worthy, but earthly objects; the latter works most efficiently through the benevolent affections, as exercised toward God and man.

Exterior motives are of a secondary order, acting not directly upon the will, but influencing it indirectly, through the springs of action, or through the principles which direct and govern them.

The action of exterior motives takes place in three different ways. 1. When they are in harmony with any predominant appetite, desire, or affection, they at once intensify it, and prompt acts by which it may be gratified. Thus, for instance, a sump. tuously spread table gives the epicure a keener appetite, and invites him to its free indulgence. The 
opportunity of a potentially lucrative, though hazardous investment, excites the cupidity of the man who prizes money above all things else, and tempts him to incur the doubtful risk. The presence of the object of love or hatred adds strength to the affection, and induces expressions or acts of kindness or malevolence. 2. An exterior motive opposed to the predominant spring of action often starts that spring into vigorous and decisive activity, and makes it thenceforth stronger and more imperative. It is thus that remonstrances, obstacles, and interposing difficulties not infrequently render sensual passion more rabid; while temptation, by the acts of resistance which it elicits, nourishes the virtue it assails. 3. An exterior motive may have a sufficient stress and cogency to call forth into energetic action some appetite, desire, or affection previously dormant or feeble, thus to repress the activity of those which before held sway, and so to produce a fundamental change in the character. In this way the sudden presentation of vice, in attractive forms, may give paramount sway to passions which had previously shown no signs of mastery; and, in like manner, a signal experience of peril, calamity, deliverance, or unexpected joy may call forth the religious affections, and invest them with enduring supremacy over a soul previously surrendered to appetite, inferior desires, or meaner loves.

An undue influence in the formation or change of character is often ascribed to exterior motives. They are oftener the consequence than the cause of 
character. Men, in general, exercise more power over their surroundings, than their surroundings over them. A very large proportion of the circumstances which seem to have a decisive influence upon us, are of our own choice, and we might - had we so willed - have shosen their opposites. A virtuous person seldom nnds it necessary to breathe a vicious atmosphere. A willingness to be tempted is commonly the antecedent condition to one's being led into temptation. Sympathy, example, and social influences are second in their power, whether for good or for evil, to no other class of exterior motives; and there are few who cannot choose their own society, and who do not choose it in accordance with their elective affinities. It is true, indeed, that the choice of companions of doubtful virtue is often the first outward sign of vicious proclivities; while a tenacious adherence to the society of the most worthy not infrequently precedes any very conspicuous development of personal excellence ; but in either case the choice of friends indicates the predominant springs of action, and the direction in which the character has begun to grow. So far then is man from being under the irresistible control of motives from without, that these motives are in great part the results and the tokens of his own voluntary agency.

Christianity justly claims preëminence, not only as a source of knowledge as to the right, but equally as presenting the most influential and persistent motives to right conduct. 'These motives we have in 
its endearing and winning manifestation of the $\mathrm{Di}$ vine fatherhood by Jesus Christ; in his own sacrifice, death, and undying love for man; in the assurance of forgiveness for past wrongs and omissions, without which there could be little courage for future well-doing; in the promise of Divine aid in every right purpose and worthy endeavor ; in the certainty of a righteous retribution in the life to come; and in institutions and observances designed and adapted to perpetuate the memory of the salient facts, and to renew at frequent intervals the recognition of the essential truths, which give the religion its name and character. The desires and affections, stimulated and directed by these motives, are incapable of being perverted to evil, while desires with lower aims and affections for inferior objects are always liable to be thus perverted. These religious motives, too, resting on the Infinite and the Eternal, are of inexhaustible power ; if felt at all, they must of necessity be felt more strongly than all other motives; and they cannot fail to be adequate to any stress of need, temptation, or trial.

Passion implies a passive state, - a condition in which the will yields without resistance to some dnminant appetite, desire. or affection, under whos imperious reign reason is silenced, considerations of expediency and of right suppressed, and exterior counteracting motives neutralized. It resembles insarity in the degree in which the actions induced by 
it are the results of unreasoning impulse, and in the unreal and distorted views which it presents of persons, objects, and events. It differs from insanity, mainly in its being a self-induced madness, for which, as for drunkenness, the sufferer is morally accountable, and in yielding to which, as in drunkenness, he, oy suffering his will to pass beyond the control of reason, makes himself responsible, both legally and morally, for whatever crimes or wrongs he commits in this state of mental alienation.

There is no appetite, desire, or affection which may not become a passion, and there is no passion which does not impair the sense of right, and interfere with the discharge of duty. The appetites, the lower desires, the malevolent affections, and, not infrequently, love, when they become passions, have their issues in vice and crime. The nobler desires and affections when made passions, may not lead to positive evil, but can hardly fail to derange the fitting order of life, and to result in the dereliction of some of its essential duties. Thus, the passion for knowledge may render one indifferent to his social and religious obligations. Philanthropy, when a passion, overlooks nearer for more remote claims of duty, and is very prone to omit self-discipline and self-culture in its zeal for world-embracing charities. Even the religious affections, when they assume the character of passions, either, on the one hand, are kindled into wild fanaticism, or, on the other, lapse into a self-absorbed quietism, which forgets outside duties in the luxury of 
devout contemplation; and though either of these is to be immeasurably preferred to indifference, they both are as immeasurably inferior to that piety, equally fervent and rational, which neglects neither man for God, nor God for man, and which remains mindful of all human and earthly relations, fitnesses, and duties, while at the same time it retains its hold of faith, hope, and habitual communion, on the higher life.

Habit also involves the suspension of reason and motive in the performance of individual acts; but it differs from passion in that its acts were in the bcginning prompted by reason and motive. Indeed, it may be plausibly maintained that in each habitual act there is a virtual remembrance - a recollection toc transient to be itself remembered - of the reasoning or motive which induced the first act of the series. In some cases the habitual act is performed, as it is said, unconsciously, certainly with a consciousness so evanescent as to leave no trace of itself. In other cases the act is performed corisciously, but as by a felt necessity, in consequence of an uneasy sensation - analogous to hunger and thirst - which can be allayed in this way only. Under this last head we may class, in the first place, habits of criminal indulgence, including the indulgence of morbid and depraved appetite; secondly, many of those morally indifferent habits, which constitute a large portion of a regular and systematic life, and thirdly, habits of virtuous conduct, of industry, of punctuality, of charity. 
Habit bears a most momentous part in the formation and growth of character, whether for evil or for good. It is in the easy and rapid formation of habit that lies the imminent peril of single acts of vicious indulgence. The first act is performed with the determination that it shall be the last of its kind. But of all examples one's own is that which he is most prone to follow, and of all bad examples one's own is the most dangerous. The precedent once established, there is the strongest temptation to repeat it, still with a conscious power of self-control, and with the resolution to limit the degree and to arrest the course of indulgence, so as to evade the ultimate disgrace and ruin to which it tends. But before the pre-determined limit is reached, the indulgence has become a habit; its suspension is painful ; its continuance or renewal seems essential to comfortable existence; and even in those ultimate stages when its very pleasure has lapsed into satiety, and then into wretchedness, its discontinuance threatens still greater wretchedness, because the craving is even more intense when the enjoyment has ceased.

The beneficent agency of habit no less deserves emphatic notice. Its office in practical morality is analogous to that of labor-saving inventions in the various departments of industry. A machine by which ten men can do the work that has been done by thirty, disengages the twenty for new modes of pruductive labor, and thus augments the products of industry and the comfort of the community. A good 
habit is a labor-saving instrument. The cultivating of any specific virtue to such a degree that it shall become an inseparable and enduring element of the character demands, at the outset, vigilance, self-discipline, and, not infrequently, strenuous effort. But when the exercise of that virtue has become habitual. and therefore natural, easy, and essential to one's conscious well being, it ceases to task the energies; it no longer requires constant watchfulness; its occasions are met spontaneously by the appropriate dispositions and acts. The porvers which have been employed in its culture are thus set free for the acquisition of yet other virtues, and the formation of other good habits. Herein lies the secret of progressive goodness, of an ever nearer approach to a perfect standard of character. The primal virtues are first made habits of the unceasing consciousness and of the daily life, and the moral power no longer needed for these is then employed in the cultivation of the finer traits of superior excellence, - the shaping of the delicate lines, roundings, and proportions, which constitute "the beauty of holiness," the symmetry and grace of char acter that win not only abounding respect and confidence, but universal admiration and love.

What has been said of habit, is true not only as to outward acts, but equally as to wonted directions and currents of thought, study, reflection, and reverie. It is mainly through successive stages of habit that the mind grows in its power of application, research, and invention. It is thus that the spirit of devotion 
is trained to ever clearer realization of sacred truth and a more fervent love and piety. It is thus that minds of good native capacity lose their apprehensive faculties and their working power; and thus, also, that moral corruption often, no doubt, takes place before the evil desires cherished within find the opportunity of actualizing themselves in a depraved life. 


\section{CHAPTER VIII.}

\section{VIRTUES, AND THE VIRTUES.}

THE term virtue is employed in various senses, very closely allied to one another, and to the initial conception in which they all have birth. Its primitive signification, as its structure ${ }^{1}$ indicates, is manliness. Now what preëminently distinguishes, not so much the human race from the lower animals, as the fullgrown and strong man from the feebler members of lis own race, is the power of resolute, strenuous, persevering conflict and resistance. It is the part of a man worthy of the name to maintain his own position, to hold his ground against all invaders, to show a firm front against all hostile force, and to prefer death to conquest. All this is implied in the Greek and Roman idea of virtue, and is included in the Latin virtus, when it is used with reference to military transactions, so that its earliest meaning was, simply,

1 Latin, virtus, from vir, which denotes not, like homo, simply a human being, but a man endowed with all appropriate manly attributes, and comes from the same root with $v i s$, strength. The Greek synonyme of virtus, doetri, is derived from "Aons, the god of war, who in the heroic days of Greece was the ideal man, the standard of human excellence, and whose name some lexicographers regard - as it seems to me, somewhat fancifully - as allied through its root to $a \nu \eta \dot{p}$, which beans about the same relstion to $a_{\nu} \theta_{\rho}$ us $\pi$ os that $v i r$ bears to homo. 
military prowess. But with the growth of ethical philosophy, and especially with the cultivation by the Stojes of the sterner and hardier traits of moral excellence, men learned that there was open to them a more perilous battle-ground, a severer conflict, and a more giorious victory, than in mere physical warfare, - that there was a higher type of manliness in self. conquest, in the resistance and subdual of appetite and passion, in the maintenance of integrity and purity under intense temptation and amidst vicious surrourndings, than in the proudest achievements of military valour. Virtue thus came to mean, not moral goodness in itself considered, but goodness militant and triumphant. ${ }^{1}$

But words which have a complex signification ulways tend to slough off a part of their meaning; and, especially, words that denote a state or property, together with its mode of growth or of manifestation, are prone to drop the latter, even though it may have given them root and form. Thus the term virtue is

1 In the languages which have inherited or adopted the Latin virtus, it retains its original signification, with one striking exception, which yet is perhaps an exception in appearance rather than in reality. In the Italian, virtu is employed to signify taste, and virtuoso, which may denoto a virtuous man, oftener means a collector of objects of taste. We have here an historical landmark. There was a period when, under civil despotism, the olc Roman manhood had entirely died out on its native soil, whily ecclesiastical corruption rendered the nobler idea of Christian manhood effete; and then the highest type of manhood that renuained was the culture of thrse refined sensibilities, those ornamental arts, and that keen sense of the beautiful, in which Italy as far surpassed other lands, as it was for centuries inferior to them in physical braverv and in moral rectitude 
often used to denote the qualities that constitute human excellence, without direct reference to the conflict with evil, whence it gets its name, and in which those qualities have their surest growth and most conspicuous manifestation. There is still, however, a tacit reference to temptation and conflict in our use of the term. Though we employ it to denote goodness that has stood no very severe test, we use it only where such a test may be regarded as possible. Though we call a man virtuous. who has been shielded from all corrupt examples and influences, and has had no inducements to be otherwise than good, we do not apply the epithet to the little child who cannot by any possibility have been exposed to temptation. Nor yet would we apply it to the perfect purity and holiness of the Supreme Being, who "cannot be tempted with evil."

Virtue then, in its more usual sense at the present time, denotes conduct in accordance with the right, or with the fitness of things, on the part of one who has the power to do otherwise. But in this sense there are few, if any, perfectly virtuous men. There are, perhaps, none who are equally sensitive to all that the right requires, and it is often the deficiencies of a character that give it its reputation for distinguished excellence in some one form of virtue, the vigilance, self discipline, and effort which might have sustained the character in a well-balanced mediocrity being so concentrated upon some single department of duty as to excite high admiration and extended praise. There 
may be a deficient sensitiveness to some classes of obligations, while yet there is no willing or conscious violation of the right, and in such cases the character must be regarded as virtuous. But if in any one department of duty a person is consciously false to his sense of right, even though in all other respects he conforms to the right, he cannot be deemed virtuous, nor can there be any good ground for assurance that he may not, with sufficient inducement, violate the very obligations which he now holds in the most faithful regard. This is what is meant by that saying of St. James, "Whosoever shall keep the whole law, and yet offend in one point, is guilty of all," - not that he who commits a single offence through inadvertency or sudden temptation, is thus guilty; but he who willingly and deliberately violates the right as to matters in which he is the most strongly tempted to wrong and evil, shows an indifference to the right which will lead him to observe it only so long and so far as he finds it convenient and easy so to do.

Here we are naturally led to inquire whether there is any essential connection between virtue and piety, - between the faithful discharge of the common duties of life and loving loyalty toward the Supreme Being. On this subject extreme opinions have been heid, sceptics and unbelievers, on the one side, Chris" ijans with a leaven of antinomianism on the other, maintaining the entire independence of virtue on piety; while Christians of the opposite tendency have represented them, in spite of ample evidence to the 
contrary, as inseparable. We shall find, on examination, that they are separable and independent, yet auxiliary each to the other. Virtue is conduct in accordance with the right, and we have seen that right and wrong, as moral distinctions, depend not on the Divine nature, will or law, ${ }^{1}$ but on the inherent, necessary conditions of being. The atheist cannot escape or disown them. Whatever exists - no mat. ter how it came into being - must needs have its due place, affinities, adaptations, and uses. An intelligent dweller among the things that are, cannot but know something of their fitnesses and harmonies, and so far as he acts upon them cannot but feel the obligation to recognize their fitnesses, and thus to create or restore their harmonies. Even to the atheist, vice is a violation of fitnesses which he knows or may know. It is opposed to his conscientious judgment. He has with regard to it an inevitable sense of wrong. We can, therefore, conceive of an atheist's being rigidly virtuous, and that on principle. Though among the ancient Stoics there were some eminently devout men, there were others, men of impregnable virtue, whose

I It is obriously on this ground alone that we call affirm moral attributes of the Supreme Being. When we say that he is perfectly just, pure, holy, beneficent, we recognize a standard of judgment logically independent of his nature. We mean that the fitness which the human conscience rocos nizes as its only standard of right, is the law which he has elected for ais own admmistration of the universe. Could we conceive of omnipotence not lecrynizing this law, the decrees and acts of such a being would not bo nevessarily right. Omnipotence cannot make that which is fitting wrong, or that which is untitting right. God's decrees and acts are not right bu. canse they are his, but his because they are right. 
theology was too vague and meagre to furnish either ground or nourishment for piety. While, therefore, in the mutual and reciprocal fitnesses that pervade the universe we find demonstrative evidence of the being, unity, and moral perfectness of the Creator, wo are constrained to acknowledge the possibility of these fitnesses being recognized in the conduct of life by those who do not follow them out to the great truths of theology to which they point and lead.

But, on the other hand, where there is a clear knowledge of, or an undoubting belief in the being and providence of God, and especially for persons who receive Christianity as a revelation of the truth, though, as an affection, piety is independent of virtue, the duties of piety are an essential part of virtue. If God is, we stand in definable relations to Him, and those relations are made definite through Christianity. Those relations have their fitnesses, and we see not how he can be a thoroughly virtuous man, who, discerning these fitnesses with the understanding, fails to recognize them in conduct. Conscience can take cognizance only of the fitnesses which the individual man knows or believes; but it does take cognizance of all the fitnesses which he knows or believes. Virtue may coexist with a very low standard of emotional piety; but it cannot coexist, in one who believes the truths of religion, with blasphemy, irreverence, or the conscious violation or neglect of religious obligations. He who is willingly false to his relations with the Supreme Being, needs only adequate temptation to 
make him false to his human relations, and to the fitnesses of his daily life. Moreover, while, as we have said, virtue may exist where there is but little emotional piety, virtue can hardly fail to cherish piety. Loyalty of conduct deepens loyalty of spirit, obedience nourishes love; he who faithfully does the will of God can hardly fail to become worshipful and devout; and while men are more frequently led by emotional piety to virtue, there can be no doubt that with many the process is reversed, and virtue leads to emotional piety. Then again, we have seen that religion supplies the most efficient of all motives to a virtuous life, - motives adequate to a stress of temptation and trial which suffices to overpower and neutralize all inferior motives.

Virtue is one and indivisible in its principle and essence, yet in its external manifestations presenting widely different aspects, and eliciting a corresponding diversity in specific traits of character. Thus, though intrinsic fitness be equally the rule of conduct at a pleasure-party and by a pauper's bedside, the conduct of the virtuous man will bo widely different on these two occasions; and not only so, but with the same purpose of fidelity to what is fitting sund right, his dispositions, aims, and endeavors on these two occasions will have little or nothing in commuri except the one pervading purpose. Hence virtue may under lifferent forms assume various names, and may thus be broken up into separate virtues. These are 
many or few, according as we distributc in smaller or larger groups the occasions for virtuous conduct, or analyze with greater or less minuteness the sentiments and dispositions from which it proceeds.

The cardinal ${ }^{1}$ virtues are the hinge-virtues, those on which the character hinges or turns, those, the possession of all which, would constitute a virtuous character, while the absence of any one of them would justly forfeit for a man the epithet virtuous. There are other less silient and essential qualities - minor virtues - the possession of which adds to the symmetry, beauty, and efficiency of the character, but which one may lack, and yet none the less deserve to be regarded as a virtuous man. Thus, justice is a cardinal virtue; gentleness, one of the lesser rank.

We propose to adopt as a division of the virtues one which recognizes four cardinal virtues, corresponding to four classes under which may be comprehended all the fitnesses of man's condition in this world, and the duties proceeding from them respectively. ${ }^{2}$ There are fitnesses and duties appertaining, first, to one's own being, nature, capacities, and needs; secondly, to his relations to his fellow-beings; thirơly, to his disposition and conduct with reference to external objects and events beyond his control: and fourthly, to his arrangement, disposal, and use of objects under his control. It is difficult to find narnes which in their common use comprehend severally all the contents of each of these four divisions; but yet

1 From cardo, a hinge.

2 It is virtuallv Cicero's divigion in the De Officiis. 
they are all comprised within the broadest significance of the termis Prudence, Justice, Fortitude, and Order. Thus employed, Prudence, or providence, includes all the duties of self-government and self-culture; Justice denotes all that is due to God and man, embracing piety and benevolence; Fortitude, which is but a synonyme for strength, is an appropriate general name for every mode, whether of defiance, resistance, or endurance, in which man shows himself superior to his inevitable surroundings; and Order is extended to all subjects in which the question of duty is a question of time, place, or measure.

We can conceive of no right feeling, purpose, or action, which does not $\operatorname{com} \theta$ under one of these heads. It is obvious, too, that these are all cardinal virtues, not one of which could be wanting or grossly deficient in a virtuous man. For, in the first place, he who omits were it only the duties of self-culture, and thus leaves himself ignorant of what he ought to know, takes upon himself the full burden, blame, and penalty of whatever wrong he may commit in consequence of needless ignorance; secondly, he who is willingly unfaithful in any of his relations to God or man, cannot by any possibility be worthy of approbation ; nor, thirdly, can he be so, who is the slave, not the master, of his surroundings; while, fourthly, fitnesses of tinie, place, and measure are so essential to right-doing that the violation of them renders what else were right, wrong.

Moreover, each of these four'virtues, if genuine 
and highly developed, implies the presence of all the others. 1. There is a world of wisdom in the question asked in the Hebrew Scriptures: "Have all the workers of iniquity no knowledge?" There is in all wrong-doing either ignorance, or temporary hallucination or blindness, and imprudence is but ignorance or delusion carried into action. Did we see clearly the certain bearings and consequences of actions, we should need no stronger dissuasive from all evil, no more cogent motive to every form of virtue. 2. There is no conceivable duty which may not bo brought under the head of justice, either to God or to man; for our duties to ourselves are due to God who has ordained them, and to man whom we are the more able to benefit, the more diligent we are in self-government and self-improvement. 3. Our wrong-doing of every kind comes from our yieiding to outward things instead of rising above them; and he who truly lives above the world, can hardly fail to do all that is right and good in it. 4. Perfect order - the doing of everything in the right time, place, and measure - would imply the presence of all the virtues, and would include all their work.

With this explanation we shall use the terms Prudence, Justice, Fortitude, and Order in the titles of the four following chapters, at the same time claiming the liberty of employing these words, as wo shall find it convenient, in the more restricted sense which they commonly bear. 


\section{CHAPTER IX.}

\section{PRUDENCE; OR DUTIES TO ONE'S SELF.}

CAN there be duties to one's self, which are of absolute obligation? Duties are dues, and they imply two parties, - one who owes them, and one to whom they are due, - the debtor and the creditor. But the creditor may, at his will, cancel the debt, and release the debtor. In selfward duties, then, why may I not, as creditor, release myself as debtor? Why may I not - so long as I violate no obligation to others - be, at my own pleasure, idle or industrious, self-indulgent or abstinent, frivolous or serious? Why, if life seem burdensome to me, may I not relieve myself of the trouble of living? The answer is, that to every object in the universe with which I am brought into relation I owe its fit use, and that no being in the universe, not even the Omnipotent, can absolve me from this obligation. Now my several powers and faculties, with reference to my will, are objects on which my volitions take effect, and I am bound to will their fit uses, and to abstain from thwarting or violating those uses, on the same ground on which I am bound to observe and reverence the fitnesses of objects that form no part of my personality. Moreover, this earthly life is, with ref. 
erence to my will, an object on which my volitions may take effect; I learn - if not by unaided reason, from the Christian revelation - that my life has its fit uses, both in this world and in preparation for a higher state of being, and that these uses are often best served by the most painful events and experiences; and I thus find myself bound to take the utmost care of my life, even when it seems the least worth caring for.

The duties due to one's self are self-preservation, the attainment of knowledge, self-control, and moral self-culture.

\section{SECTION I.}

\section{SELF-PRESERVATION.}

The uses of life, both to ourselves, and to others through us, suffice, as we have said, to render its preservation a duty, enjoined upon us by the law of fitness. This duty is violated not only by suicideagainst which it is useless to reason, for its victims in modern Christendom are seldom of sound mind -. but equally by needless and wanton exposure to peril. Such exposure is frequently incurred in reckless feats of strength or darin's, sometimes consummated in immodiate death, and still oftener in slower selfdestruction by disease. There are, no dorbt, occasions when self-preservation must yield to a higher duty, and humanity has made no important stage of progress without the free sacrifice of many noble 
lives; but because it may be a duty to give life in the cause of truth or liberty, it by no means follows that one has a right to throw it away for the gratification of vanity, for a paltry wager, or to win the fame of an accomplished athlete.

The duty of self-preservation includes, of course, a reasonable care for health, without which the uses of life are essentially restricted and impaired. Here a just mean must be sought and adhered to. There is, on the one hand, an excessive care of the body, which, if it does not enfeeble the mind, distracts it from its true work, and makes the spiritual nature a mere slave of the material organism. This solicitude is sometimes so excessive as to defeat its own purpose, by creating imaginary diseases, and then making them real; and the number is by no means small of those who have become chronic invalids solely by the pains they have taken not to be so. On the other hand, there is a carelessness as to dress and diet, to which the strongest constitution must at length yield; and the intense consciousness of strength and vigor, which tempts one to deem himself invulnerable, not infrequently is the cause of life-long infirmity and disability. Of the cases of prolonged and enfeebling disease, probably more are the result of avoidable than of unavoidable causes, and if we add to these the numerons instances in which the failure of health is to be ascribed to hereditary causes which might have been avoided, or to defective sanitary arrangements that may be laid to the charge of the public, we have an 
enormous amount of serviceable life needlessly wasted for all purposes of active usefulness; while for the precious examples of patience, resignation, and cheerful endurance, the infirmities and sufferings incident to the most favorable sanitary conditions might have been amply sufficient.

There are, no doubt, such wide diversities of constitution and temperament that no specific rules of self-preservation can be laid down; and as regards diet, sleep, and exercise, habit may render the most unlike methods and times equally safe and beneficial. But wholesome food in moderate quantity, sleep long enough for rest and refreshment, exercise sufficient to neutralize the torpifying influence of sedentary pursuits, and these, though not with slavish uniformity, yet with a good degree of regularity, may be regarded as essential to a sound working condition of body and mind. The same may be said of the unstinted use of water, which has happily become a necessity of high civilization, of pure air, the worth of which as a sanitary agent is practically ignored by the major part of our community, and of the direct light of heaven, the exclusion of which from dwellings from motives of economy, while it may spare carpets and curtains, wilts and depresses their owners. These topics are inserted in a treatise on ethics, because whatever has a bearing on health, and thus on the capacity for usefulness selfward and manward which constitutes the whole value of this earthly life, is of grave moral significance. If the preservation of life is a dut.v. 
then all hygienic precautions and measures are duties, and as such they should be treated by the individual moral agent, by parents, guardians, and teachers, and by the public at large.

Self-preservation is endangered by poverty. In the lack ur precariousness of the means of subsistence, the health of the body is liable to suffer, and even where there is not absolute want, but a condition straitened in the present and doubtful as to the future, the mind loses much of its working power, and life is deprived of a large portion of its utility. Hence the duty of industry and economy on the part of those dependent on their own exertions. It is not a man's duty to be rich, though he who in acquiring wealth takes upon himself its due obligations and responsibilities, is a public benefactor; but it is every man's duty to shun poverty, if he can, and he who makes or keeps himself poor by his own indolence, thriftlessness, or prodigality, commits a sin against his own life, which he curtails as to its capacity of good, and against society, which has a beneficial interest in the fully developed life of all its members.

\section{SECTION II. \\ THE ATTAINMENT OF KNOWLEDGE.}

Inasmuch as knowledge, real or supposed, must needs precede every act of the will, and as the adaptation of our actions to our purposes depends on the accuracy of our knowledge, it is intrinsically fitting 
that our cognitive powers should be thoroughly developed and trained, and diligently employed. Especially is this fitting, because - as has been al. ready shown - it is through knowledge alone that we can bring our conduct into conformity with the absolute right, and there is nothing within the range of our possible knowledge, which may not become in some way connected with our agency as moral beings.

It is of prime importance that what we seem to know we know accurately; and as it is through the senses that we acquire our knowledge, not only of the outward objects with which we are daily conversant, but of other minds than our own, the education of the senses is an obvious duty. There are few so prolific sources of social evil, injustice, and misery, as the falsehood of persons who mean to tell the truth, but who see or hear only in part, and supply the deficiencies of perception by the imagination. In the acquisition of knowledge of the highest interest and importance this same hindrance is one of the most frequent obstacles. The careless eye and the heedless ear waste for many minds a large portion of the time ostensibly given to serious pursuits, and render their growth pitifully slow and scanty as compared with their means of culture. The senses may, especially in early life, be trained to alertness and precision, so that they shall carry to the mind true and full reports of what they see and hear; and it is only by such training that the perceptive faculties can accomplish the whole work for which they are designed and fitted. 
There are, also, interior senses, apprehensive pow. ers of the mind, which equally crave culture, and which depend for their precision and force on careful education and diligent use. Mere observation, experience, or study, cannot give knowledge that will be of any avail. One may have a largely and variously stocked memory, and yet be unable to employ its contents to his own advantage or to the benefit of others. Indeed, there are minds that are paralyzed by being overloaded, - by taking in freight faster than they have room for it. It is only materials which the mind has made its own, incorporated into its substance, that it can fully utilize. Knowledge must be acted upon by the understanding, the reason, the judgment, before it can be transmuted into wisdom, and employed either in the acquisition of new truth or in the conduct of life. Mental activity, then, is a duty; for if we are bound to preserve life, by parity of reason, we are bound to improve its quality and increase its quantity, and this cannot be done unless the intellectual powers are strengthened by diligent exercise, as well as nourished by the facts and truths which are the raw material of wisdom.

The fit objects of knowledge vary indefinitely with one's condition in life. Things in themselves trivial or evanescent may, under certain circumstances. claim our careful attention and thorongh cognizance. We ought, on the one hand, to know all we can about matters concerning which we must speak or act, and, on the other hand. to refrain from voluntarily speak. 
ing or acting in matters of which we are ignorant. Thus our social relations and our daily intercourse may render it incumbent on us to obtain for current use a large amount of accurate knowledge which is not worth our remembering. Then a man's profession, stated business, or usual occupation opens a large field of knowledge, with which and with its allied provinces it is his manifest duty to become conversant to his utmost ability; for the genuineness and value of his work must be in a great degree contingent on his intelligence. At the same time, every man is bound to make his profession worthy of respect; in failing to do so, he wrongs and injures the members of his profession collectively; and no calling can obtain respect, if those who pursue it show themselves uncultivated and ignorant. Thus far, then, should knowledge be extended on grounds of practical utility. Beyond and above this range, there is an unlimited realm of truth, the knowledge of which is inestimably precious for the higher culture of the mind and character. In this realm, of which only an infinitesimal portion can be conquered during an earthly lifetime, there is no unfruitful region, - there is no department of nature, of psychology, or of social science, through which the mind may not be expanded, exalted, energized, led into more intimate relations with the Supreme Intelligence, endowed with added power of beneficent agency. While, therefore, knowledge of things as they are, and of their underlying principles and laws, so far as we are able to acquire it, is not only a 
privilege beyond all price, but an absolute duty, there are no moral considerations which need direct or limit our choice of the themes of research or study. These may properly be determined by native or acquired proclivity, by opportunity, or by considerations of usefulness. Nor, if the love of truth be formed and cherished, can it be of any essential importance whether this or that portion of truth be pursued or neglected during the brief period of our life in this world; for, at best, what we leave unattained must immeasurably exceed our attainments, and there is an eternity before us for what we are compelled to omit here. At the same time, the unbounded scope and the vast diversity of things knowable and worthy to be known are adipted to stimulate self-culture, and in that same proportion to invest human life with a higher dignity, a larger intrinsic value, and a more enduring influence.

SECTION III.

SELF-CONTROL.

A man must be either self-governed, or under s worse government than his own. God governs næn, only by teaching and helping them to govern themselves. Good men, if also wise, seek not, even for the highest ends, to control their fellow-men, but, so far as they can, to enable and encourage them to exercise a due self-control. It is only unwise or bad 
men who usurp the government of other wills than their own. But the individual will is oftener made inefficient by passion, than by direct influence from other minds. Man, in his normal state, wills either what is expedient or what is right. Passion suspends, ans to its objects, all reference to expediency and right, even when there is the clearest knowledge of the tendencies of the acts to which it prompts. Thus the sensualist often knows that he is committing sure and rapid suicide, yet cannot arrest himself on the declivity of certain ruin. The man in whom avarice has become a passion is perfectly aware of the comforts and enjoyments which he is sacrificing, yet is as little capable of procuring them as if he were a pauper. Anger and revenge not infrequently force men to crimes which they know will be no less fatal to thernselves than to their victims. Now if a man will not put and keep himself under the government of conscience, it concerns him at least to remain under the control of reason, which, if it do not compel him to do right, will restrain him within the limits of expediency, and thus will insure for him reputation, a fair position, and a safe course in life, even though it tail of the highest and most enduring good.

Self-control is easily lost, and is often lost unconsisiously. The first surrender of it is prone to be final and lifelong. Indeed, in many cases, the passion destined to be dominant has nearly reached the maturity of its power previously to any outward violation of the expedient or the right. Where the re- 
straining influences of education and surroundings are strong, where important interests are at stake, or where conscience has not been habitually silenced or tampered with, the perilous appetite, desire, or affection broods long in the thought, and is so largely indulged in reverie and anticipation, that it becomes imperious and despotic before it assumes its wonted forms of outward manifestation. Hence, the sudden infatuation and rapid ruin which we sometimes witness, - the cases in which there seems but a single step between innocence and deep depravity. In truth there are many steps ; but until they become precipitous, they are veiled from human sight.

Self-control, then, in order to be effective, must be exercised upon the thoughts and feelings, especially upon the imagination, which fills so largely with its phantasms and day-dreams our else unoccupied hours. Let these hours be as few as possible, and let them be filled with thoughts which we would not blush to utter, with plans which we could actualize with the approving suffrage of all good men. The inward life which would dread expression and exposure, already puts the outward life in peril; for passion, thus inwardly nourished and fostered, can bardly fail to assume sooner or later the control of the conduct and the shaping of the character. Let the thoughts be well governed, and the life is emancipated from passion, and under the control of reason and principle. 


\section{SECTION IV.}

MORAL SELF-CULTURE.

It is evident that, whatever a man's aims may be, the attainment of them depends more upon himself than upon any agency that he can employ. If his aim be extended influence, his words and acts have simply the force which his character gives them. If his aim be usefulness, his own personality measures in part the value of his gifts, and determines entirely the worth of his services. If his aim be happiness, the more of a man he is, the larger is his capacity of enjoyment; for as a dog gets more enjoyment out of life than a zoöphyte, and a man than a dog, so does the fully and symmetrically developed man exceed in receptivity of happiness him whose nature is imperfectly or abnormally developed. Now it is through the thorough training and faithful exercise of his moral faculties and powers that man is most capable of influence, best fitted for usefulness, and endowed with the largest capacity for happiness. History shows this. The men whose lot (if any but our own) we would be willing to assume, have been, without an exception, good rell. If there are in our respective circles those whose position we deem in every respect enviable, they are men of preëminent moral excellence. We would not take - could we have it the most desirable external position with a damaged character. Probably there are few who do not regard 
a virtuous character as so much to be desired, that in yielding to temptation and falling under the yoke of vicious habits they still mean to reform and to become what they admire. Old men who have led profligate lives always bear visible tokens of having forfeited all the valuable purposes of life, often confess that their whole past has been a mistake, and not infrequently bear faithful testimony to the transcendent worth of moral goodness. To remain satisfied without this is, therefore, a sin against one's own nature, a sacrifice of well-being and happiness which no one has a right to make, and which no prudent man will make.

Self-culture in virtue implies and demands reflection on duty and on the motives to duty, on one's own nature, capacities and liabilities, and on those great themes of thought, which by their amplitude and loftiness enlarge and exalt the minds that become familiar with them. The mere tongue-work or handwork of virtue slackens and becomes deteriorated, when not sustained by profound thought and feeling. Moreover, it is the mind that acts, and it puts into its action all that it has - and no more - of moral and spiritual energy, so that the same outward act means more or less, is of greater or less worth, in proportion to the depth and vigor of feeling and purpose from which it proceeds. It is thus that religious devotion nourishes virtue, and that none are so well fitted for the duties of the earthly life as those who, in their habitual meditation, are the most intimately conversant with the heavenly life. 
In moral self-culture great benefit is derived from example, whether of the living or the dead. Perhaps the dead are, in this respect, more useful than the living. In witnessing the worthy deeds and beneficent agency of a person of superior excellence, the tendency is to an over-exact imitation of specific acts and methods, which, precisely because they are spontaneous and fitting in his case, will not be so in the case of his copyist; while the biography of an eminently good man enlists our sympathy with his spirit rather than with the details of his life, and stimulates us to embody the same spirit in widely different forms of duty and usefulness. Thus the school-master who in Dr. Arnold's lifetime heard of his unprecedented success as an educator, would have been tempted to go to Rugby, to study the system on the ground, and then to adopt, so far as possible, the very plans which he there saw in surcessful operalion, - plans which might have been fitted neither to his genius, the traditions of his school, nor the demands of its patrons. At the same time, the interior of Rugby School was very little known, the principles of its administration still less, to persons other than teachers. But Arnold's biography, revealing the foundation-principles of his character and his work, raised up for him a host of imitators of all classes and conditions. Price, who converted his immenso candle-factory near London into a veritable Christian seminary for mutual improvement in knowledge, vir. tue, and piety, professed to owe his impulse to this 
entorprise solely to the "Life of Arnold,' and liko instances were multiplied in very various professions throughout the English-speaking world. In fine, example is of service to us, not in pointing out the precise things to be done, but in exhibiting the beauty, loveliness, and majesty of moral goodness, the possibility of exalted moral attaimments, and the varied scope for their exercise in human life. Even he whose example we, as Christians, hold in a reverence which none other shares, is to be imitated, not by slavishly copying his specific acts, which, because they were suitable in Judæa in the first century, are for the most part unfitting in America in the nineteenth century, but by imbibing his spirit, and then incarnating it in the forms of active duty and service appropriate to our time and land.

Finally, and sbviously, the practice of virtue is the most efficient means of moral self-culture. As the thought uttered or written becomes indelibly fixed in the mind, so does the prineiple or sentiment em. bodied in action become more intimately and persistently an element of the moral self-consciousness. 


\section{CHAPTER X.}

JUSTICE; OR, DUTIES TO ONE'S FELLOW-BEINGS.

JUSTICE, in the common use of the word, refers only to such rights and dues as can be precisely defined, enacted by law, and enforced by legal authority. Yet we virtually recognize a broader meaning of the word, whenever we place law and justice in opposition to each other, as when we speak of an unjust law. In this phrase we imply that there is a supreme and universal justice, of whose requirements human law is but a partial and imperfect transcript. This justice must embrace all rights and dues of all beings, human and Divine; and it is in this sense that we may regard whatever any one being in the universe can fitly claim of another being as coming under the head of justice. Such, as we have already intimated, is the sense in which we have used the term in the caption of a chapter which will embrace piety and benevolence no less than integrity and veracity.

\section{SECTION I.}

DUTIES TO GOD.

While we cannot command our affections, we can on govern and direct our thoughts as to excite the 
affections which we desire to cherish; and if certain affections must inevitably result from rertain trains or habits of thought, those affections ma! be regarded as virtually subject to the will, and, if right, as duties. It is in this sense that gratituris and love to God are duties. We camnot contemplate the tokens of his love in the outward universe, the unnumbered objects which have no other possible use than to be enjoyed, the benignity of his perpetual providence, the endowments and capacities of our own being, the immortality of our natural aspiration and our Christian faith and hope, the forgiveness and redemption that come to us through Jesus Christ, and the immeasurable blessings of his mission and gospel, without fervent gratitude to our infinite Benefactor. Nor can we think of him as the Archetype and Source of all those traits of spiritual beanty and excellence which, in man, call forth our rererence, admiration, and affection, withnut loving in Him perfect goodness, purity, and mercy. These attributes might, indeed, of themselves fail to present the Supreme Being to our conceptions as a cognizable personality, were it not that the personal element is so elearly manifest in the visible universe and in God's constant providence. But there are numerous objects, phenomena, and rents in nature and providence which have - so to speak - a distinctive personal expression, so that the familiar metaphors of God's countenance, smile, hand, and voice do not transcend the literal experience of him who goes through life with the inward eye and ear always open. 
The omnipresence of God makes it the dictate of natural piety to address Him rirectly in thanksgiving and prayer, - not, of necessity, in words, except as words are essential to the definiteness of thoughts. but in such words or thoughts as constitute an ex. pression to Him of the sentiments of which $\mathrm{He}$ is fittingly the object. As regards prayer, indeed, the grave doubts that exist in some minds as to its efficacy might be urged as a reason why it should not be offered; but wrongly. It is so natural, so intrinsically fitting to ask what we desire and need of an omnipresent, omnipotent, all-merciful Being, who has taught us to call him our Father, that the very appropriateness of the asking is in itself a strong reason for believing that we shall not ask in vain. Nor san we ask in vain, if through this communion of the human spirit with the Divine there be an inflow of strength or of peace into the soul that prays, even though the specific objects prayed for be not granted. That these objects, when material, are often not granted, we very well know; yet we know too little of the extent of material laws, and of the degree to which a discretionary Providence may work, not in contravention of, but through those laws, to pronounce dogmatically that the prayers of men are wholly un. recognized in the course of events.

As the members of the same community have very uumerous blessings and needs in common, it is obvi. ously fitting that they should unite in public worship, praise, and prayer: and if this be a duty of 
the community collectively, participation in it must, by parity of reason, be the duty of its individual members. Public worship involves the fitness, we may even say the necessity, of appropriating exclusively to it certain places and times. Associations uttach themselves to places so indelibly, that it would be impossible to maintain the gravity and sacredness of devotional services in buildings or on spots ordinarily devoted to secular purposes, either of business or of recreation. Nor could assemblies for worship be convened, otherwise than at predetermined and stated intervals; nor could their devotional purpose be served, were there not stated portions of time sequestered from ordinary avocations and amusements. Hence the duty - on the part of all who admit the fitness of public worship - of reverence for conventionally sacred places, and of abstinence from what ever is inconsistent with the religious uses of the dayr ippropriated to worship.

1 The points at issue with regard to sabbatical observance hardly belong to an elementary treatise on ethics. I ought not, however, to leave any duubt as to my own opinion. I believe, then, the rest of the Sabbath a recessity of man's constitution, physical and mental, of that of the beasts ubservie t to his use, and, in some measure, even of the inanimate agents under his control, while the sequestration of the day from the cuurse of crdinary life is equally a moral and religious necessity. The weekly Sab. hath I regard as a dictate of natural piety, and a primeval instituticn, recnacted, $\mathbf{n}$ t established, by Moses, and sanctioned by our Sariour when te refers to the Decalogue as a compend of moral daty, as also in various wher forms and ways. As to modes of sabbatical observance, the rigid abstinences and austerities once common in New Ensland were derived from the Mosaic ceremonial law, and have no sanction either in the New Testament or in the hatits of the ear!y Christians. I can conceive of no 
It remains for us to consider the obligations im. posed by an acknowledged revelation from God. The position in which we are placed by such a revelation may best be illustrated by reference to what takes place in every human family. A judicious father's commands, precepts, or counsels to his son are of two kinds. In the first place, he lays emphatic stress on duties which the son knows or might know from his own sense of the fitting and the right, such as honesty, veracity, temperance. These duties will not be in reality any more incumbent on the son because they are urged upon him by his father; but if he be a son worthy of the name, he will be more profoundly impressed by their obligation, and will find in his filial love an additional and strong motive toward their observance. The father will, in the second place, prescribe either for his son's benefit or in his own service certain specific acts, in themselves morally indifferent, and these, when thus prescribed, are no longer indifferent, but, as acts of obedience to rightful authority, they become fitting, right, obligatory, and endowed with all the characteristics of acts that are in themselves virtuous. Now a revelation naturally would, and the Christian revelation does, contain precepts and commands of both these classes. It prescribes with solemn emphasis the natural vir-

Jetter rule for the Lord's day, than that each person so spend it as to interfere as little as possible with its fitting use by others, and to mike it as availing as he can for his own relaxation from secular cares, and growth in wirdom and gondness. 
tues which are obligatory upon us on grounds of intrinsic fitness; and though these are not thus made any the more our duty, we have, through the teach. ungs and example of Jesus Christ, a more rivid sense of our obligation, a higher appreciation of the beant of virtue. and added motives to its cultivation drrived from the love, the justice, and the retributive providence of God. The Christian revelation, also, contains certain directions, not in themselves of any intrinsic obligation, as, for instance, those relating to baptism and the eucharist. So far as we can see, other and very different rites might have served the same purpose with these. Yet it is fitting and right that these, and not others, should be observed, simply because the Divine authority which enacts them has a right to command and to be obeyed. Duties of this class are commonly called positive, in contradistinction from natural obligations. Both classes are equally imperative on the ground of fitness; but with this difference, that in the latter class the fitness resides in the duties themselves, in the former it grows out of the relation between him who gives and those who receive the command.

\section{SECTION II.}

\section{DUTIES OF THE FAMחI.}

\section{The inviolableness and permanence of marriage} are so absolutely essential to the stahility and well. 
being of families, as to be virtually a part of the law of nature. The young of other species hare but a very brief period of dependenee; while the human child advanees very slowly toward maturity, and for a considerable portion of his life needs, for both body and mind, support, protection, and guidance from lis sf niors. The separation of parents by other causes than death might leave it an unsolvable question, to rhich of them the custody of their children apper$t$ ined; and in whichever way they were disposed of, their due nurture and education would be inadequately secured. The children might be thrown upon the mother's cire, while the means of supporting them belonged exclusively to the father. Or in the father's house they might suffer for lack of a mother's personal attention and services; while if he contracted a new matrimonial connection, the children of the previous marriage could hardly fail of neglect, or even of hatred and injury, from their mother's successful rival, especially if she had children of her own. ${ }^{1}$

The life-tenure of the marriage-contract contributes equally to the happiness of the conjugal relation, in the aggreşate. There are, no doubt, individual cases of hardship, in which an utter and irremediable in.

1 It was the malignity displayed toward the children of divorced knves by the women who succeeded them in the affections and homes of their nusbands, that in Roman literature attached to the name of a stepmothet (noverca) the most hateful associations, which certainly have no place in inodern Christendom, where the stepmother oftener than not assumes the matemal cares of the deceased wife as if they were natively her $\mathrm{c}$ wn. 
compatibility of temper and character makes married life a burden and a weariness to both parties. But the cases are much more numerous, in which discrepancies of taste and disposition are brought by time and habit into a more comprehensive harmony, and the husband and wife, because unlike, become only the more essential, each to the other's happiness and weltare. Where there is sincere affection, there is little danger that lapse of years in a permanent marriage will enfeeble it; while, were the contract voidable at will, there might be after marriage, as often hefore marriage, a series of attachments of seemingly equal ardor, each to be superseded in its turn by some new attraction. Where, on the other hand, the union is the result, not of love, but of mutual esteem and confidence, aided by motives of convenience, the very possibility of an easy divorce would render each party captious and suspicious, so that confidence could be easily shaken, and esteem easily impaired; while in those who expect always to have a common home the tendency is to those habits of mutual tolerance, accommodation, and concession, through which confidence and esteem ripen into smcere and lasting affection.

As in many respects each family must be a unit, and as the conflict of rival powe's is no less ruinous to a household than to it state, the family must needs have one recognized head or representative, and this place is fittingly held by the husband rather than by the wife; for by the laws and usages of all civilized 
wations he is held responsible - except in criminal matters - for his wife and his minor children. But in the well-ordered family, each party to the marriagecontract is supreme in his or her own department, and in that of the other prompt in counsel, sympathy, and aid, and slow in dissent, remonstrance, or reproof. These departments are defined with perfect distinctness by considerations of intrinsic fitness, and any attempt to interchange them can be only subversive of domestic peace and social order.

The parent's duties to the child are maintenance in his own condition in life, care for his education and his moral and religious culture, advice, restraint when needed, punishment when both deserved and needed, pure example and wholesome influence, aid in the formation of habits and aptitudes suited to his probable calling or estate in his adult years, and provision for his favorable entrance on his future career. Some of these duties are obviously contingent on the parent's ability; others are absolute and imperative. The judicious parent will, on the one hand, retain his parental authority as long as he is legally responsible for his child; but, on the other hand, will train him gradually to self-help and self-dependence, and will concede to him, as he approaches years of unaturity, such freedom of choice and action as is consistent with his permanent well-being.

The child's duty is unqualified submission to the parent's authority, obedience to his commands, and compliance, with his wishes, in all things not 
morally wrong, and this, not only for the years of minority, but so long as he remains a member of his parent's family, or dependent on him for subsistence. Subsequently, it is undoubtedly his duty to consult the reasonable wishes of his parent, to hold him in respect and reverence, to minister assiduously to his comfort and happiness, and, if need be, to sustain him in his years of decline and infirmity.

\section{SECTION III}

\section{VERACITY.}

The duty of veracity is not contingent on the rights of any second person, but is derived from considerations of intrinsic fitness. If representations of facts, truths, or opinions are to be made, it is obviously fitting and right that they should be conformed to one's knowledge or belief ; and no one can make represcntations which he knows to be false without the consciousness of unfitness and wrong.

The most important interests of society depend on the confidence which men repose in one another's veracity. But for this, history would be worth no more than fiction, and its lessons would be unheeded. But for this, judicial proceedings would be a senseless mockery of justice, and the administration of law and equity, the merest haphazard. But for this, the common intercourse of life would be inraded by incessant doubt and suspicion, and its daily 
transactions, aimless and tentative. Against this condition of things man is defended by his own nature. It is more natural to tell the truth than to utter falsehood. The very persons who are the least scrupulons in this matter utter the truth when they have no motive to do otherwise. Spontaneous falsehood betokens insanity.

The essence of falsehood lies in the intention to deceive, not in the words uttered. The words may bear a double sense; and while one of the meanings may be true, the circumstances or the mamner of utterance may be such as inevitably to impose the false meaning upon the hearer. A part of the truth may be told in such a way as to convey an altogether false impression. A fact may be stated with the express purpose of misleading the hearer with regard to another fact. Looks or gestures may be framed with the intent to communicate or confirm a falsehood. Silent acquiescence in a known falsehood may be no less criminal than its direct utterance.

But has not one a right to conceal facts which another has no right to know? In such a case, concealment is undoubtedly a right; but falsehood, or equivocation, or truth which will convey a false impression, is not a right. This question has not un. frequently arisen with regard to anonymous publica. tions. It might be a fair subject of inquiry, whether anonymous writing is not in all cases objectionable, on the ground that a sense of personal responsibility for statements given to the public would insure a 
more uniform regard to truth and justice, as well as greater care in the ascertainment of facts, and more mature deliberation in the formation of judgments and opinions. But if anonymous writing be justified, the writer is authorized to guard his secret by ernploying a copyist, or by covert modes of transmissiun to the press, or by avoiding such peculiarities of style as might betray him. But if, notwithstanding these precautions, the authorship be suspected and charged upon him, we cannot admit his right to denial, whether expressly, or by implication, or even by the utterance of a misleading fact. He undertook the authorship with the risk of discovery; he had no right to give publicity to what he has need to be ashamed of ; and if there be secondary, though grave reasons why he would prefer to remain unknown, they cannot be sufficient to justify him in falsehood.

Is truth to be told to an insane person, when it might be dangerous to him or to others? May not he be deceived for his benefit, decoyed into a place of safe detention, or deterred by falsehood from some intended act of violence? Those who have the guardianship of the insane are unanimous in the opinion that falsehood, when discovered by them, is always attended with injurious consequences, and that it should be resorted to only when imperatively required for their immediate safety or for that of others. But in such cases the severest moralist could not deny the necessity, and therefore the right, of falsehood. But it would be falsehood in form, and 
not in fact. Truth-telling implies two conscious parties. The statement from which an insane person will draw false inferences, and which will drive him to an act or paroxysm of madness, is not truth to him. The statement which is indispensable to his safety, repose, or reasonable conduct, is virtually true to him, inasmuch as it conveys impressions as nearly conformed to the truth as he is capable of receiving.

Is falsehood justifiable for the safety of one's own life or that of others? This is a broad question, and comprehends a very wide diversity of cases. It includes the cases, in which the alternative is to deny one's political or religious convictions, or to suffer death for the profession of them. Here, however, there can be no difference of opinion. Political freedom and religious truth have been, in past ages, propagated more effectively by martyrdoms, than by any other instrumentality; and no men have so fully merited the gratitude and reverence of their race as those who have held the truth dearer than life.

But the form which the question ordinarily assumes is this: If by false information I can prevent the commission of an atrocious crime, am I justified in the falsehood? It ought first to be said, that this is hardly a practical question. Probably it has never presented itself practically to any person under whose eye these pages will fall, or in any instance within his knowledge. Nor can the familiar discussion of such extreme cases be of any possible benefit. On the other hand, he who familiarizes 
himself with the idea that under such a stress of circumstances what else were wrong becomes right, will be prone to apply similar reasoning to an exigency somewhat less urgent, and thence to any case in which great apparent good might result from a departure from strict veracity. Far better is it to make literal truth the unvarying law of life, and then to rest in the assurance that, should an extreme case present itself, the exigency of the moment will suggest the course to be pursued. Yet, in ethical strictness, falsehood from one self-conscious person to another cannot be justified; but we can conceive of circumstances in which it might be extenuated. There are no degrees of right; but of wrong there may be an infinite number of degrees. One straight line cannot be straighter than another; but we can conceive of a curve or a waving line that shall have but an infinitesimal divergence from a straight line. So in morals, there may be an infinitesimal wrong, _ an act which cannot be pronounced right, yet shall diverge so little from the right that conscience would contract from it no appreciable stain, that man could not condemn it, and that we cannot conceive of its being registered against the soul in the chancery of heaven. Such may be the judgment which would properly attach itself to a falsehood by which an atrocious crine was prevented.

Promises belong under the head of veracity for a double reason, inasmuch as they demand in their 
making the truthful declaration of a sincere purpose, and in their execution an equal loyalty to the truth, even though it involve inconvenience, cost, or loss. The words of a promise may often bear more than one interpretation; but it is obviously required by veracity that the promiser should fulfil his promise in the sense in which he supposed it to be understood by him to whom it was made.

There are cases in which a promise should not be kept. The promise to perform an immoral act is void from the beginning. It is wrong to make it, and a double wrong to keep it. The promise to perform an act, not intrinsically immoral, but unlawful, should be regarded in the same light. If both parties were aware, when the promise was made, of the unlawfulness of the act, then neither party has the right to deem himself injured by the other. If, however, the promiser was aware of the unlawfuhness of his promise, while the promisee supposed it lawful, the promiser, though not bound by his promise, is under obligation to remunerate the promisee for his disappointment or loss. If the act promised becomes unlawful between the making and the execution of the promise, the promise is made void, and the promisee has no ground of complaint against the promiser. Thus, if a man promised to send to a correspondent goods of a certain description at a certain time, and before that time the exportation of such goods were prohibited by law, he would be free both from his promise and from responsibility for its non-fulfilment. 
A prumise neither immoral nor unlawful, but made under a mistake common to both parties, and such as - had it been known - would have prevented the promise, is void. An extorted promise to perform an immoral or unlawful act cannot be binding. One has, indeed, no moral right to make such a promise, though if the case be one of extreme urgency and peril, extenuating circumstances may reduce the wrong to an infinitesimal deviation from the right; but, when the duress is over, no considerations can justify the performance of what it was wrong to promise. But a promise, not in itself immoral or unlawful, is binding, though made under duress. Thus, if a man attacked by bandits has had his life spared on condition of a pecuniary ransom, he is bound to pay the ransom ; for at the moment of peril he thought his life worth all he promised to give for it, and it is neither immoral nor unlawful to give money, even to a robber. In a case like this, regard for the safety of others should, also, have weight; for in a country liable to such perils, the breach of a promise by one man might cost the community the lives of many.

Contracts are mutual promises, in which each party puts himself under specific obligations to the other. They are to be interpreted on the same principles, and to be regarded as void or voidable on the same grounds, with promises.

An oath is an invocation of the protection and 
blessing of God, or of his indignation and curse, upon the person swearing, according as his assertion is true or false, or as his promise shall be observed or violated. "So help you God," the form in common use in this country, expresses the idea that underlies an oath, so being, of course, the emphatic word Oaths are exacted of witnesses in courts of justice in confirmation of their testimony, and of incumbents of public offices in pledge of their fidelity. They are required, too, in attestation of invoices, inventories of estates, returns of taxable property, and various financial and statistical statements made under public authority. There are, also, not a few persons of whom, and occasions on which an oath of allegiance to the government of the state or nation is demanded.

An oath does not enhance one's obligation to tell the truth, or to fulfil his promise. This obliga.. tion is entire and perfect in all cases, on the ground of intrinsic fitness, and of the known will and command of God. But the tendency of oaths is to establish in the minds of men two classes of assertions and promises, one more sacred than the other. He who is required under the solemn sanction of an oath merely to tell the truth or to make a promise in good faith, arrives naturally at the conclusion that he is bound to a less rigid accuracy or fidelity in ordinary statements or promises. The law of the land, as wo have seen, bears an important part in the ethical education of the young; and by means of the legal distinction created between assertions or promises under 
oath and those made without that sanction, children and youth are trained to regard simple truth-telling and promise-keeping as of secondary obligation. This effect of legal oaths is attested by the prevalence of profane swearing; and by the frequent use of oath. like forms of asseveration, not regarded as profane, by persons of a more serious character. Except in the religious sects that abjure the use of oaths, nine per. sons out of ten swear more or less, and spontaneously confirm statements which are in the least degree strange or difficult of belief, or promises to which they wish to give an air of sincerity and earnestness, by the strongest oaths they dare to use. This comes of a felt necessity, which will exist as long as preëminent sanctity is attached to legal oaths.

Oaths are notoriously ineffective in insuring truth and fidelity. So far as their educational in fluence is concerned, they tend, as we have seen, to undermine the reverence for truth in itself considered, which is the surest safeguard of individual veracity. Then too, so far as reliance is placed upon an oath, the attention of those concerned is directed with the less careful scrutiny to the character for veracity borne by him to whom it is administered. In point of fact, men swear falsely whenever and wherever they would be willing to utter falsehorod without an oath. In sourts of justice, the pains and penaliies of perjury undoubtedly prevent a great deal of false swearing; but precisely the same penalties are attached to the affirmation of persons who, on the ground of relig- 
ious scruples, are excused from swearing, and they certainly are none too severe for false testimony, in whatever way it may be given. Notwithstanding this check, however, it is well known that before a corrupt or incompetent tribunal, an umprincipled advocate never finds any difficulty in buying false testimony; and even where justice is uprightly and skilfully administered, it is not rare to encounter between equally credible witnesses such flagrant and irreconcilable contradictions as to leave no room for any hypothesis other than perjury on one side or both. Perjury in transactions with the national revenue and with municipal assessors is by no means unprecedented among persons of high general reputation. False oaths of this description are, indeed, not infrequently preceded by some fictitious formalism, such as an unreal and temporary transfer of property; but this is done, not in order to evade the guilt of perjury, but, in case of detection, to open a technical escape from its legal penalty. Promissory oaths are of equally little worth. There is not a public functionary from the President of the United States to the village constable, who does not take what is meant to be a solemn oath (though often administered with indecent levity) to be loyal to the constitution of the country or state, and faithful in the discharge of his official duties. Yet what effect has this vast amount of swearing, if it be not to make perjury so familiar an offence as to be no longer deemed disgraceful? Not a bribe is taken by a 
member of Congress, not a contract surreptitiously obtained by a municipal official, not an appointment made to the known detriment of the public on personal or party grounds, without the commission of a crime, in theory transcendently heinous, in practice constantly condoned and ignored. Nor can we be mistaken in regarding the sacrilege and virtual blasphemy resulting from the institution of judicial, assertory, and promissory oaths, as holding no secondary place among the causes of the moral decline and corruption of which we witness so manifest tokens.

To one who does not carry foregone conclusions of his own to the interpretation of the New Testament, it can hardly appear otherwise than certain that the Founder of Christianity intended to prohibit all oaths. His precept, "Swear not at all," occurs in a series of specifications of maxims drawn from the standard morality of his day, under each of which he sets aside the existing ethical rule, and substitutes for it one covering precisely the same ground, and conformed to tho intrinsic right as represented in his own spirit and life. "Ye have heard that it hath been said, An eye for an eye, and a tooth for a tooth; but I say unto you, that ye resist not evil." "Ye have heard that it hath been said, Thou shalt love thy neighbor, and hate thine enemy; but I say unto you, Love your enemies." The analogy of these and other declarations of the same series compels us to believe that when Jesus said, "Ye have heard that it 
hath been said by them of old time, Thou shalt not forswear thyself, but shalt perform unto the Lord thine oaths," the precept which followed, "I say unto you, Swear not at all," must have applied to the same subject-matter with the maxim which precedes it,-that Jesus must have intended to disallow something that had been previously permitted. If so, not trivial or profane oaths alone, but oaths made in good taith and with due solemnity must have been included in the precept, "Swar not at all." 1 It is historically certain that the primitive Christians thus understood the evangelic precept. They not only refused the usual idolatrous forms of adjuration, but maintained that all oaths had been forbidden by their Divine Lawgiver; nor have we any proof of their

1 When Jesus forbids swearing by heaven, because "it is God's throne," and by the earth, because "it is his footstool," the inference is obvious that, for still stronger reasons, all direct swearing by God himself is prohibited. The rord $\mu \dot{\eta} \tau \epsilon$, which introduces the oaths by inferior objects specified in the text under discussion, not infrequently corresponds to our phrase not even. With this sense of $\mu \dot{\eta}_{\tau \epsilon}$, the passage would be rendered, "But I say unto you, Swear not at all, not even by heaven," etc.

I find that some writers on this subject quote in vindication of oaths on solenm occasions the instances in the scriptures in which God is said to have sworn by Himself. The reply is obvious, that no being can swear by himself, the essential signiticance of an oath being an appeal to some being or object other than one's self. Because God "can swear by no greater," it is certain that when this phraseology is used concerning Him, it is employed figuratively, to aid the poverty of human conceptions, and to express the certainty of his promise by the strongest terms which human lanance affords. In like manner, God is said by the sacred writes to repent of intended retribution to evil-toers, not that infinite justice and love can change in thought, plan, or purpose, but because a change of disposition and feeling is wont to precede human clemency to evil-doers. 
having receded from this position, until that strange fusion of church and state under Constantine, in which it is hard to say whether Christianity mounted the throne of the Cæsars or succumbed to their rule.

\section{SECTION IV.}

\section{HONESTY.}

Honesty relates to transactions in which money or other property is concerned. In its broadest sensc, it forbids not only the violation of the rights of individuals, but, equally, acts and practices designed to gain unfair emolument at the expense of the community, or of any class or portion of its members. It enjoins not merely the paying of debts and the performance of contracts, but rigid fidelity in every trust, whether private or public. Its ground is intrinsic fitness; and a sense of fitness will suggest its general rules, and will always enable one to determine his duty in individual cases. Its whole field may be covered by two precepts, level with the humblest understanding, and infallible in their application. 'The first relates to transactions between man and man, - Do that, and only that, which you would regard as just and right, if it were done to you. 'The second embraces concerns that affect numbers or rlasses of persons, - Do that, and only that, which. were you the responsible trustee and guardian of the public good, you would prescribe or sanction as just and right. 
Notwithstanding the undoubted increase of dishonesty in recent times and its disastrous frequency, there can be no doubt that the majority of men are honest, and that the transactions in which there is " deception or wrong, largely outnumber those which are frandulent. Were this not so, there could be neither confidence nor credit, enterprise would be paralyzed, business would be reduced to the lowest demands of absolute necessity, and every man would be the sole custodian of what he might make, produce, or in any way acquire. There can, therefore, be no element more directly hostile to the permanence, not to say the progress, of material civilization and of the higher interests which depend upon it, than fraud, peculation, and the violation of trust, in pecuniary and mercantile affairs, and with reference to public funds and measures. Yet there are methods, for which to a large degree honest men are responsible, in which dishonesty is created, nourished, and rewarded. In political life, if few office-holders are inaccessible to bribes, it is not becanse men of impregnable integrity might not, as in earlier times, be found in ample numbers for all places of trust; but because the compromises, humiliations, and concessions through which alone, in many of our constituencies, one can become the candidate of a party, are s.ıch as an honest man either would spurn at the outset, or could endure only by parting with his honesty. So long as men will persist in electing to municipal trusts those whose sole qualification is blind loyalty 
and unscrupulous service to a party, they can expect only robbery under the form of taxation; and, in fact, the financial revelations that have been made in the commercial metropolis of our country are typical of what is taking place, so far as opportunity serves, in cities, towns, and villages all over the land. As regards embezzlements, forgeries, and frauds in the management of pecuniary trusts, there can be no doubt that the number is greatly multiplied by the morbid sympathy of the public with the criminals, by their frequent evasion of punishment or prompt pardon after conviction, and by the ease with which they have often recovered their social position and the means of maintaining it.

In addition to this complicity with fraud and wrong on the part of the public, there are many ways in which dishonesty engenders, almost necessitates dishonesty. A branch of business, in itself honest, may be virtually closed against an honest man. The adulterations of food, so appallingly prevalent, will suggest an illustration of this point. There are commodities in which the mixture of cheaper ingredients cannot be detected by the purchaser, and which in their debased form can be offered at so low a price as to drive the genuine commodities which they replace out of the market; and thus the alternative is presented to the hitherto honest dealer to participate in the fraud, or to quit the business. The former course is, no doubt, taken by many who sincerely regret the seeming necessity 
Dishonesty not only injures the immediate sufferer by the fraud or wrong, but when it becomes frequent, is a public injury and calamity. In one way or another it alienates from the use of every honest man a very large proportion of his earnings or income. In this country, at the present time, we probably fall short of the truth in saying that at least a third part of every citizen's income is paid in the form of either direct or indirect taxation, and of this amount a percentage much larger than would be readily believed is pillaged on its way into the treasury, or in its disbursement. Then, as regards bad debts (so-called), most of them fraudulently contracted or evaded, they are not, in general, the loss of the immediate creditor, nor ought they to be; he is obliged to charge for his goods a price which will cover these debts, and honest purchasers must thus pay the dues of the insolvent purchaser. Nor is this a solitary instance in which innocent persons are obliged to suffer for wrongs with which they seem to have no necessary connection. There are very few exceptions to the rule, under which, however, we have room for but one more example. It is a well known fact that many American railways have not only cost very much more money than was ever laid out upon them, but are made, by keeping the construction-account long and generously open, to represent on the books of the respective corporations much larger sums than they cost, - especially in cases where the enterprise is lucrative and the dividends are limited by statute. 
Now in some sections of our country a transaction if this kind - essentially fraudulent, under however respectable auspices - is a disastrous wieck on productive industry by the heavy freight-tariff which it imposes, - so heavy sometimes as to keep bulky commodities, as wheat and corn, out of the markets where, at a fair cost for transportation, they might find remunerative sale. Thus the very means devised for opening the resources of a region of country may be abused to their obstruction and hindrance. In fine, dishonesty in all its forms has a diffusive power of injury, and, on the mere ground of selfdefence, demands the remonstrance and antagonism of the entire community.

While in most departments of conduct there is a wide neutral ground between the right and the condemnably wrong, there are matters of business in which there seems to be no such intermediate territory, but in which what is fair, honorable, and even necessary, is closely contiguous to dishonesty. Thus, except in the simplest retail business, all modern commerce is speculation, and the line between legitimate and dishonest speculation is to some minds difficult of discernment. Yet the discrimination may be made. A man has a right to all that he earns by services to the community, and these earnings may in individual instances reach an immense sum. We can easily understand how this may be, nay, must needs be the case with the very high salaries paid to master manufacturers. Such salaries would not be paid, did 
not the intelligence, skill, and organizing capacity of these men cheapen by a still larger amount the commodities made under their dirution. The case is precisely similar with the merchant engaged in legitiinate commerce. By his knowledge of the right times and best modes of purchasing, by his enterprise and sagacity in maintaining intercourse with and between distant markets, and by his outlay of capital and skill as a carrier of commodities from the place of their production to the place where they are needed for use, he cheapens the goods that pass through his hands by a greater amount than the toll he levies upon them, which - however large - is his rightful due.

Thus also, when, in anticipation of a scarcity of some one commodity, a merchant so raises the price as essentially to diminish the sale, he earns his increased profits; for an enhanced price is the only practicable check on consumption. For instance, if at the actual rate of consumption the bread-stuff on hand would be consumed a month before the new harvest could be made availing, no statistical statement could prevent the month of famine; but experienced grain-merchants can adjust the price of the stock in hand so as to induce precisely the amount of econony which will make that stock last till it can be replaced. They will, indeed, obtain a large profit on their sales, and will be accused by ignorant persons of speculating on scarcity and popular apprehension; but it will be due wholly to their prescience that the 
scarcity did not become famine, and the apprehension suffering; and they will have merited for this service more than the largest profits that can accrue to them.

The same principles will apply to speculation in stocks, which is in many minds identified with dishonest gain. Stocks are marketable commodities, equally with sugar and salt. They are liable to legitimate fluctuations in value, their actual value being affected, often by facts that transpire, often by opinions that rest on assignable grounds. Now if a man possess skill and foresight enough to buy stocks at their lowest rates and to sell them when they will bring him a profit, he makes a perfectly legitimate investment of his intelligence and sagacity, and in facilitating sales for those who need to sell, and purchases for those who wish to buy, and thus preventing capital from lying unused, or remaining inconvertible at need, he earns all that his business yields him by the substantial services which he renders.

The legitimate business of the merchant and the broker is contingent, as we have seen, on fluctuations in the market, and he who has the sagacity to foresee these fluctuations and the enterprise to prepare for them, derives from them advantage to which he is fairly entitled. But it is precisely at this point that the stress of temptation rests, and the opportunity presents itself for dishonesty in ways of which the laws take no cognizance, and on which public opinion is by no means severe. The contingencies which sagacity can foresee, capital and credit can 
often create. Virtual scarcity may be produced by forestalling and monopoly. When there is no actual dearth, even famine-prices may be obtained for the necessaries of life by the skilful manipulation of the grain-market. So, too, in the stock-market, bonds and shares, instead of being bought or sold for what they are worth, of actual owners and to real purchasers, may be merely gambled with, - bought in large amounts in order to create a demand that shall swell their price, or so thrown upon the market as to reduce their price below their real value, and all this with the sole purpose of mutual contravention and discomfiture. By operations of this kind, not only is no useful end subserved, but the financial interests and relations of the community are injuriously, often ruinously, deranged; while not a few private holders of stock have their credit essentially impaired by a sudden fall of price, or by the inflation of nominal value are led into rash speculations.

In the cases cited it may be seen how closely the right abuts upon the wrong, so that one may overpass the line almost unconsciously. Yet it is believed that a man may determine for himself on which side of the line he belongs. The department of business, or the mode of transacting business, which cannot by any possibility be of benefit to the community, still more, that which in its general course is of positively injurious tendency, is essentially dishonest, even though there be no individual acts of fraud. He 
really defrauds the public who lives upon the publio without rendering, or purposing to render any valuable return ; and if there be any profession or department of business to which this description applies, it should be avoided or forsaken by every man who means to be honest.

Among the many mooted cases in which the question of honesty is involved, our proposed limits will permit us to consider only that of usury ${ }^{1}$ (so-called). There can be no doubt that usury laws and the opinion that sustains them sprang from the false theory, according to which money was regarded, not as value, but merely as the measure of value. It is now understood that it owes its capacity to measure value solely to its own intrinsic value; that its paper representatives can equal it in purchasing power only when convertible at pleasure into coin; and that paper not immediately convertible can obtain the character of money only so far as there is promise or hope of its ultimate conversion into coin. It follows that money stands on the same footing with all other values, that its use, therefore, is a marketable commodity, varying indefinitely in its fitting price, according as money is abundant or scarce, the loan for a long or a short period, and the borrower of more or less certain solvency. For ordinary loans the relations of supply and demand are amply competent to regulate the rate

1 The odious meaning of excessive interest, as attached to usury, is of comparatively recent date. In the earlier English, as in our translation of the Bible, it denotes ary sum griven for the use of money. 
of interest, while he who incurs an extra-hazardous risk fairly earns a correspondingly high rate of compensation. There is, therefore, no intrinsic wrong in one's obtaining for the use of his money all that it is worth; and while we cannot justify the violation of any lizws not absolutely immoral, dishonesty forms no part of the offence of the man who takes more than legal interest. ${ }^{1}$

\section{SECTION V.}

\section{BENEFICENCE.}

We have a distinct consciousness of the needs of human beings. If we have not suffered destitution in our own persons, we yet should deprecate it. What we should dread others feel. The things which we find or deem essential to our well-being, many lack. We, it may be, possess them or the means of procuring them, beyond our power of personal use. This larger share of material goods has come to us, indeed, honestly, by the operation of laws inherent in the structure of society, and thus, as we believe, by Divine appointment. At the same time we are conscious, in a greater or less degree, of the benevolent affections. We are moved to pity by the sight or knowledge of want or suffering. Our sense of fit-

1 In this country usury laws are fast yielding to the growth of intelli gence in monetary affairs. Wherever they exist in their severer forms, they only enhance the rate of interest paid by the major portion of the class of borrowers, as the lender must be compensated, not only for the aze of his money, and for the risk of his creditor's inability to repay it,

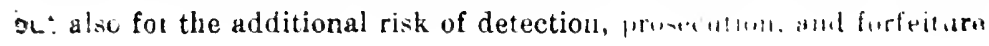


ness is painfully disturbed by the existence of needs unsupplied, of calamities unrelieved. We cannot but be aware of the adaptation of such superfluity of material goods as we may possess to beneficent uses; and it can hardly be that we shall not rest in the belief that, in the inevitable order of society, it is the predetermined design and purpose of abundance to supply deficiency, - of the capacity of service, to meet the ever pressing demands for service. Beneficence, then, is a duty based on considerations of intrinsic fitness.

But beneficence must be actual, not merely for mal, good-doing. Some of the most easy and obvious modes of supply or relief are adapted to perpetuate the very evils to which they minister, either by destroying self-respect, by discouraging self-help, or by granting immunity to positively vicious habits. The tendency of instinctive kindness is to indiscriminate giving. But there can be very few cases in which this is not harmful. It sustains mendicants as a recognized class of society; and as such they are worse than useless. They necessarily lose all sense of personal dignity; they remain ignorant or become incapable of all modes of regular industry, and it is impossible for them to form associations that will be otherwise than degrading and corrupting.

Of equally injurious tend are the various modes of relief at the public charge. They affix upon their beneficiaries the indelible brand of pauperism, which in numerous instances becomes hereditary, and in not a few cases has been transmitted throngk 
several generations. Experience has shown that re. covery from a condition this dependent is exceedingly rare, even with the young and strong, who, had they been tided over the stress of need by private and judicious charity, would shortly have resumed their place among the self-subsisting members of the community. Public alms, while they are thus harmful to their recipients, impose upon society a far heavier burden than private charity. This is due in part to the permanent pauperism created by the system, in part to the wastefulness which characterizes public expenditures of every kind. By special permission of the national legislature, the experiment was tried in Glasgow, under the direction of Dr. Chalmers, of substituting private munificence for relief from the public chest, in one of the poorest territorial parishes of the city, embracing a population of ten thousand, and the result was the expenditure of little more than one third of what had been expended under legal author. ity. At the same time, the poor and suffering were so much more faithfully and kindly cared for, that there was a constant overflow of poverty from the other districts of the city into this. Publi charity, when thoroughly systematized, is liable to the still stronger objection, that those who are able to give relief, in ceasing to feel the necessity. lose the will and the capacity of benevolent effort. Yet, were there no public provision for the poor, there would be cases of destitution, disease, disability, and mental imbecility, which would elude private charity, how- 
ever diligent and generous. It must be remembered, too, that the same causes may at once enhance the demand for benefirent aid, and cripple its resources. Thus, in a conflagration, a flood, a dearth, or a com. mercial panic, while the stress of need among the poor is greatly intensified, the persons on whose charity under ordinary circumstances, they could place the most confident reliance, may be among the chief sufferers. Thus, also, during the prevalence of infectious disease, a large proportion of those who are wont to perform the offices of humanity for the suffering, are withdrawn by their own fears, or those of their friends, from their wonted field of service. Then, too, there are various forms of disease and infirmity, which de mand special treatment or a permanent asylum; and while institutions designed to meet these wants are more wisely and economically administered under private than under public auspices, the state should never suffer them to fail or languish for lack of subsidy from private sources. The most desirable condition of things undoubtedly is that - more nearly realized in France than in any other country in Christendom - in which the relief of the poor and suffering in ordinary cases, and the charge of charitable institutions to a large degree, are left to individuals, voluntary organizations, and religious fraternities and sisterhoods, while government supplements and subsidizes private charity whe $e$ it is found inadequate to the need

The demands upon beneficence are by no means 
exbausted, when material relief and aid have been bestowed. Indeed, alms are often given as a purchase of quitclaim for personal service. But the manifestation and expression of sympathy may make the gift of immeasurably more worth and efficacy. Considerate courtesy, delicacy, and gentleness are essential parts of beneficence. There are very few so abject that they do not feel insulted and degraded by what is coldly, grudgingly, supercilicasly, or chidingly bestowed; while the thoughtful tenderness which never forgets the sensibilities of those whom it relieves, inspires comfort, hope, and courage, arouses whatever capacity there may be of self-help, and is often the means of replacing the unfortunate in the position from which they have fallen.

Beneficence has a much broader scope than the mere relief of the poor and suffering. In the daily intercourse of life there are unnumbered opportunities for kindness, many of them slight, yet in their aggregate, of a magnitude that eludes all computation. There is hardly a transaction, an interview, a casual wayside meeting, in which it is not in the power of each person concerned to contribute in an appreciable degree to the happiness or the discomfort of those whom he thus meets, or with whom he is brought into a relation however transient. In all our movements among our fellow-men, it is possible for us to "go about doing good." What we can thus do we are bound to do. We perceive and feel that this is fitting for us as social and as mutually dependent beings. We are con. 
scious of the benefit accruing to us from little, name. less attentions and courtesies, often of mere look, or manner, or voice; and from these experiences we infer that the possibility, and therefore the duty of beueficence is coextensive with our whole social life.

The measure of beneficence, prescribed for us on the most sacred authority, "All things whatsoever ye would that men should do to you, do ye even so to them," needs only to be stated to be received as authentic. It supplies a measure for our expectations also, as well as for our duties. We have a right to expect from other's as much courtesy, kindness, service as, were they in our place and we in theirs, we should feel bound to render to them, - a rule which would often largely curtail our expectations, and in the same proportion tone down our disappointments and imagined grievances.

There is another scriptural precept, "Thou shalt love thy neighbor as thyself," which might at first sight seem impracticable, yet which, as we shall see on closer examination, represents not only a possible attainment, but one toward which all who heartily desire and love to do good are tending. There are various conditions under which, confessedly, human beings love others as well as themselves, or better. What else can we say of the mother's love for her child, for whose well-being she would make any conceivable sacrifice, nay, were there need, would surrender life itself? Have we not also sometimes witnessed a filial devotion equally entire and self-forgetting? 
Nor are instances wanting, in which brothers and sis ters, or friends who had no bonds of consanguinit! have shom by unmistakable deeds and sufferings th" their love for one another was at least equal to thei self-love. This same love for others, as for himself is manifested by the self-devoting patriot, the prac tical philanthropist, the Christian missionary. Ther is ample ground for it in the theory of humanity which forms a part of our accustomed religious utterance. We call our fellow-men our brethren, as children of the same Father. So far as sayings like these are sentiments, and not mere words, there must be in our feelings and conduct toward and for our fell'w-men in general a kindness, forbearance, self-forgetfulness, and self-sacrifice similar to that of which, toward our near kindred, we would not confess our selves incapable. Here it must be borne in mind that the precepts of Christianity represent the perfection which should be our constant aim and our only goal, not the stage of attainment which we are conscious of having reached, or of being able to reach with little effort.

The love of enemier is also enjoined upon us by Jesus Christ. Is this possible? Why not? There are cases where one's nearest kindred are his worst enemies; and we have known instances in which love has survived this rudest of all trials. Were the Christian idea of universal brotherhood a profound sentiment, it would not be quenched by enmity, however bitter. Enmity toward ourselves need not affect our 
estimate of one's actual merit or clains. If we should not think the worse of a man because he was the enemy of some one else, why should we think the worse of him because he is our enemy? He may have mistaken our character and our dispositions; and if so, is he more culpable for this than for any other mistake? Or if, on the other hand, he has some substantiai reason for disliking us, we should either remove the cause, or submit to the dislike without feeling aggrieved by it. At any rate we can obey the precept, "Do good to them that hate you ;" and this is the only way, and an almost infallible way, in which the enmity may be overcome, and superseded by relations of mutual kindness and friendship 


\section{CHAPTER XI.}

FORTITUDE; OR DUTIES WITH REFERENCE TO UNAVOIDABLE EVILS AND SUFFERINGS.

HERE are, in almost every prolonged human ex-
perience, privations and sufferings to be endured, disappointments to be submitted to, obstacles and difficulties to be surmounted and overcome. From whatever source these elements of experience proceed, even if from blind chance, or from fate (which denotes the utterance or decree of arbitrary and irresponsible power), the strong man will brace himself up to bear them; the wise man will shape his conduct by them; the man of lofty soul will rise above them. But the temper in which they will be borne, yielded to, or surmounted, must be contingent on the belief concerning them. If they are regarded as actual evils, they will probably be endured with sullerness, or submitted to with defiance and scorn, or surmounted with pride and self-inflation. Even in the writings of the later Stoics, which abound in edifying precepts of fortitude and courage under trial, there is an undertone of defiance, as if the sufferer were contending with a hostile force, and a constant tendency to extol and almost deify the energy of soul which the good man displays in fighting with a hard destiny. If, on the other hand, physical evils are regarded as wise and 
benign appointments of the Divine love and fatherhood, the spirit in which they are borne and struggled against is characterized by tenderness, meekness, humility, trust, and hope. It is instructive in this regard to read alternately the Stoics and St. Paul, and to contrast their magnanimous, but grim and stern resignation, with the jubilant tone in which, a hundred times over, and with a vast variety of gladsome utterance, he repeats the sentiment contained in those words, "As sorrowful, yet always rejoicing." As ours is the Christian theory as to the (so-called) evils of human life, we shall recognize it in our treatment of the several virtues compreliended under the general title of Fortitude.

\section{SECTION 1.}

\section{PATIENCE. ${ }^{1}$}

Patience is incumbent on us, only under inevitable sufferings or hardships, or under such as are incurred in the discharge of manifest duty, or for the benefit of our fellow-men. Needless sufferings or privations we are bound to shun or to escape, not to bear. The caution and foresight by which they may

1 The reader need not be told that patience and passion are derived from different participles of the same verb. Patience comes from the present participle, and fit1'ingly denotes the spirit in which present suffering should be met; while passion comes from the perfect or past participle, and as fittingly denotes the condition ensuing upon any physical, mental, or moral affection, induced from without, which has been endured without protest or resistance. 
be evaded huld an essential place among the duties of prudence. Nor doer reason or religion sanction selfimposed burdens or hardships of any kind, whether in penance for wrong-doing, as a means of purchasing the Divine favor, or as a mode of spiritual discipline.

Patience implies serenity, cheerfulness, and hope fulness, under burdens and trials. It must be distinguished from apathy, which is a temperament, not a virtue. There are some persons whose sensibilities are so sluggish that they are incapable of keen suffering, and of profound and lasting sorrow. We can hardly call this a desirable temperament; for its capacity of enjoyment is equally defective, and, as there is more happiness than misery in almost every life, he whose susceptibility of both pain and pleasure is quick and strong is, on the whole, the gainer thereby. The serenity of patience requires vigorous self-command. It is essential, first of all, to control, and as far as possible to suppress, the outward tokens of pain and grief. They, like ail modes of utterance, deepen the feeling they express; while a firm and self-contained bearing enhances the fortitude which it indicates. Control must also be exercised over the thoughts, that they be abstracted from the painful experiense, and employed on themes that will fill and task them. Mental industry is the best relief that mere philosophy has for pain and sorrow; and though it certainly is not a cure, it never fails to be of service as a palliative. Even when bodily distress or infirmity 
renders continuous thought impossible, the effort of recollection, or the employment of the mind in matters too trivial for its exercise in health, may relieve the weariness and iighten the stress of suffering. Nor let devices of this sort be deemed unworthy of a place even among duties: for they are often essential means to ends of high importance. They assert and main tain the rightful supremacy of the mind over the body; they supersede that morbid brooding upon painful experiences which generates either melancholy or querulousness; and they leave in the moral nature an unobstructed entrance to all soothing and elevating influences.

Cheerfulness in the endurance of pain and hardship must result in great part from the belief. If I regard myself as irresistibly subject to an automatic Nature, whose wheels may bruise or crush me at any moment, I know not why or how I could be cheerful, even in such precarious health or prosperity as might fal to my lot; and there could certainly be no reassuring aspect to my adverse fortune. But if I believe that under a fatherly Providence there can be no suffering without its ministry of mercy, no loss without its greater gain within my reach and endeavor, no hardshir without its reflex benefit in inward growth and energy, then I can take and bear the inevitable burdens of this earthly life in the same spirit in which $I$ often assume burdens not impased upon me from without, for the more than preponderant benefit which I hope to derive from them. But if I have this faith 
in a benignant Providence shich will not afflict me uselessly, I am under obligation not tc let my faith, if real, remain inactive in my seasons of pain, loss, or grief. I am bound so to ponder on my assured belief, and on such proofs of it as may lie in my past experience, that it shall give its hue to my condition, its tone to my thought, its direction to the whole current of my sentiment and feeling. Thus may endurance be not only calm, but cheerful, because pervaded by the conviction that at the heart of all that seems evil there is substantial good.

Yet, it cannot be denied that there are life-long burdens and griefs, - incurable illnesses, irretrievable losses, bereavements that will never cease to be felt, and cannot be replaced. Especially in advanced years there are infirmities, disabilities, and privations, which cannot by any possibility have a resultant revenue equivalent to what they take from us; for in old age the growth of character is too slow to be worth the sacrifice which in earlier life may be more than cornpensated by the consciousness of spiritual enlargement and increase. How shall these burdens be borne cheerfully? They cannot, unless they be also borne hopefully. But if there be presented to the faith, beyond the earthly life, a future, the passage into which is to be made the easier by loss and sorrow here; if families are there to be reunited, and roid places in the affections filled again ; if worthy hopes, seemingly disappointed, are only postponed for a richer and happier fulfilment, - there is in that fu- 
ture exhaustless strength for solace and support under what must be endured here. Earthly trial must seem light and momentary in view of perfect and eternal happiness; and thus the hope that lays hold on an infinite domain of being is coined into utilities for the daily needs of the tried, suffering, afflicted, and agebowed, supplying to patience an element without which it cannot be made perfect.

\section{SECTION II.}

SUBMISSION.

There are events, seemingly adverse, which in themselves are transient, and inflict no permanent dis. comfort, but which necessitate the surrender of cherished expectations, the change of favorite plans, it may be, the life-long abandonment of aims and hopes that had held the foremost place in the anticipated future. Here submission of some sort is a necessity. But the submission may be querulous and repining; it may be bitter and resentful; it may be stern and rigid. In the last of these types only can there be any semblance of virtue: and this last can be virtuous, only where inevitable events are attributed to Fate, and not to Providence. But if a wise and kind Providence presides over human affairs, its decrees are our directory. The very events which hedge in, mark out our way. The tree which has its upward growth checked spreads its branches; that which is 
circumsuibed in its lateral expansion attains the greater height. The tendrils of the vine are guided by the very obstacles placed in its way. Thus, in hunan life, impassable barriers in one direction prescribe aims and endeavors in a different direction. The things that we camnot do determine the things that we ought to do. The growth which is impeded must give place to growth of a different type, and to us undoubtedly more wholesome, more congenial with our capacities, more conducive to our true well-being. What seem obstacles may be supports, giving the best possible direction to our active powers, and so training our desires and affections as to lead to higher happiness and more substantial good than could have otherwise been attained.

Submission, then, must be grounded in faith. The inevitable must be to us the appointment of Omniscient Love. In our childhood the very regimen and discipline that were least to our taste proceeded often from the wisest counsels, and in due time we acquiesced in them as judicious and kind, nor would we in the retrospect have had them otherwise. As little as we then knew what was best for our well-being in the nearer future, we may now know as to what is best for us in a remote future, whether in the present or in a higher state of being. All that remains for us is acquiescence, cheerful and hopeful, in a Wisdom that cannot err, in a Love which can will only the best of which we are capable.

Submission is not merely a passive, but equally 
an active virtue. Inevitable events impose imperatire duties. In the direction which they indicate there is work for us, of self-culture, of kinduess, of charity. Our characters can be developed, not by yielding, however cheerfully, to what seem misfortunes, but by availing ourselves of the opportunities which they present, in place of those of which they have deprived us. When the way we had first chosen is barred against us, we are not to lie still, but to move onward with added diligence on the way that is thus opened to us. If outward success is arrested and reverted, there is only the more reason for improving the staple of our inward being. If those dearest to us have passed beyond the reach of our good offices, there are the more remote that may be brought near, and made ours, by our beneficence. If our earthly life is rendered desolate, the affections, hopes, and aims thus unearthed may by our spiritual industry and thrift be trained heavenward. All this is included in full submission to the will of the Divine providence; for that will is not our loss, disappointment, or suffering, but our growth, by means of it, in quantity of mental and spiritual life, in capacity of duty, and in the power of usefulness.

\section{SECTION III.}

COURAGE.

Patience, as its name imports, is a passıve quality ; Submission blends the passive and the active; while 
Courage is preëminently an active virtue. Patience resigns itself to what must be endured; submission "onforms itself to what it gladly would, but cannot reverse; courage resists what it cannot evade, surmounts what it camnot remove, and declines no con. fict in which it is honorable to engage. It is obvious that the occasions for these virtues are widely different. Patience has its place where calm and cheerful endurance is the only resource; submission, where there must be voluntary self-adaptation to altered circumstances; courage, where there is threatened evil which strenuous effort can avert, mitigate, or subdue.

Courage is a virtue, only when it is a necessity. There is no merit in seeking danger, in exciting op. position, in courting hostility. Indeed, conduct of this description more frequently proceeds from persons who know themselves cowards and fear to be thought so, than from those who are actually possessed of courage. . But there are perils, encounters, enmities, which cannot by any possibility be avoided, and there are others which can be avoided only by the sacrifice of principle, or by the surrender of opportunities for doing good, and which, therefore, to a virtuous man are inevitable.

The physical courage, commonly so called, which is prompt and fearless in the presence of imminent danger, or in armed conflict with enemies, may be, or may not be, a virtue. It may proceed from a mind too shallow and frivolous to appreciate the worth of 
life or the magnitude of the peril that threatens it; it may, as often in the case of veteran soldiers, be the result of discipline without the aid of principle; or it nay depend wholly on intense and engrossing excitement, so that he who would march fearlessly at the head of a forlorn hope might quail before a solitary foe. But if one be, in the face of peril, at the same time calm and resolute, self-collected and firm, cautious and bold, fully aware of all that he must encounter and unfalteringly brave in meeting it, such courage is a high moral attainment. Its surest source is trust in the Divine providence, - the fixed conviction that the inevitable cannot be otherwise than of benignant purpose and ministry, though that purpose may be developed and that ministry effected only in a higher state of being. To this faith must be added a strong sense of one's manhood, and of his superiority by virtue of that manhood over all external surroundings and events. We are conscious of a rightful supremacy over the outward world, and deem it unworthy to succumb, without internecine resistance, to any force by which we may be assailed, whether that force be a power of nature or a wrongful assault from a fellow-man. It is the presence of this consciousness that wins our admiration for all genuine heroism, and the absence of it at the moment of need that makes cowardice contemptible.

There is a moral courage required in pursuing our legitimate course in life, or in discharging our manifest duty, notwithstanding straitnesses, hindrances, 
obstacles, to which the feeble and timid sould not but yield. The constituent elements of this type of courage are precisely the same that are needed in the encounter with physical peril. In both cases it is equally unmanly to succumb until we have resisted to the utmost. But while physical courage can at best only insure our safety, moral courage contributes essentially to the growth of mind and character; and the larger the opportunity for its exercise, the greater will be the mass of mind, the quantity of character, the power of duty and of usefulness. Straitnesses develop richer resources than they bar. Hindrances nurture hardihood of spirit in the struggle against them, or in the effort to neutralize them. Obstacles, when surmounted, give one a higher position than could be attained on an unobstructed path. The school of difficulty is that in which we have our most efficient training for eminence, whether of capacity or of moral excellence. What are accounted inevitable evils are, when met with courage, only benefits and blessings, inasmuch as they bring into full and vigorous exercise the hardier muscles and sinews of the inner man, to measure strength with them or to rise above them.

Courage is needed in the profession and maintenance of the true and the right, when denied, assailed, or vilipended. Communities never move abreast in the progress of opinion. There are always pioneer minds and consciences; and the men who are in advance of their time must encounter obloquy at least, 
often persecution, loss, hardship, sometimes legai penalties and disabilities. Under such circumstances, there are doubtless many more thist inwardly acknowledge the unpopular truth or the cuntested riglit, than there are who are willing to arow and defend their belief. Many are frightened into false ntterance or deceptive silence. But there must be in such minds a conscious mendacity, fatal to their own selfrespect, and in the highest degree detrimental to their moral selfhood. It demands and at the same time nurtures true greatness of soul to withstand the current of general opinion, to defy popular prejudice, to make one's self "of no reputation" in order to preserve his integrity unimpaired. Therefore is it that, in the lapse of time, the rery men who have been held in the lowest esteem rise into eminence in the general regard, sometimes while they are still living, oftener with a succeeding generation. Martyrs in their day, they receive the crown of martyrdom when the work which they commenced is consummated. The history of all the great reforms which have been successive eras in the moral progress of Christendom is full of names, once dishonored, now among the foremost of their race.

This type of courage has, in less enlighıened ages than our own, been made illustrious by those who have sacrificed life rather than deny or suppress beliefs which they deemed of vital moment. It cun hardly be anticipated that the civilized world will recele so far into barbarism as to light again th 
death-flame of persecution; but it may be questioned whether the chronic sacrifice if all which men most desire in life requires or manifests less of heroism than in earlier times furnished victims for the arena or the stake.

In the moral hierarchy the first rank is probably due to the courage that inspires and sustains ardua ous and perilous philanthropic enterprise. The martyr for opinion suffers or dies rather than stain his soul with the positive guilt of falsehood; while the philanthropist might evade toil and danger without committing any actual sin, or making himself liable to censure or disapproval either from God or man. In the former case, hardship or danger is rendered inevitable by the felt necessity of self-respect; in the latter, by the urgency of a love for man equal or superior to the love for self. As examples of this highest type of courage, it may suffice to name Howard, whose labors for prison-reform were pursued at the well-known risk and the ultimate cost of his life; Florence Nightingale and the noble sisterhood inaugurated by her, who have won all the untarnished and undisputed laurels of recent wars on both sides of the Atlantic; and the Christian missionaries to sav. age tribes and in pestilential climates, who have often gone to their work with as clear a consciousness $o$; deadly peril as if they had been on their way to $a$ battle-field. 


\section{CHAPTER XII.}

\section{ORDER; OR DUTIES AS TO OBJECTS UNDER ONE'S OWN CONTROL.}

'THERE are many duties that are self-defined and self-limited. Thus, the ordinary acts of justice and many of the charities of daily life include in themselves the designation of time, place, and measure. There are other duties, of equal obligation, which admit of wide variance as to these particulars, but which can be most worthily and efficiently performed only when reference is had to them. There are, also, many acts, in themselves morally indifferent, which acquire their moral character as right or wrong solely from one or more of these particulars. Thus recreations that are innocent and fitting on Saturday, may be inconsistent with the proprieties of Sunday ; conversation and conduct perfectly befitting the retirement of home may be justly offensive in a place of public concourse; or there may be great guilt in the excessive use of that which used in moderation may be blameless, fitting, and salutary. 


\section{SECTION 1 .}

\section{TLME.}

A life-time is none too long for a life's work. Hence the fitness, and therefore the duty, of a careful economy of time. This economy can be secured only by a systematic arrangement of one's hours of labor, relaxation, and rest, and the assignment to successive portions of the day, week, or year, of their appropriate uses. The amount of time wasted, even by an industrious man who has no method or order in his indus. try, bears a very large proportion to the time profitably employed. In the needlessly frequent change of occupations, there is at each beginning and ending a loss of the working power, which can neither start on a new career at full speed, nor arrest itself without previous slackening. This waste is made still greater by the suspense or vacillation of purpose of those who not only have no settled plans of industry, but often know not what to do, or are liable, so soon as they are occupied in one way, to feel themselves irresistibly drawn in a different direction.

But in the distribution of time a man should be the master, not the slave of his system. The regular work and the actual duty of the moment do not always coincide. Due care for health, the opportunity for earned and needed recreation, the claims of charity, courtesy, and hospitality, in fine, the immediate urgency of any duty selfward, manward, or 
Godward, should always take precedence of routine. work however wisely planned. Obstinate adherence to system may lead to more and greater criminal omissions of duty than would be incurred, even in the spasmodic industry which takes its impulse from the passing moment. It must be remembered that timeliness is the essential element of right and obligation in many things that ought to be done, especially in all forms of charity, alike in great services, and in those lesser amenities and kindnesses which contribute so largely to the charm of society and the happiness of domestic life. There are many good offices which, performed too late, were better left undone, - courtesies which, postponed, are incivilities, - attentions which, out of season, are needless and wearisome.

Every day, every waking hour has its own duty, either its special work, or its due portion of one's normal life-work. Procrastination is, therefore, as unwise as it is immoral, or rather, it is immoral because it is unwise and unfitting. The morrow has its own appropriate duties; and if to-day's work be thrown into it, the massing of two days' good work into one exceeds ordinary ability. The consequence is, either that both days' works are imperfectly performed, or that part of what fitly belongs to the morrow is pushed farther on, and the derangement of duty made chronic. Thus there are persons who are always in arrears with their engagements and occupations, - in chase, as it were, after duties which they never lose from sight, and never overtake. 
Hardly less grave, though less common, is the error of those who anticipate duty, and do to-day what they ought to do to-morrow. The work thus anticipated may be superseded, or may be performed under better auspices and with fewer hindrances in its own time; while it can hardly fail to interfere injuriously with the fit employment or due relaxation of the passing day. Moreover, the habit of thus performing work before its time at once betokens and intensifies an uneasy, self-distrusting frame of mind, unfavorable to vigorous effort, and still more so to the quiet enjoyment of needed rest and recreation. There are those, who are perpetually haunted by the forecast shadows, not only of fixed, but of contingent obligations and duties, - shadows generally larger than the substance, and often wholly destitute of substance.

Punctuality ${ }^{1}$ denotes the most scrupulous precision as to time, - exactness to a moment in the observance of all times that can be designated or agreed upon. In matters with which we alone are concerned, we undoubtedly have of right, and may often very fittingly exercise, the dispensing power. Thus, in the arrangement of our own pursuits, the clock may measure and direct our industry, without binding us by its stroke. It is often of more consequence that we finish what is almost done, than that we change our work because the usual hour for a change has arrived. But where others are concerned, rigid 
punctuality is an imperative duty. A fixed time for an assembly, a meeting of a committee or board of trust, or a business interview, is a virtual contract into which each person concerned has entered with every other, and the strict rules that apply to contracts of all kinds are applicable here. Failure in punctuality is dishonesty. It involves the theft of time, which to some men is money's worth, to others is worth more than money. It ought not to surprise us if one wantonly or habitually negligent in this matter should prove himself oblivious of other and even more imperative obligations; for the dullness of conscience and the obscure sense of right, indicated by the frequent breach of virtual contracts as to time, betoken a character too feeble to maintain its integ. rity against any strong temptation.

\section{SECTION II.}

\section{PLACE.}

The trite maxim, A place for everything, and everything in its place, so commends itself to the sense of fitness, as hardly to need exposition or enforcement; yet while no maxim is more generally admitted, scarce any is so frequently violated in practice. In duty, the elements of time and place are intimately blended. Disorder in place generates derangement in time. The object which is out of place can be found only by the waste of time; and the most 
faithful industry loses a large part of its value when its materials are wanting where they ought to be, and must be sought where they ought not to be.

Apart from considerations of utility, order is an msthetic duty. It is needed to satisfy the sense of beauty. Its violation offends the eye, insults the taste. The æsthetic nature craves and claims culture. It has abundant provision made for it in external nature; but so large a part of life must be passed within doors, at least in a climate like ours, that it is starved and dwarfed, if there be not in interior arrangements some faint semblance of the symmetry and harmony of the universe. To effect this needs neither abundance nor costliness of material. A French man or woman wili charm the eye at a cost which in England would be represented by bare and squalid poverty. A Parisian shop-window will make with a few francs' worth of goods an exhibition of artistical beauty which might challenge the most fastidious criticism. These effects are produced solely by prime reference to fitness of place, - to orderly arrangement, - to a symmetry which all can understand, and which any one might copy. Our very capacity of receiving gratification from this source is the measure of our duty in this regard. If with the simplest materials we can give pleasure to the soul through the eye by merely assigning its th place to every object, order is among the plainest dictates of beneficence.

Order is essential to domestio comfort and well- 
being, and thus to all the virtues which have their earliest and surest nurture in domestic life. There are homes at once affluent and joyless, groaning with needless waste and barren of needed comfort, in which the idea of repose seems as irrelevant as Solomon's figure of lying down on the top of a mast, and all from a pervading spirit of disorder. In such dwellings there is no love of home. The common house is a mere lodging and feeding place. Society is souglit elsewhere, pleasure elsewhere; and for the young and easily impressible there is the strongest inducement to those modes of dissipation in which vice conceals its grossness behind fair exteriors and under attractive forms. On the other hand, the well-ordered house affords to its inmates the repose, comfort, and enjoyment which they crave and need, and for those whose characters are in the process of formation may neutralize allurements to evil which might else be irresistible.

\section{SECTION III.}

MEASURE.

There are many objects, as to which the question of duty is a question of more or less. To this class belong not only food and drink, but all forms of lux. ury, indulgence, recreation, and amusement. In all these the choice lies between excess, abstinence, and temperance. The tendency to excess is intensely strong, when not restrained by prudence or principle. 
This tendency is by no means confined to the appetite for intoxicating liquors, though modern usage has restricted to excess in this particular the term intem. perance, which properly bears a much more extended signification. There is reason to believe that there is fully as much intemperance in food as in drink, and with at least equally ruinous consequences as to capacity, character, health, and life, - with this difference only, that gluttony stupefies and stultifies, while drunkenness maddens; and that the glutton is merely a dead weight on the community, while the drunk. ard is an active instrument of annoyance and peril. There are probably ferver who sink into an absolutely beastly condition by intemperance in food than by intemperance in drink; but of persons who do not expose themselves to open scandal, those whose brains are muddled, whose sensibilities are coarsened, and whose working power is impaired by over-eating, are more numerous than those in whom similar effects are produced by over-free indulgence in intoxicating drinks. Intemperance in amusements, also, is not uncommon, and would undoubtedly be more prevalent than it is, were not the inevitable necessity of labor imposed on most persons from a very early period. In this matt $r$ the limit between temperance and excess is aptly fixed by the term recreation, as applied to all the gay and festive portions of life. Re-creation is making over, that is, replacing the waste of tissue, brain-power, and physical and mental energy occasioned by hard work. Temperance per- 
mits the most generous indulgence of sport, mirth, and gayety that can be claimed as needful or conducive to this essential use, but excludes all beyond this measure.

Abstinence from all forms of luxury and recreation, and from food and drink beyond the lowest demands of subsistence, has, under various cultures, been regarded as a duty, as an appropriate penance for sin, Hs a means of spiritual growth, as a token of advanced excellence. This notion had its origin in the dualistic philosophy or theology of the East. It was believed that the sovereignty of the universe was divided between the semi-omnipotent principles of good and evil, and that the earth and the human body were created by the evil principle, - by Satan or his analogue. Hence it was inferred that the evil principle could be abjured and defied, and the good principle propitiated in no way so effectually as by renouncing the world and mortifying the body. Fasting, as a religious observance, originated in this belief. It was imported from the East. The Hebrew fasts were not established by Moses; they were evidently borrowed from Babylon, and seem to have been regarded with no favor by the prophets. The Founder of Christianity prescribed no fast, nor have we any reason to believe that his immediate disciples regarded atstinence as a duty. Christian asceticism in all its forms is, like the Jewish fasts, of Oriental origin, and had its first developments in close connection with those hybrids of Christianity and Oriental philosophy of 
which the dualism already mentioned forms a prominent feature.

With regard to all objects of appetite, desire, and enjoyment, temperance is evidently fitting, and therefore a duty, unless there be specific reasons for abstinence. Temperance demands and implies moral activity. In the temperate man the appetites, desires, and tastes have their continued existence, and need vigilant and wise control, so that he has always work to do, a warfare to wage; and as conflict with the elements gives vigor to the body, so does conflict with the body add strength continually to the moral nature. The ascetic may have a hard struggle at the outset; but his aim is to extirpate his imagined enemies in the bodily affections, and when these are completely mortified, or put to death, there remains no more for him to do, and moral idleness and lethargy ensue. Simon Stylites, who spent thirty-seven years on pillars of different heights, had probably stupefied his moral faculties and sensibilities as effectually as he had crushed to death the appetites and cravings of the body. It must not be forgotten that the body no less than the soul is of God's building, and that in his purpose all the powers and capacities of the body are good in their place and uses, and therefore to be controlled and governed, not destroyed or suppressed. The mediæval saint, feeding on the offal of the streets, was unwittingly committing sacrilege, by degrading and imbruting an appetite for which God had pro. vided decent and wholesome nutriment. 
Temperance is better than abstinence, also, because the moderate use of the objects of desire is a source of refining and elevating influences. It is not without meaning that, in common speech, the possession or loss of the senses is made synonymous with mental sanity or derangement. By the temperate gratifica rion of the senses the mind is sustained in its freshness, vigor, and serenity; while when they are perverted by excess, impaired by age, or deadened by disease, in that same proportion the mental powers are distracted, enfeebled, or benumbed. Taste, the faculty through which we become conversant with the whole realm of beauty, and than which devotion has no more efficient auxiliary, derives its name from what the ascetic deems the lowest animal enjoyment, which, however, has its range of the very highest ministries. The table is the altar of home-love and of hospitality, and there are clustered around it unnumbered courtesies, kindnesses, and charities that make a large part of the charm and joy of life. So far is thoughtfulness for its graceful and generous service from indicating a low type of character, that there is hardly any surer index of refinement and elegant culture than is furnished by the family meal. Similar remarks apply to the entire range of pleasurable objects and experiences. While there are none of them in which excess is safe, they all, when enjoyed in moderation, stimulate the mental powers, develop and train the æsthetic faculty, and multiply beneficial relations alike with nature and with society. 
Temperance, rather than abstinence, is needed on grounds connected with social economy. Labor for the mere nucessaries of life occupies hardly a tithe of human industry. A nation of ascetics would be a nation of idlers. It is the demand for objects of enjoyment, taste, luxury, that floats ships, dams rivers, stimulates invention, feeds prosperity, and creates the wealth of nations. It is only excess and extravagance that sustain and aggravate social inequalities, wrongs, wants, and burdens; while moderate, yet generous use oils the springs and speeds the wheels of universal industry, progress, comfort, and happiness.

But there are cases in which abstinence, rather than temperance, is a duty.

Past excess may render temperance hardly possible. From the derangement consequent upon excess, an appetite may lose the capacity of healthy exercise. In such a case, as we would amputate a diseased and useless limb, we should suppress the appetite which we can no longer control. Physiological researches have shown that the excessive use of intoxicating drinks, when long continued, produces an organic con dition, in which the slightest indulgence is liable to excite a craving so intense as to transcend the control of the will.

Inherited proclivities may, in like manner, render temperance so difficult as to make abstinence a duty. It is conceivable that a nation or a community may, oy the prevalence of excess in past generations, be sharacterized by so strong a tendency to intemperance 
as to render general abstinence a prerequisite to general temperance.

Abstinence may also become a duty, if to many around us our example in what we may enjoy innocently would be ensnaring and perilous. The recreation, harmless in itself, which by long abuse has become a source of corruption, it may be our duty to forego. The indulgence, safe for us, which would be unsafe for our associates, it may be incumbent on us to resign. The food, the drink which would make our table a snare to our guests, we may be bound to refrain from, though for ourselves there be in it no latent evil or lurking danger. This, however, is a matter in which each person must determine his duty for himself alone, and in which no one is authorized to legislate for others. It may seem to a conscientious man a worthy enterprise to vindicate and rescue from its evil associations an amusement or indulgence in itself not only harmless, but salutary; and there may be an equally strong sense of right on both sides of a question of social morality falling under this head. The joyous side of life must be maintained. The young, sanguine, and happy will at all events have recreations, games, festivities, and of these there is not a single element, material, or feature that has not been abused, perverted, or invested with associations offensive to a pure moral taste. To disown and oppose them all in the name of virtue, is to prescribe a degree of abstinence which can have the assent or those only who have outlived the capacity of enjoy- 
ment. The more judicious course is to favor, or at least to tolerate such modes of indulgence as may for the present be the least liable to abuse, or such as may in prospect be the safest in their moral influence, and by sanctioning these to render more emphatic and efficient the disapproval and rejection of such as are intrinsically wrong and evil.

\section{SECTION IV.}

\section{MANNERS.}

The ancients had but one word for manners and morals. It might be well if the same were the case with us, - yet with this essential difference, that while they degraded morals to the level of manners, a higher culture would lead us to raise manners to the level of morals. The main characteristics of good manners are comprised in the three preceding Sections. They are the observance, in one's demeanor and conduct toward others, of the fitnesses of time and place, and of the due and graceful mean between overwrought, extravagant, or fantastic manifestations of regard on the one hand, and coldness, superciliousness, or indifference on the other. Courtesies, like more substantial kindnesses, are neutralized by delay, and, when slow, seem forced and reluctant. Attentions, which in their place are gratifying, may, if misplaced, oceasion only mortification and embarrassment, as when civilities befitting interior home-life 
are rehearsed for the public eye and ear. Nor is there any department of conduct in which excess or deficiency is more painfully felt, - a redundance of compliments and assiduities tending to silence and abash the recipient, while their undue scanting inflicts a keen sense of slight, neglect, and injury.

Politeness must, indeed, in order even to appear genuine, be the expression of sincere kindness. There is no pretence so difficult to maintain as the false show of genial and benerolent feeling. The mask cannut be so fitted to the face as not to betray its seams and sutures. Yet kindness is not of itself politeness. Its spontaneous expressions may be rude and awkward; or they may take forms not readily understood and appreciated. There are conventional modes of polite demeanor no less than of courteous speech. These modes may have no intrinsic fitness, yet they acquire a fitness from their long and general use; and while the mere repetition of stereotyped formulas whether in word or deportment is justly offensive, he who would have his politeness recognized and enjoyed must beware lest he depart too widely from the established sign-language of society. There is a brusquerie often underlying hearty kindness and good fellowship, which at the outset pains, wounds, and repels those brought within its sphere, and which the most intimate friends endure and excuse rather than approve.

Politeness is to be regarded as an indispensable disty. It is believed that from its neglect or violation 
more discomfurt ensues than from any other single cause, and in some circles and conditions of society more than from all other causes combined. There are neighborhoods and communities that are seldom disturbed by grave offences against the criminal law, but none which can insure itself against the affronts, enmities, wounded sensibilities, rankling grievances: occasioned by incivility and rudeness. Moreover, there are persons entirely free from vice, perhaps ostentatious in the qualities which are the opposites of vices, and not deficient in charitable labors and gifts, who cultivate discourtesy, are acrid or bitter in their very deeds of charity, and carry into every society a certain porcupine selfhood, which makes their mere presence annoying and baneful. Such persons, besides the suffering they inflict on individuals, are of unspeakable injury to their respective circles or communities, by making their very virtues unlovely, and piety, if they profess it, hateful. On the other hand, there is no truer benefactor to society - if the creation of happiness be the measure of benefit - than the genuine gentleman or gentlewoman, who adds grace to virtue, politeness to kindness; who under the guilance of a sincere fellow-feeling, studies the fitnesses of speech and manner, in civility and courtesy endeavors to render to all their due, and in the least details that can affect another's happiness, does carefully and conscientiously all that the most fastidious sensibility could claim or desire. 


\title{
SECTION $\nabla$.
}

\author{
GOVERNMENT.
}

The establishment and preservation of order is the prime and essential function of government; the prevention and punishment of crime, its secondary, incidental, perhaps even temporary use. In a perfect state of society, government would still be necessary; for it would be only by the observance of common and mutual designations of time, place, and measure, that each individual member of society could enjoy the largest liberty and the fullest revenue from objects of desire, compatible with the just claims and rights of others. These benefits can, under no conceivable condition in which finite beings can be placed, be secured except by system, under a central administration, and with the submission of individual wills and judgments to constituted and established authority. A bad government, then, is better than none ; for a bad government can exist only by doing a part of its appropriate work, while in a state of anarchy the whole of that work is left undone and unattempted.

Obedience to government is, then, fitting, and therefore a duty, independently of all considerations as to the wisdom, or even the justice of its decrees or statutes. If they are unwise, they yet are rules to which the community can conform itself, and by wh.ich its members can make their plans and govern 
their expectations, while lawlessness is the negation alike of guidance for the present and of confidence in the future. If they are unjust, they yet do less wrong and to fewer persons, than would be done by individual and sporadic attempts to evade or neutralize them. Nay, unwise and inequitable laws, to which the habits and the industrial relations of a people have adjusted themselves, are to be preferred to vacillating legislation, though in a generally right direction. Laws that affect important interests should be improved only with reference to the virtual pledges made by previous legislation, and so as to guard the interests involved against the injurious effects of new and revolutionary measures. The tariff regulations of our own country will illustrate the bearing of this principle. It forms no part of our present plan to discuss the mooted questions of free trade and protection. But in the confession of even extreme partisans on either side, the capital and industry of our people could never have suffered so much from any one tariff of duties, however injudicious, as they suffered for a series of years from sudden clianges of policy, by which investments that had been invited by the legislation of one Congress were made fruitless by the action of the next, and manufactures stimulated into rapid growth by high protective duties, were arrested and often ruined by their sudden repeal. The stability of laws is obvously a higher good than their conformity to the theoretical views of the more enlightened citizens. Except under a despotism, laws are virtually an ex 
pression of the opinion or will of the majority; and laws which by any combination of favoring circumstances are enacted in advance of the general opinion, are always liable to speedy repeal, with a double series of the injurious consequences which can hardly fail to ensue immediately on any change.

But are there no limits to obedience? Undoubtedly there are A bad law is to be obeyed for the sake of order; an immoral law is to be disobeyed for the sake of the individual conscience; and of the moral character of a particular law, or of action under it, the individual conscience is the only legitimate judge. Where the law of the land and absolute right are at variance, the citizen is bound, not only to withhold obedience, but to avow his belief, and to give it full expression in every legitimate form and way, by voice and pen, by private influence and through the ballot-box. But in the interest of the public order, it is his duty to confine his opposition to legal and constitutional methods, to refrain from factious and seditious resistance, to avoid, if possible, the emergency in which disobedience would become his duty, and in case his conscience constrains him to disobedience, still to show his respect for the majesty of law by quietly submitting to its penalty. The still recent history of our country furnishes a case in point. By the Fugitive-Slave Law - which the Divine providence, indeed, repealed without waiting for the action of Congress - the private citizen who gave shelter, sustenance, or comfort to a fugitive slave; wbo, 
knowing lis hiding-place, omitted to divulge it, or who, when called upon to assist in arresting him, refused his aid, was made liable to a heavy fine and a long imprisonment. Now as to this law, it was obvisusly the duty of a citizen who regarded the slave as entitled to the rights of a man, to seek its repeal by ll constitutional methods within his power. It was equally his duty to refrain from all violent interference with the functionaries charged with its execution, and to avoid, if possible, all collision with the government. But if, without his seeking, a fugitive slave had been cast upon his humane offices, the question then would have arisen whether he should obey God or man; and to this question he could have had but one answer. Yet his obedience to God would have lacked its crowning grace, if he had not meekly yielded to the penalty for his disobedience to the law of the land. It was by this course that the primitive Christians attested their loyalty at once to God and to "the powers that be," which were "ordained of God." They refused obedience to the civil authorities in matters in which their religious duty was compromised ; but they neither resisted nor evaded the penalty for their disobedience. Similar was the course of the Quakers in England and America almost down to our own time. They were quiet and useful citizens, performing the vame functions with their fellow-citizens, so far as heir consciences permitted, and, where conscience interposed its veto, taking patiently the distraining of their goods, and the imprisonment of their bodies, 
until, by their blameless lives and their meek endurance, they won from the governments both of the mother country and of the United States, amnesty for their conscientious scruples.

There may be a state of society in which it becomes the duty of good citizens to assume an illegal attitude, and to perform illegal acts, in the interest of law and order. If those who are legally intrusted with executive and judicial offices are openly, notoriously, and persistently false to their trusts, to such a degree as to derange and subvert the social order which it is their function to maintain, good citizens, if they have the power, have undoubtedly the right to displace them, and to institute a provisional government for the temporary emergency. A case of this kind occurred a few years ago in San Francisco. The entire government of the city had for a series of years been under the control of ruffians and miscreants, and force and fraud had rendered the ballot-box an ineffectual remedy. No law-abiding citizen deemed his life or property safe; gross outrages were committed with impunity; and thieves and murderers alone had the protection of the municipal authorities. Despairing of legal remedy, the best eitizens of all parties organized themselves under the direction of a Committee of Safety, forcibly deposed the municipal magistrates and judges, brought well-known criminals to trial, conviction, and punishment, reëstablished the integrity of suffrage, and resigned their power to functionaries lawfully elected. under whom and their 
successors the city has enjoyed a degree of order, tranquillity, and safety at least equal to that of any other great city on the continent.

The right of revolution undoubtedly is inherent in a national body politic; but it is an extreme right, and is to be exercised only under the most urgent necessity. Its conditions cannot be strictly defined, and its exercise can, perhaps, be justified only by its results. A constitutional govermment can seldom furnish occasion for violent revolutionary measures; for every constitution has its own provisions for legal amend ment, and the public sentiment ripe for revolution can hardly fail to be strong enough to carry the amendments which it craves, through the legal processes, which, if slow and cumbrous, are immeasurably preferable to the employment of force and the evils of civil war. On the other hand, a despotic or arbitrary government may admit of abrogation only by force ; and if its administration violates private rights, imposes umrighteous burdens and disabilities, suppresses the development of the national resources, and supersedes the administration of justice or the existence of equitable relations between class and class or berween man and man, the people - the rightful source and arbiter of government - has manifestly the right to assert its own authority, and to substitute a constitution and rulers of its own choice for the sovereignty which has betrayed its trust. Under similar oppression, the same right unquestionably exists in a remote colony, or in a nation subject by conquest to a foreign 
power. If that power refuses the rights and prinleges of subjects to a people over which it exercises sovereignty, and governs it in its own im:igined interests, with a systematic and persistent disregard to the well-being of the people thus governed, resistance is a right, and may become a duty. In fine, the function of government is the maintenance of just and beneficent order; a government forfeits its rights when it is false to this function; and the rights thus forfeited revert to the misgoverned people. 


\section{CHAPTER XIII.}

\section{CASUISTRY}

CASUISTRY is the application of the general principles of morality to individual cases in which there is room for question as to duty. The question may be as to the obligation or the rightfulness of a particular act, as to the choice between two alternative courses, as to the measure or limit of a recognized duty, or as to the grounds of preference when there seems to be a conflict of duties. A large proportion of these cases disappear under any just view of moral obligation. Most questions of conscience have their origin in deficient conscientiousness. He who is determined to do the right, the whole right, and nothing but the right, is seldom at a loss to know what he ought to do. But when the aim is to evade all difficult duties which can be omitted without shame or the clear consciousness of wrong, and to go as close as possible to the boundary line between good and evil without crossing it, the questions that arise are often perplexing and complicated, and they are such as, in the interest of virtue, may fittingly remain unanswered. There are always those whose aim is, not to attain any definite, still less any indefinitely high, standard of goodncss, but to be saved from the penal conse- 
quences of wrong-doing; and there are even (socalled) religious persons, and teachers too, with whom this negative indemnity from punishment fills out the whole meaning of the sacred and significant term salvation. It must be confessed that questions which could emanate only from such minds, furnish a very large part of the often voluminous and unwieldy treatises on casuistry that have come down to us from earlier times, especially of that entire class of moralists whose chief endeavor is to lay out a border-path just outside the confines of acknowledged wrong and evil.

Yet there are cases in which the most consc1entious persons may be in doubt as to the right. We can here indicate only the general principles on which such cases are to be decided, with a very few specific illustrations.

The question of duty is often a question, not of principle, but of fact. It is the case, the position and relations of the persons or objects concerned, that we do not fully understand. For instance, when a new appeal is made for our charitable aid, in labor or money, the question is not whether it is our duty to assist in a work of real beneficence, but whether for the proposed object, and under the direction of those who make the appeal, our labor or money will be lucratively invested in the service of humanity. There are, certainly, benevolent associations and enterprises for the very noblest ends, whose actual utility is open tw the gravest doubt. It is sometimes difficult even 
to determine a question of justice or equity, simply because the circumstances of the case, so far as we can understand them, do not define the right. Instances of this class might be multiplied; but they are all instances in which there is no obscurity as to our obligation or duty, and therefore no question for moral casuistry. We are, however, obviously bound, by considerations of fitness, to seek the fullest information within our power in every case in which we are compelled to act, or see fit to act; nor can we regard action without knowledge, even though the motive be virtuous, as either safe or blameless.

The measure or limit of duty is with many conscientious persons a serious question. Here an exact definition is hardly possible, and a generous liberty may be given to individual taste or judgment; yet considerations of fitness set bounds to that liberty. Thus direct and express self-culture is a duty incumbent on all, yet in which diversity of inclination may render very different degrees of diligence equally fitting and right; but all self-centred industry is fittingly limited by domestic, social, and civic obligations. Thus, also, direct acts of beneficence are obviously incumbent on all; but the degree of self-sacrifice for beneficent ends need not, nay, ought not to be the same for every one; and while we hold in the highest admiration those who make the entire surrender of all that they have and are to the service of mankind, we have no reason to scant our esteem for those who are simply kind and generous, while they at the same 
time labor, spend, or save for their own benefit. Indeed, the world has fully as much need of the latter as of the former. Were the number of self-devoting philanthropists over-large, a great deal of the necessary business and work of life would be left undone; and did self-denying givers constitute a very numerous body, the dependent and mendicant classes would be much more numerous than they are; while the withdrawal of expenditure for personal objects would paralyze industrial enterprise, and arrest the creation of that general wealth which contributes to the general comfort and happiness, and the accumulation of those large fortunes which are invaluable as safetyfunds and movement-funds for the whole community.

There are cases in which there is manifestly a conflict of duties. This most frequently occurs between prudence and beneficence. Up to a certain point they coincide. No prudent man will suffer himself to contract unsocial, or selfish, or miserly habits, or to neglect the ordinary good offices and common charities of life. But is one bound to transcend the limits of prudence, and, without any specific grounds of personal obligation, to incur loss, hardship, or peril, in behalf of another person? One is no doubt bound to do all that he could reasonably expect from another, were their positions reversed; but is it his duty to do more than this? In answer, it must be admitted that he who in such a case suffers prudence to limit his beneticence has done all that duty absolutely requires, but, in proportion to the warmth of his benevolence and 
the loftiness of his spirit and character, he will find himself constrained to transcend this limit, and to sacrifice prudence to beneficence Thus - to take an instance from a class of events by no means infrequent - if I see a man in danger of drowning, it is ob viously my duty to do all that I can do for his rescue without putting my own life in jeopardy. But I owe him no more than this. My own life is precious to me and to my family, and I have a right so to regard it. I shall not deserve censure or self-reproach, if I decline exposing myself to imminent peril. Yet if I have the generosity and the courage which belong to a truly noble nature, I shall not content myself with doing no more than this, - I shall hazard my own safety if there is reason to hope that my efforts may have a successful issue; and in so doing I shall perform an act of heroic virtue. The same principle will apply to exposure, danger, and sacrifice of every kind, incurred for the safety, relief, or benefit of others. We transgress no positive law of right, when we omit doing for others more than we could rightfully expect were we in their place. Prudence in such a case is our right. But it is a right which it is more noble to surrender than to retain; and the readiness with which and the degree in which we are willing to surrender it, may be taken as a fair criterion of our moral growth and strength.

Inder the title of Justice, with the broad scope which we have given to it, there nay be an apparent conflict of duties, and there are certain obvious laws 
of precedence which may cover all such cases. We should first say that our obligations to the Supreme Being have a paramount claim above all duties to inferiur beings, had we not reason to believe that God is in no way so truly worshipped and served as by acts of justice and mercy to his children. The Divine Teacher has given us to understand, not that there is no time or place too sacred for charity, but that holy times and places have their highest consecration in the love to man which love to God inspires.

Toward men, it hardly needs to be said that justice (in the limited and ordinary acceptation of the word) has the precedence of charity. Indeed, were it not for the prevalence of injustice - individual, social, and civic - there would hardly be any scope for the active exercise of charity. Want comes almost wholly from wrong. Were justice universal, that is, were the rights and privileges which fitly belong to men as men, extended to and made available by all classes and conditions of men, there would still be great inequalities of wealth and of social condition; but abject and squalid poverty could hardly exist. In alnost every individual instance, the withholding or delay of justice tends more or less directly toward the creation of the rery evils which charity relieves. No amount of generosity, then, can palliate injustice, or itand as a substitute for justice.

As regards the persons to whom we owe offices of kindness or charity, it is obvious that those related to us by consanguinity or affinity have the first 


\section{PERMANENT GOOD TO BE BESTOWED. 193}

claim. These relations have all the elements of a natura: alliance for mutual defence and help; and it is impossible that their essential duties should be faithfully discharged and their fitnesses duly observed, without creating sympathies that in stress of need will find expression in active charity. In the next rank we may fittingly place our benefactors, if their condition be such as to demand a return for their kind offices in our behalf. Nearness in place may be next considered; for the very fact that the needs of our neighbors are or may be within our cognizance, commends them especially to our charity, and enables us to be the more judicious and effective in their relief, Indeed, in smaller communities, where the dwellings of the rich and of the poor are interspersed, a general recognition of the claims of neighborhood on charity would cover the field of active beneficence with an efficiency attainable in no other way, and at a greatly diminished cost of time and substance. There is yet another type of neighborhood, consecrated to our reverent observance by the parable of the Good Samaritan. There are from time to time cases of want and suffering brought, without our seeking, under our immediate regard, - cast, as it were, directly upon our kind offices. The person thus commended to us is, for the time, our nearest neighbor, nay, our nearest kinsman, and the very circumstances which have placed him in this relation to us, make him fittingly the foremost object of our charity.

The question sometimes presents itself whether 
we shall bestow an immediate, yet transient benefit, or a more remote, but permanent good. If the two are incompatible, and the former is not a matter of absolute necessity, the latter is to be preferred. Thus remunerative employment is much more beneficial than alms to an able-bodied man, and it is better that he suffer some degree of straitness till he can earn a more comfortable condition, than that he be first made to feel the dependence of pauperism. Yet if his want be entire and urgent, the delay of immediate relief is the part of cruelty. On similar grounds, beneficence which embraces a class of cases or persons is to be preferred to particular acts of kindness to individuals. Thus it seems harsh to refuse alms to an unknown street beggar; but as such relief gives shelter to a vast amount of fraud, idleness, and vice, it is much better that we should sustain, by contributions proportioned to our ability, some system by which cases of actual need, and such only, can be promptly and adequately cared for, and that we then - however reluctantly - refuse our alms to applicants of doubtful merit. 


\section{CHAP'TER XIV.}

\section{ANCIENT HISTORY OF MORAL PHILOSOPHY.}

\section{THE numerous ethical systems that have had}

currency in earlier or later times, may be divided into two classes, - the one embracing those which make virtue a means; the other, those which make it an end. According to the former, virtue is to be practised for the good that will come of it; according to the latter, for its own sake, for its intrinsic excellence. These classes have obvious subdivisions. The former includes both the selfish and the utilitarian theory; while the latter embraces a wide diversity of views as to the nature, the standard, and the criterion of virtue, according as it is believed to consist in conformity to the fitness of things, in harmony with an unsophisticated taste, in accordance with the interior moral sense, or in obedience to the will of God. There are, also, border theories, which blend, or rather force into juxtuposition, the ideas that underlie the two classes respectively.

It is proposed, in the present chapter, to give an outline of the history of ethical philosophy in Greece and Rome, or rather, in Greece; for Rome had no philosophy that was not born in Greece.

Socrates was less a moral philosopher than a 
preacher of virtue. Self-ordained as a censor and reformer, he directed his invective and irony principally against the Sophists, whose chief characteristic as to philosophy seems to have been the denial of objective trith, and thus, of absolute and determinate right. Socrates, in contrast with them, seeks to elicit duty from the occasions for its exercise, making his collocutors define right and obligation from the nature of things as presented to their own consciousness and reflection. Plato represents him, whenever a moral question is under discussion, as probing the very heart of the case, and drawing thence the response as from a divine oracle.

Plato held essentially the same ground, as may be seen in his identifying the True, the Beautiful, and the Good; but it is impossible to trace in his writings the outlines of a definite ethical system, whether his own, or one derived from his great master.

The three principal schools of ethical philosophy in Greece were the Peripatetic, the Epicurean, and the Stoic.

The Peripatetics derived their philosophy from Aristotle, and their name from his habit of walking up and down under the plane-trees of the Lyceum. According to him, virtue is conduct so conformed to human nature as to preserve all its appetites, proclivilies, desires, and passions, in mutual check and limitation. It consists in shunning extremes. Thus courage stands midway between cowardice and rashness: temperance, between excess and self-denial: 
generosity, between prodigality and parsimony ; meekness, between irascibility and pusillanimity. Happiness is regarded as the supreme good; but while this is not to be attained without virtue, virtue alone will not secure it. Happiness requires, in addition, certain outward advantages, such as health, riches, friends, which therefore a good man will seek by all lawful means. Aristotle laid an intense stress on the cultivation of the domestic virtues, justly representing the household as the type, no less than the nursery, of the state, and the political well-being of the state as contingent on the style of character cherished and manifested in the home-life of its members.

There is reason to believe that Aristotle's personal character was conformed to his theory of virtue, - that he pursued the middle path, rather than the more arduous route of moral perfection. Though much of his time was spent in Athens, he was a native of Macedonia, and was for several years resident at the court of Philip as tutor to Alexander, with whom he retained friendly relations for the greater part of his royal pupil's life. Of his connection with the Macedonian court and public affairs, there are several stories that implicate him dishonorably with political intrigues, and though there is not one of these that is not denied, and not one which rests on competent historical authority, such traditions are not apt so to cluster as to blur the fair fame of a sturdily incorruptible man, but are much more likely to cling to the memory of a trimmer and a time-server. 
Epicurus, from whom the Epicurean philosophy derives its name, was for many years a teacher of philosophy in Athens. He was a man of simple, pure, chaste, and temperate habits, in his old age bore severe and protracted sufferings, from complicated and incurable disease, with singular equanimity, and had his memory posthumously blackened only by those who - like theological bigots of more recent times inferred, in despite of all contemporary evidence, that he was depraved in character, because they thought that his philosophy ought to have made him so.

He represented pleasure as the supreme good, and its pleasure-yielding capacity as the sole criterion by which any act or habit is to be judged. On this ground, the quest of pleasure becomes the prime, or rather the only duty. "Do that you may enjoy," is the fundamental maxim of morality. There is no intrinsic or permanent distinction between right and wrong. Individual experience alone can determine the right, which varies according to the differences of taste, temperament, or culture. There are, however, some pleasures which are more than counterbalanced by the pains incurred in procuring them, or by those occasioned by them; and there are, also, pains which are the means of pleasures greater than themselves. The wise man, therefore, will measure and govern his conduct, not by the pleasure of the moment, but with reference to the future and ultimate effects of acts, habits, and courses of conduct, upon his happiness. What are called the virtues, as justice, temperance, 
chastity, are in themselves no better than their opposites; but experience has shown that they increase the aggregate of pleasure, and diminish the aggregate of pain. Therefore, and therefore alone, they are duties. The great worth of philosophy consists in its enabling men to estimate the relative duration, and the permanent consequences, as well as the immediate intensity, of every form of pleasure.

Epicurus specifies two kinds of pleasure, that of rest and that of motion. He prefers the former. Action has its reaction; excitement is followed by depression ; effort, by weariness ; thought for others involves the disturbance of one's own peace. The gods, according to Epicurus, lead an easy, untroubled life, leave the outward universe to take care of itself, are wholly indifferent to human affairs, and are made ineffably happy by the entire absence of labor, want, and care; and man becomes most godlike and most happy, therefore most virtuous, when he floats through life, unharming and unharmed, idle and useless, selfcontained and self-sufficing, simple in his tastes, moderate in his requirements, frugal in his habits.

It may be doubted whether Epicurus denoted by pleasure, ${ }^{1}$ mere physical pleasure alone. It is certain that his later followers regarded the pleasures of the body as the only good; and Cicero says that Epicurus himself referred all the pleasures of the intellect to the memory of past and the hope of future sensual gratification. Yet there is preserved an ex- 
tract of a letter from Epicurus, in which he says that his own bodily pains in his years of decrepitude are outweighed by the pleasure derived from the memory of his philosophical labors and discoveries.

Epicureanism numbered among its disciples, not only men of approved virtue, but not a few, like Pliny the Younger, of a more active type of virtue than Epicurus would have deemed consistent with pleasure. But in lapse of time it became the pretext and cover for the grossest sensuality; and the associations which the unlearned reader has with the name are only strengthened by conversance with the literature to which it gave birth. Horace is its poet-laureate; and he was evidently as sincere in his philosophy as he was licentious in his life. There is a certain charm in good faith and honesty, even when on the side of wrong and vice; and it is his perfect frankness, self-complacency, nay, self-praise, in a sensuality which in plain prose would seem by turns vapid and disgusting, that makes Horace even perilously fascinating, so that the guardians of the public morals may well be thankful that for the young the approach to him is warded off by the formidable barriers of grammar and dictionary.

While Epicureanism thus generated, on the one hand, in men of the world laxity of moral principle and habit, on the other hand, in minds of a more contemplative cast, it lapsed into atheism. From otiose gods, careless of human affairs, the transiticn was natural to a belief in no gods. The universe 
which could preserve and govern itself, could certainly have sprung into uncaused existence; for the tendencies which, without a supervising power, maintain order in nature, continuity in change, erer-new life evolved from incessant death, must be inherent tendencies to combination. harmony, and organization, and thus may account for the origin of the system which they sustain and renew. This type of atheism has its most authentic exposition in the "De Rerum Natura" of Lucretius. He does not, in so many words, deny the being of the gods, - he, indeed, speaks of them as leading restful lives, withdrawn from all care of mortal affairs; but he so scoffs at all practical recognition of them, and so jeers at the reverence and awe professed for them by the multitude, that we are constrained to regard them as rather the imagery of his verse than the objects of his faith. $\mathrm{He}$ maintains the past eternity of matter, which consists of atoms or monads of various forms. These, drifting about in space, and impinging upon one an. other, by a series of happy chances, fell into orderly relations and close-fitting symmetries, whence, in succession, and by a necessity inherent in the primitive atoms, came organization, life, instinct, love, reason, wisdom. This poem has a peculiar value at the present day, as closely coincident in its cosmogony with one of the most recent phases of physical philosophy, and showing that what calls itself progress may be notion in a circle.

The Stoics, so called from a portico ${ }^{1}$ adorned with 
magnificent paintings by Polygnotus, in which their doctrines were first taught, owe their origin to Zeno, who lived to a very great age, illustrious for self-con$\operatorname{trol}$, temperance, and the severest type of virtue, and at length, in accordance with a favorite dogma and practice of his school, when he found that he had before him only growing infirmity with no hope of restoration, terminated his life by his own hand.

According to the Stoic philosophy, virtue is the sole end of life, and virtue is the conformity of the will and conduct to universal nature. Virtue alone is good ; vice alone is evil ; and whatever is neither virtue nor vice is neither good nor evil in itself, but is to be sought or shunned, according as it is auxiliary to virtue or conducive to vice, - if neither, to be regarded with utter indifference. Virtue is indivisible. It does not admit of degrees. He who only approximates to virtue, however closely, is yet to be regarded as outside of its pale. Only the wise man can be virtuous. He needs no precepts of duty. His intuitions are always to be trusted. His sense of right cannot be blinded or misled. As for those who do not occupy this high philosophic ground, though they cannot be really virtuous, they yet may present some show and semblance of virtue, and they may be aided in this by precepts and ethical instruction. ${ }^{1}$ It

1 The words employed by the Stoics to indicate specific duties, as presented to the comnion understanding, recognize intrinsic fitness as the

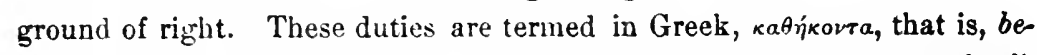
fitting, and in Latin, fficin, from ob and facio, that which is cone ob ali-

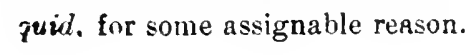


was for the benefit of those who, on account of their lack of true wisdom, needed such direction, and were at the same time so well disposed as to receive and follow it, that treatises on practical morality were written by many of the later Stoics, and that in Rome there were teachers of this school who exercised functions closely analogous to those of the Christian preacher and pastor.

Stoicism found its most congenial soil in the stern, hardy integrity and patriotism of those Romans, whose incorruptible virtue is the one redeeming feature of the declining days of the Republic and the effeminacy and coarse depravity of the Empire. Seneca's ethical writings ${ }^{1}$ are almost Christian, not only in their faithful rebuke of every form of wrong, but in their tender humanity for the poor, the slaves, the victims of oppression, in their universal philanthropy, and in their precepts of patience under suffering, forbearance, forgiveness, and returning good for evil. Epictetus, the deformed slave of a capricious and

1 How far Seneca's character was represented by his philosophy is, wo believe, a fairly open question. That the beginning and the close of his career were in accordance with his teachings, is certain. That as a courtier, he was in suspicious proximity to, if not in compiclity with, gross scandals and crimes, is equally certain. The evidence against him is weighty, but by no means conclusive. He may have lingered in the purlieus of the palace in fond memory of what Nero had been in the promse of his youth, and in the groundless hope of bringing him again undes mcre humane influences. This supposition is rendered the more probable by the well-known fact, that during his whole court life, and notwithstanding his great wealth, Seneca's personal habits were almost those of an anchorite. 
cruel master, beaten and crippled in mere wantonness, enfranchised in his latter years, only to be driven into exile and to sound the lowest depths of poverty, exhibited a type of heroic virtue which has hardly been equalled, perhaps never transcended by a mere mortal; and though looking, as has been already said, to annihilation as the goal of life, he maintained a spirit so joyous, and has left in his writings so attractive a picture of a soul serenely and supremely happy, that he has given support and consolation to multitudes of the bravest and best disciples of the heaven-born religion, which he can have known - if at all - only chrough its slanderers and persecutors. Marcus Aurelius, in a kindred spirit, and under the even heavier burdens of a tottering empire, domestic dissensions, and defeat and disaster abroad, maintained the severest simplicity and purity of life, appropriated portions of his busiest days to devout contemplation, meditated constantly on death, and disciplined himself to regard with contempt alike the praise of flatterers and the contingency of posthumous fame. We have, especially in Nero's reign, the record of not a few men and women of like spirit and character, whose lofty and impregnable virtue lacked only loving faith and undoubting trust in a fatherly Providence to assimilate them to the foremost among the A postles and martyrs of the Christian Church.

The Sceptical school of philosophy claims in this connection a brief notice. Though so identified in common speech with the name of a single philosonher. 
that Pyrrhonism is a synonyme for Scepticism, it was much older than Pyrrho, and greatly outnumbered his avowed followers. It was held by the teachers of this school that objective truth is unattainable. Not only do the perceptions and conceptions of difierent persons vary as to every object of knowledge; but the perceptions and conceptions of the same persons as to the same object vary at different times. Nay, more, at the same time one sense conveys impressions which another sense may negative, and not infrequently the reflective faculty negatives all the impressions derived from the senses, and forms a conception entirely unlike that which would have taken shape through the organs of sense. The soul that seeks to know, is thus in constant agitation. But happiness consists in imperturbableness of spirit, that is, in suspense of judgment; and as it is our duty to promote our own happiness, it is our duty to live without desire or fear, preference or abhorrence, love or hatred, in entire apathy, - a life of which Moliammed's fabled coffin is the fittest symbol.

The New Academy, whose philosophy was a hybrid of Platonism and Pyrrhonism, while it denied the possibility of ascertaining objective truth, yet taught trat on all subjects of speculative philosophy probahility is attainable, and that, if the subject in hand be one which admits of being acted upon, it is the duty of the moral agent to act in accordance with probability, - to pursue the course in behalf of which the more aml the better reasons can be given. There 
are moral acts and habits which seem to he in accordance with reason and the nature of things. We may be mistaken in thinking them so ; yet the probability that they are so creates a moral obligation in their favor. The New Academy professed a hypothetica. acquiescence in the ethics of the Peripatetic school, maintainung, therefore, that the mean between two extremes is probably in accordance with right and duty, and that virtue is probably man's highest good, yet probably not sufficient in itself without the addition of exterior advantages.

Cicero considered himself as belonging to the New Academy. His instincts as an adrocate, often induced by professional exigencies to deny what he had previously affirmed, made the scepticism of this school congenial to him; while his love of elegant ease and luxury and his lack of moral comrage were in closer harmony with the practical ethics of the Peripatetics than with the more rigid system of the Stoics. At the same time, his pure moral taste and his sincere reverence for the right brought him into sympatly with the Stoic school. His "De Officiis" is an exposition of the Stoic system of ethics, though by the professed disciple of another philosophy. It is as if a Molnammedan, without disclaiming his own religion, should undertake an exposition of the ethics of Christianity, on the ground that, though Mohammed was a genuine prophet, there was, nevertheless, a higher and purer morality in the New Testament than in the Koran 


\section{CHAPTER XV.}

\section{MODERN HIS TORY OF MORAL PHILOSOPHY.}

HOR several centuries after the destruction of the Western Empire, philosophy had hardly an existence except in its records, and these were preserved chiefly for their parchment, balf-effaced, covered by what took the place of literature in the (so called) Dark Ages, and at length deciphered by such minute and wearisome toil as only mediaeval cloisters have ever furmished. For a long period, monasteries were the only schools, and in these the learned men of the day were, either successively or alternately, learners and teachers, whence the appellation of Schoolmen. The learned men who bear this name were fond of casuistry, and discussed imagined and often impossible cases with great pains (their readers would have greater) ; but, so far as we know, they have left no systematic treatises on moral philosophy, and have transmitted no system that owes to them its distinguishing features. Yet we find among them a very broad division of opinion as to the ground of right. The fundamental position of the Stoics, that virtue is conformity to nature, and thus independent of express legislation, - not created by law, human or divine, but the source and origin of law, - had its 
champions, strong, but few; while the Augustinian theology, then almost universal, replaced Epicureanism in its denial of the intrinsic and indelible moral qualities of actions. The extreme Augustinians regarded the positive command of God as the sole cause and ground of right, so that the very things which are forbidden under the severest penalties would become virtuous and commendable, if enjoined by Divine authority. IVilliam of Ockham, one of the most illustrious of the English Schoolmen, wrote: "If God commanded his creatures to hate himself, the hatred of God would be the duty of man."

The earliest modern theory of morals that pre sented striking peculiarities was that of Hobbes (A. D. 1588-1679), who was indebted solely to the stress of his time, alike for his system and for what. ever slender following it may have had. He was from childhood a staunclı royalist, was shortly after leaving the University the tutor of a loyal nobleman, and, afterward, of Charles II. during the early years of his exile; and the parliamentary and Puritan outrages seemed to him to be aimed at aii that was august and reverend, and adapted to overturn society, revert progress, and crush civilization. According to him, men are by nature one another's enemies, and can be restrained from internecine hostility only by force or fear. An instinctive perception of this truth in the infancy of society gave rise to monarchical and absolute forms of government; for only by thus centralizing and massing power, which could be directed 
against any disturber of the peace, could the individual members of society hold property or life in safety. The king thus reigns by right of human necessity, and obedience to him and to constituted anthorities under him is man's whole duty, and the sum of virtue. Might creates right. Conscience is but another name for the fear of punishment. The intimate connection of religion with civil freedom in the English Commonwealth no doubt went far in uprooting in Hobbes all religious faith; and while he did not openly attack Christianity, he maintained the duty of entire conformity to the monarch's religion, whatever it might be, which is of course tantamount to the denial of objective religious truth. ${ }^{1}$

Hobbes may fairly be regarded as the father of modern ethical philosophy, - not that he had children after his own likeness; but his speculations were so revolting equally to thinking and to serious men, as to arouse inquiry and stimulate mental activity in a department previously neglected.

The gauntlet thus thrown down by Hobbes was taken up by Cudworth (A. D. 1617-1688), the most learned man of his time, whose "Intellectual System of the Cniverse" is a prodigy of erudition, - a work

I Spinoza's ethical system was closely parallel to that of Hobbes. Ho senied the intrinsic difference between right and wrong; but ha recorded aristocrary as the natural oriler of society. With him, as with Hobbes, virtue consists solely in obedlence (1) constituted authority ; and *) utterly did he ignore a higher law, that he maintained it to be the right of a state to abjure a treaty with another state, when its terms ceased to be convenient or protitable. 
in which his own thought is so blocked up with quota tions, authorities, and masses of rerondite lore, that it is hardly possible to trace the windings of the river for the débris of auriferous rocks that obstruct its flow. The treatise with which we are concerned is that in "Eternal and Immutable Morailty." In this he maintains that the right exists, independently of all authority, by the very nature of things, in co-eternity with the Supreme Being. So far is he from admitting the possibility of any dissiliency between the Divine will and absolute right, that he turns the tables on his opponents, and classes among Atheists those of his contemporaries who maintain that God can command what is contrary to the intrinsic right; that $\mathrm{He}$ has no inclination to the good of his creatures; that $\mathrm{He}$ can justly doom an innocent being to eternal torments; or that whatever God wills is just because He wills it.

Samuel Clarke (A. D. 1675-1729) followed Cudworth in the same line of thought. He was, it is believed, the first writer who employed the term fitness as defining the ground of the immutable and eternal right, thongh the idea of fitness necessarily underlies every system or theory that assigns to virtue intrinsic validity.

Shaftesbury (A. D. 1671-1713) represents virtue as residing, not in the nature or relations of things, but in the bearing of actions on the welfare or happiwess of beings other than the actor. Benevolence onstitutes virtue: and the merit of the artion and 
of the actor is determined by the degree in which particular affections are merged in weneral philanthropy, and reference is had, not to ind winhal beneficiaries or benefits, but to the whole system of things of which the actor forms a part. The affections from which such acts spring commend themselves to the moral sense, and are of necessity objects of estecm and love. But the moral sense takes cognizance of the affections only, not of the acts themselves; and as the conventional standard of the desirable and the useful varies with race, time, and culture, the acts which the affections prompt, and which therefore are virtuous, may be in one age or country such as the people of another century or land may repudiate with loathing. Las Casas, in introducing negro slavery into America, with the fervently benevolent purpose of relieving the liardships of the feeble and overtasked aborigines, performed, acerrding to this theory, a virtuous act : but had he once considered the question of intrinsic right or natural fitness, a name so worthily honored would never have been associated with the foulest crime of modern civilization.

According to Adam Smith (A. D. 1723-1790), moral distinctions depend wholly on sympathy. Wo approve in others what corresponds to our own tastes and habits; we disapprove whatever is opposed to them. As to our own conduct, "we suppose ourselves," he writes, "the spectators of our own behav. ior and endeavor to imagine what effect it would in this light produce in us." Our sense of duty is de. 
rived wholly from our thus putting ourselves in the place of others, and inquiring what they would approve in us. Conscience, then, is a collective and corporate, not an individual faculty. It is created by the prevalent opinions of the community. Solitary virtue there cannot be; for without sympathy there is no self-approval. By parlity of reason, the duty of the individual can never transcend the average conscience of the community. This theory describes society as it is, not as it ought to be. IVe are, to a sad degree, conventional in our practice, much nore so than in our beliefs; but it is the part of true manliness to have the conscience an interior, not an external organ, to form and actualize notions of right and duty for one's self, and to stand and walk alone, if need there be, as there manifestly is in not a few critical moments, and as there is nut infrequently in the inward experience of every man who means to do his duty.

Butler (A. D. 1692-1752), in his "Ethical Discourses," aims mainly and successfully to demonstrate the rightful supremacy of conscience. His favorite conception is of the human being as himself a household [an economy], - the various propensities, appetites, passions, and affections, the members, - Conscience, the head, recognized as such by all, so that there is, when leer sovereignty is owned, an inward repose and satisfaction; when she is disobeyed, a sense of discord and rebellion. of unrest and disturbance. This is sound and indisputable, and it cannot be more 
clearly stated or more vividly illustrated than by Butler; but he manifestly regards conscience as legislator no less than judge, and thus fails to recognize any objective standard of right It is evident that on his ground there is no criterion by which honestly erroneous moral judgments can be revised, or by which a discrimination can be made betiveen the results of education or involuntary prejudice, and the right as determined by the nature of things and the standard of intrinsic fitness.

Of all modern ethical writers since the time of Cudworth and Clarke, none so much as approaches the position occupied by Richard Price (A. D. 17231791), a London dissenting divine, a warm advocate of American independence, and the intimate friend of John Adams. He maintained that right and wrong are inherent and necessary, immutable and eternal characteristics, not dependent on will or command, but on the intrinsic nature of the act, and determined with unerring accuracy by conscience, whenever the nature of the case is clearly known. "Morality," he writes, " is fixed on an immovable basis, and appears not to be in any sense factitious, or the arbitrary production of any power, human or divine ; but equally everlasting and necessary with all truth and reason." "Virtue is of intrinsic value and of indispensable obligation; not the creature of will, but necessary and immutable; not local and temporary, but of equal extent and antiquity with the Divine mind; not dependent on power, but the guide of all power." 1

1 Price's theory of morals is developed with singular precision and force 
Paley (A. D. 1743-1805) gives a definition of virtue, remarkable for its combination of three partial theories. Virtue, according to him, is "the doing good to mankind, in obedience to the will of God, and for the sake of everlasting happiness." Of this lefinition it may be said, 1 . The doing good to mankind is incleed virtue; but it is by no means the whole of virtue. 2. Obedience to the will of God is our duty; but it is so, because his will must of necessity be in accordance with the fitting and right. Could we conceive of Omnipotence commanding what is intrinsically unfit and wrong, the virtuous man would not be the God-server, but the Prometheus suffering the implacable vengeance of an unrighteous Deity. 3. Though everlasting happiness be the result of virtue, it is not the ground or the reason for it. Were our being earth-limited, virtue would lose none of its obligation. Epictetus led as virtuous a life as if heaven had been open to his faith and hope. - Paley's system may be deseribed in detail as Shaftesbury's, with an external washing of Christianity; Shaftesbury having been what was called a freethinker, while Paley was a sincere believer in the Christian revelation, and contributed largely and efficiently to the defence of Christianity and the illustration of its records. The chief merit of Paley's treatise on Moral Philosolyy is that it clearly and emphatially recognizes the Divine authority of the

in one of the Racealatireate Aldiresses if the late President Appleten, of Bowdoin College. 
moral teachings of the Neiv Testament, though in expounding them the author ton frequently dilutes them by considerations of expediency.

Jeremy Bentham (A. D. 174-1892) is Paley minus Christianity. The greatest gond of the greatest number is, according to him, the aim and criterion of virtue. Moral rules should be constructed with this sole end; and this should be the pervading purpose of all legislation. Benthan's works are very voluminous, and they cover, wisely and well, almost every department of domestic, social, public, and national life. The worst that can be said of his political writings is that they are in advance of the age, - literally Utopian ;' but it would be well with the country which was prepared to embody his views. But, unfortunately, his principles have no power of self-realization. They are like a watch, perfect in all other parts, but without the mainspring. Bentham contemplates the individual man as an agency, rather than as an intellectual and moral integer. He must work under yoke and harness for ends vast and remote, beyond the appreciation of ordinary mortals ; and he must hold all partial affections and nearer aims subordinate to rules deduced by sages and legislators from considerations of general utility. Bentham's influence on legislation, especially on criminal law, has been beneficially felt on both sides of the Atlantic. In the department of pure ethics, there are no essen

\section{Oirórtos.}


tial points of difference between him and other writers of the utilitarian school. ${ }^{1}$

In France there has been a large preponderance of sensualism, expediency, and selfishmess in the ethical systems that have had the most extensive currency. There was a great deal of elaborate ethical speculation and theory among the French philosophers of the last century; but among them we camnot recall a single writer who maintained a higher ground than Bentham, except that Rousseau - perhaps the most immoral of them all - who was an Epicurean so far as he had any philosophy, sometimes soars in sentimental rhapsodies about the intrinsic beauty and loveliness of a virtue which he knew only by name.

Malebranche (A. D. 1638-1714), whose principal writings belong to the previous century, represents entirely opposite views and tendencies. He hardly differs from Samuel Clarke, except in phraseology. He resolves "virtue into love of the universal order, and conformity to it in conduct. This order requires

1 The reader who is conversant with the literature of ethics in England and America will miss in this chapter many names which merit a place by the side of those that have been given. But within the limits proposed for this mauual, the a'ternative was to select a few writers among those who have largely influenced the thought of their own and succeeding times, and to associate with each "f them something that should mark his individuality; or to make the chapur r little more than a catalogue of names. The former is evidently the more judicious course. Nothing has been said of living writers, - not because there are none who deserve an honored place among the contributors to this department of science, but because; were the list to be once opened, we should hardly know where to close it. 
that we should prize and love all beings and objects in proportion to their relative worth, and that we should recognize this relative worth in our rules and tadoits of life. Thus man is to be more highly valued and more assiduously served than the lower animals, because worth more ; and God is to be loved infinitely more than man, and to be always obeyed and served in preference to man, because he is worth immeasurably more than the beings that derive their existence from him. Malebranche ascribes to the Supreme Being, not the arbitrary exercise of power in constituting the right, but recognition, in his government of the world and in his revealed will, of the order, which is man's sole law. "Sovereign princes," he says, "have no right to use their authority without reason. Even God has no such miserable right."

At nearly the same period commenced the ethical controversy between Fónelon (A. D. 1651-1715) and Bossuet (A. D. 1627-1704), as to the possibility and obligation of disinterested virtue. Fénelon and the Quietists, who sympathized with him, maintained that the pure love of God, without any self-reference, or regard for one's own well-being either here or hereafter, is the goal and the test of human perfection, and that nothing below this - nothing which aims or aspires at anything less than this - deserves the name of virtue. Bossuet defended the selfish theory of virtue, attacked his amiable antagonist with unconscionable severity and bitterness, and succeeded in obtaining from the court of Rome - though against 
the wishes of the Pope - the condemnation of the obnoxious tenet. The Pope remarked, with wellturned antithesis, that Fénelon might have erred from excess in the love of God, while Bossuet had sinned by defect in the love of his neighbor.

Among the recent French moralists, the most distinguished names are those of Jouffroy and Cousin, who - each with a terminology of his own - agree with Malebranche in regarding right and wrong as inherent and essential characteristics of actions, and as having their source and the ground of their validity in the nature of things. The aim of Cousin's wellknown treatise on "The True, the Beautiful, and the Good," is purely ethical, and the work is designed to identify the three members of the Platonic triad with corresponding attributes of the Infinite Being, - attributes which, virtually one, have their counterpart and manifestation in the order of nature and the government of the universe.

In Germany, the necessarian philosophers of the Pantheistic school ignore ethics by making choice and moral action impossible. Man has no distinct and separate per'sonality. IIe is for a little while detached in appearance from the soul of the universe (anima mundi), but in reality no more detached from it than is a boulder or a log of drift-wood from the surface on which it rests. He still remains a part of the universal soul, the multiform, all-embracing God, who is himself not a self-conscious, freely willing being, but 
impelled by necessity in all his parts and members, and, no less than in all else, in those human members through which alone he attains to some fragmentary self-consciousness.

According to Kant, the reason intuitively discerns truths that are necessary, absolute, and universal. The theoretical reason discerns such truths in the realm of ontology, and in the relations and laws that underlie all subjects of physical inquiry. In like manner, the practical reason intuitively perceives the conditions and laws inherent in the objects of moral action, - that is, as Malebranche would have said, the elements of universal order, or, in the language of Clarke, the fitness of things. As the mind must of necessity contemplate and cognize objects of thought under the categories intuitively discerned by the theoretical reason, so must the will be moved by the conditions and laws intuitively discerned by the practical reason. This intuition is law and obligation. Man can obey it, and to obey it is virtue. He can disobey it, and in so dning he does not yield to necessity, but makes a voluntary choice of wrong and evil.

It will be perceived from the historical survey in this and the previons chapter, that - as was said at the outset - all ethical systems resolve them. selves into the two classes of which the Epicureans and the Stoics furnished the pristine types, - those which make virtue an accident, a variable, subject to anthority, occasion, or circumstance; and 
those which endow it with an intrinsic right, immutableness, validity, and supremacy. On subjects of fundamental moment, opinion is of prime importance. Conduct results from feeling, and feeling from opinion. We would have the youth, from the very earliest period of his moral agency, grounded in the belief that rignt and wrong are immutable, - that they have no localities, no meridians, - that, with a change of surroundings, their conditions and laws vary as little as do those of planetary or stellar motion. Let him feel that right and wrong are not the mere dicta of human teaching, nay, are not created even by revelation; but let their immutable distinction express itself to his consciousness in those sublime words which belong to it, as personified in holy writ, "Jehovah possessed me from the beginning of his way, before his works of old. I was set up from everlasting, from the beginning, or ever the earth was. When $\mathrm{He}$ prepared the heavens, I was there. When He appointed the foundations of the earth, then was I by Him." This conception of the Divine and everlasting sacredness of virtue, is a perennial fountain of strength. He who has this does not imagine that he has power over the Right, can sway it by his choice, or vary its standard by his action; but it overmasters him, and, by subduing, frees him, fills and energizes his whole being, ennobles all his powers, exalts and hallows all his affections, makes him a priest to God, and a king among men. 


\section{INDEX.}

PAGB

Abstinence, when to be preferred to temperanee $\quad$. 175

Academy, the New . . . . . . . . 205

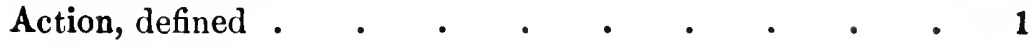

springs of $\quad . \quad+\quad . \quad+\quad . \quad . \quad . \quad 10$

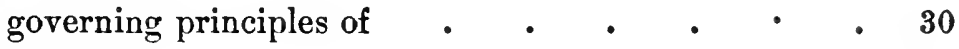

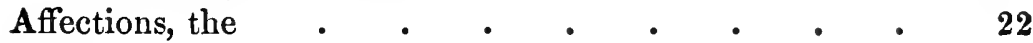

Anger . • • • • • • • . . 26

Anonymous publications . $\quad$ - . . . $\quad 123$

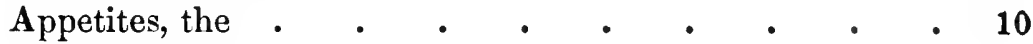

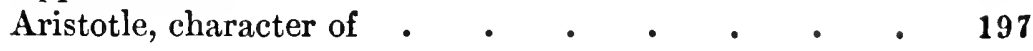

Beneficence . . . . . . . . . 143

Bentham, Jeremy - . • . . . . . 215

Bossuet, controversy of, with Fénélon ․ - $\quad$ - 217

Brotherhood, human, in its ethical relations . . . $\quad 56$

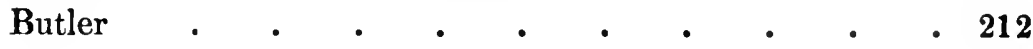

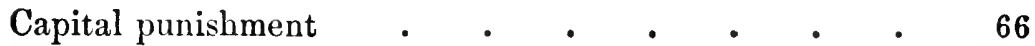

Casuistry . . . . . . . . . . 187

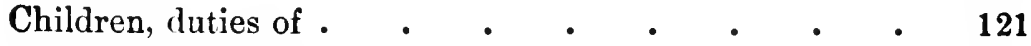

Christianity, a source of knowledge . $\quad$ • $\quad . \quad 55$

exhibiting moral perfection in the person of its Founder 68

compared, as to its ethics, with other religions . $\quad$. 59

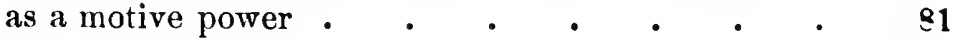

Cicero, philosophical relations of . $\quad$ • $\quad$ • 206

Ylarke, Samuel . . . . . . . . . 210

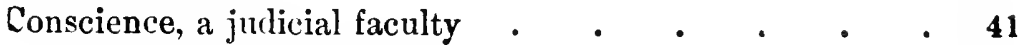

educated by use.$\quad$. $\quad . \quad$. . . 44

relation of knowledge to $. \quad . \quad$. $\quad . \quad$ 45

Contracts . . . . . . . . . 128 


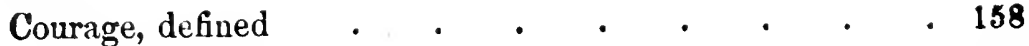

physical . . . . . . . . . . 159

moral . . . . . . . . . 160

Cousin . . . . . . . . . . 218

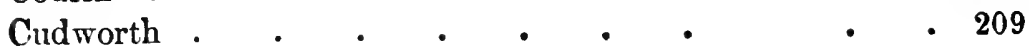

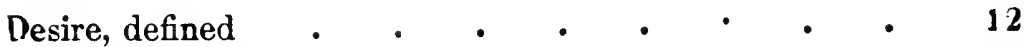

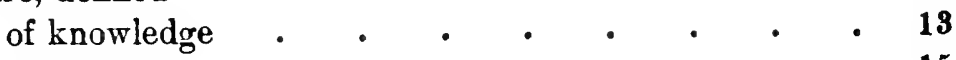

of society $\quad . \quad . \quad . \quad . \quad . \quad . \quad . \quad . \quad 15$

of esteem . . . . . . . . .

of power . . . . . . . . . . 18

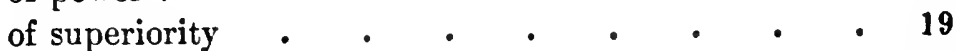

Duties, conflict of . . . . . . . . . . 190

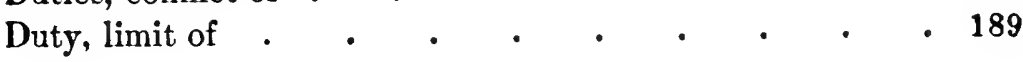

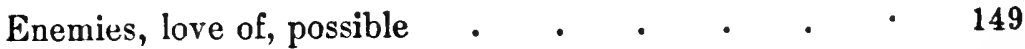

Envy . . . . . . . . . . 27

Epictetus, character of ..$\quad$. $\quad . \quad$. 203

Epicureanism . . . . . . . . . 198

Example, ethical value of . . . . . . 111

Expediency, an insufficient rule of conduct . . $\quad 31$

when to be consulted . . . . . . 33

Extreme cases in morals . . . . . . 125

Falsehood . . . . . . . . . . 151

Family, duties of the . $\quad . \quad$. $\quad . \quad$. 118

Fénélon, controversy of, with Bossuet . . . $\quad 217$

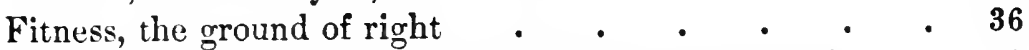

Forcknowledge, Divine, consistent with human freedom 8

Freedom of the will, arguments for . • . • • 2

objections to . $\quad . \quad$. $\quad . \quad$. 4

Government, the essential function of . . . 180

obedience to, how limited . . . . . 182

when to be opposed . . . . . . . 184

Gratitude . . . . . . . . . 24

Habit • • • • • • • •

Hatred . . . . . . . . . . 28

Hobbes . . . . . . . . 208 
Home-life, order requisite in . $\quad$ - $\quad$. $\quad . \quad$. 169

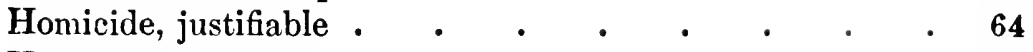

Honesty • • • • . . . . . . 134

Horace, the poet of Epicureanism . . • . 200

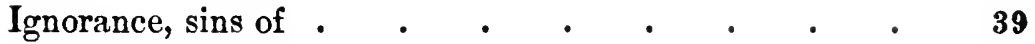

Immortality, ethical relations of $\quad . \quad$. $\quad .57$

Intemperance . $. \quad . \quad . \quad . \quad \cdot \quad . \quad$. 170

Jouffroy • • • • • • • • • • • 218

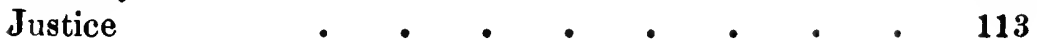

Kant, ethical system of $\quad$ - $\quad$ - $\quad$ - $\quad$ - 219

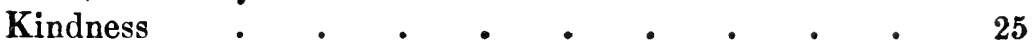

Knowledge, attainment of, a duty $\quad$ - . $\quad$ - 102

Law, the result of experience . $\quad$ - $\quad$. $\quad$. 50

an educational force . $\quad . \quad$. $\quad . \quad$. 51

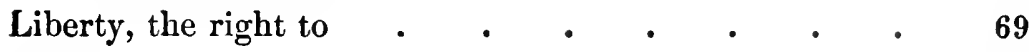

Love • • • • • • • • • • 22

Jucretius, philosophy of $\quad$ - . . . . $\quad$ - 201

Malebranche . . . . . . . . . . 216

Manners, a department of morals . . . . . 177

Marcus Aurelius, character of . • . • . . 204

Marriage . • . . • . . • . 120

Measure, duties appertaining to . . . . $\quad 170$

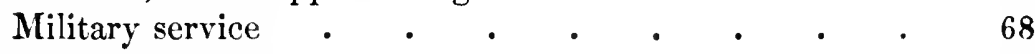

Moral philosophy, defined . . . . . . $\quad$. 34

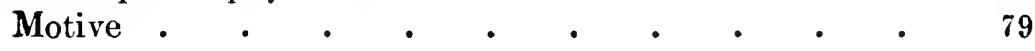

Oaths . . . . . . . . . $\quad$. 129

Ohservation, a source of ethical knowledge . . . 46

Order . . . . . . . . . . . 164

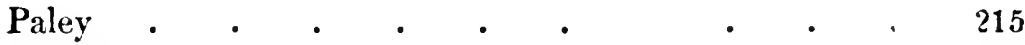

Pantheism, ethics of . . . . . . 218

Parents, duties of . . . . . . . 121

Passion . . . . . . . . . 82

Patience . . . . . . 132 
Pauperism . . . . . . . . . 144

Peripatetics, the ..$\quad$. $\quad . \quad$. $\quad 198$

Piety toward God . . . . . . . . 113

Pity . . . . . . . . . . 25

Place, duties appertaining to.$\quad$. . . . 168

Plato, as a teacher of ethics . . . . . . 193

Politeness . . . . . . . . . . 178

lositive duties . . . . . . . . 117

Price, Richard . . . . . . . . . 214

Promises . . . . . . . . . 126

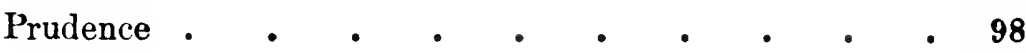

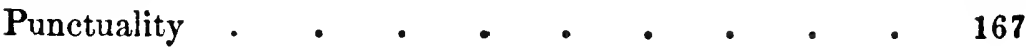

Resentment • • • • • • • • • 27

Revenge . . . . . . . . . 28

Reverence . • . . . . . . . 423

Revolution, when justifiable . $. \quad . \quad . \quad$. 185

Right, the • • • • • • • • • • 35

absolute and relative $. \quad . \quad . \quad . \quad . \quad . \quad 37$

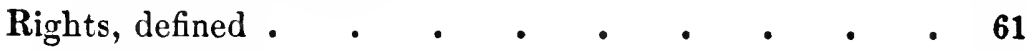

how limited . $. \quad . \quad . \quad . \quad .62$

personal . . . . . . . . 64

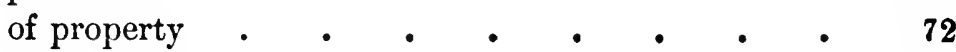

of reputation $\quad . \quad . \quad . \quad . \quad . \quad$. 76

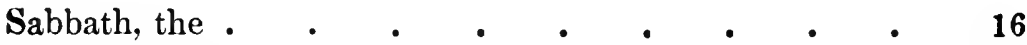

Sceptical school of philosophy . . . . . 204

Schoolmen, ethics of the $. \quad . \quad . \quad . \quad$. 207

Self-control $. \quad . \quad . \quad . \quad . \quad . \quad . \quad .106$

Self-culture, moral . . $. \quad . \quad$ • . 109

Self-preservation . $\quad . \quad$ • $\quad$ • $\quad$ • $\quad$ • 99

Seneca, writings and character of . . . . 203

Shaftesbury . . . . . . . . . 210

Slavery . . . . . . . . . . . .

Smith, Adam . . . . . . . . . 211

Socrates, as a teacher of ethics $\quad . \quad$. $\quad . \quad$. 195

Sproulation in business, when legitimate . . . 138

when lishonest . . . . . . . 140

Spinoza . . . . . . . . . . . . 209

Stoics, philosuphy of the . . . . . 201 eminent Roman . . . . . . . . 203 


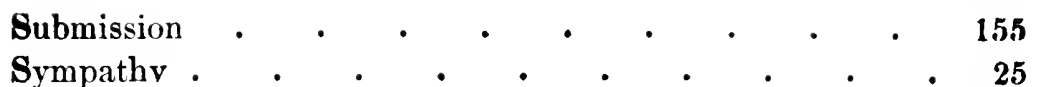

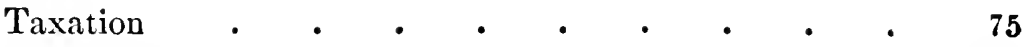

Temperance . $. \quad . \quad . \quad . \quad . \quad . \quad 173$

Time. duties appertaining to . $\quad . \quad$. $\quad . \quad$ 165

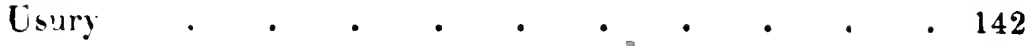

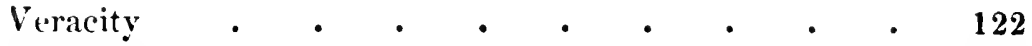

Virtue, defined . $. \quad . \quad$. $\quad . \quad$. $\quad . \quad$. 88

connection of, with piety $\quad$. . . . . $\quad 91$

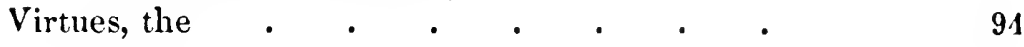

cardinal . $\quad . \quad \ldots \quad . \quad . \quad 096$

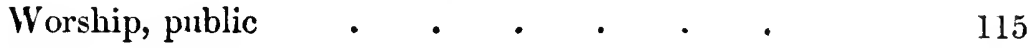

$\begin{array}{llllll}\text { Zeno, character of . } & \text { - } & \text { - } & \text { - } & \text { - } & 202\end{array}$ 



\section{BOOKS FOR TEACHERS.}

\section{PEDAGOGY.}

Calkins's (N. A.) Manual of Object Teaching

Day's (H. N.) Science of Education

Eclectic Manual of Methods (J. T. Stewart)

Question Book, or Teacher's Neiv Examiner

Hailmann's (W. N.) History of Pedagogy

Lectures on Education

Hewett's (E. C.) leuagory for Young Teachers

How to Teach (Kiddle, Harrison and Calkins)

King's (R. M.) School Interests and Duties.

Krusi's (Hermann) Life and Work of Pestalozzi .

Ogden's (Juhn) Science of Education

Art of Teaching

Page's Theory and Practice of Teaching (Payne)

Palmer's (F. B.) Science of Education.

Payne's (W. H.) School Supervision

Contributions to the Science of Education.

Sheldon's (E. A.) Lessons on Objects

Shoup's (W. J.) Graded Didactics Volume I.

Graded Didactics. Volume ?

History and Science of Education

Swett's Questions for Written Examination

Methods of Teaching

White's (E. E.) Elements of P'edagogy

School Management

KINDERGARTEN AND PRIMARY MANUALS.

Calkıns's (N. A.) Primary Ouject Lessons

Hailmann's (IV. N.) Kindergarten Culture l'rimary Methods

Sheldon's (E. A.) Elementary Instruction

Bain's (A.) Moral Science

Gow's (A. M.) Good Morals and Gentle Manners

Janet's (Paul) Elements of Norals

Peabody's (A. P.) Moral Philosophy

Smith's (W. A.) Elements of Moral Philosophy

Winslow's (H.) Eleinents of Moral Philosophy

Bain's (A.) Mental Science . . . . . . . . I.22

Champlin's Inteilectual 1 hilosophy. (Revised edition.) : $\quad$ : 1.00

Day's (H. N.) Elements of Mental Science . . . . . I.00

Hewett's (E. C.) Psychology for Young Teachers . . . $\quad .85$

Putnam's (D.) Elementary Psychology . . . . . . . . . . .

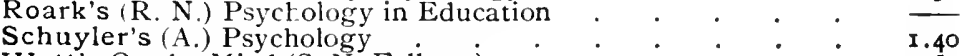

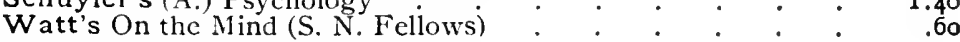

\section{SCHOOL REGISTERS AND RECORDS.}

White's New School Register. Containing forms for Daily, Term and Yearly Records, equally adapted to Graded and Ungraded Schools, and conforming to the school laws of the several States. By Emerson E.White, A.M., LL.D.

Besides the above we publish a variety of School Registers, Roll Books, Term Records, etc., etc., adapted to the convenient keeping of daily. weekly or monthly records of attendance, deportment, recitations. etc., of pupils.

Copies of any of the above books will be sent prepaid to any address, on riceipt of the price, by the Publishers:

\section{AMERICAN BOOK COMPANY NEW YORK - CINCINNATI - CHICACO \\ BOSTON - ATLANTA - PORTLAND, ORE.}




\title{
GENERAL HISTORY.
}

\section{THALHEIMER'S GENERAL HISTORY.}

\author{
$12 \mathrm{mo}, 448 \mathrm{pp}$. Haif roan, illustrated
}

Extreme brevity has here been combined with a lively and simple narrative, such as might supply the present need of young pupils while affording a symmetrical plan for the research of older ones.

\section{SWINTON'S OUTLINES OF HISTORY.}

I2mo, $500 \mathrm{pp}$. Cloth . . .. . $\$ 1.44$
Ancient, Mediæval and Modern, with special reference to the History of Mankind. Its anatomical synopses, its maps showing the political divisions at the great epochs, its collateral information, its surveys of the great events, dis. tinguished men, and important discoveries.furnish in an entertaining style just what is valuable to the beginner of the study of history.

\section{LORD'S POINTS OF HISTORY.}

\section{I $2 \mathrm{mo}, 300 \mathrm{pp}$. Cloth}

The salient points in the history of the world arranged catechetically for class use or for review and examination by teacher or pupil.

\section{GILMAN'S FIRST STEPS IN GENERAL HISTORY.}

$18 \mathrm{mo}, 385 \mathrm{pp}$. Cloth . . . . . . 75 cents

A suggestive outline of great compactness. Each country is treated by itself, and the United States receives special attention. Frequent maps, contemporary events in tables, references to standard works for fuller details, and a minute index constitute the "Illustrative Apparatus." The style is surprisingly vivid and at times even ornate.

\section{FISHER'S OUTLINES OF UNIVERSAL HISTORY". \\ $8 \mathrm{vo}, 690 \mathrm{pp}$. Cloth . . . . . . . $\$ 2.40$}

This work, designed as a text-book and for private reading, is a clear and condensed narrative, brought down to the present year, comprising not only a record of political events, but also a sketch of the progress of literature, art and science from the beginning of history to the present time.

BARNES'S GENERAL HISTORY OF THE WORLD. r2mo, $600 \mathrm{pp}$. Cloth . . . . . \$1.60

A complete outline of the world's history. Some of the prominent features comprise: blackboard analysis; summaries to assist in review ; lists of reading references: colored maps; scenes in real life : chapters on civilization; genealogical tables; foot-notes; chapters devoted to the rise of modern nations.

The pupil insensibly acquires a taste for historical reading and forgets the tediousness of the ordinary lesson in perusing the thrilling story of the past..

\section{APPLETONS' SCHOOL HISTORY OF THE WORLD.}

$$
\text { 8vo, 49I pp. Cloth . . . . . . } \$ 1.22
$$

From the earliest ages to the present time. A clear, fresh, carefully arranged and condensed work, beautifully illustrated. It treats ancient civilization in the light of the most recent discoveries. The whole history of the past condensed into a moderate-sized volume that can be readily mastered in the ordinary school year.

Copies of these or any of the pubitications of the Anerican Book Company for the use of teachers or school officers, or for examination with a view to intro duction, will be sent by mail, postpaid, on receipt of the list or introduction price.

\section{AMERICAN BOOK COMPANY,}
$\left[{ }^{*} 39\right]$
NE
CINCINNATI $\therefore$
CHICAGO. 


\section{Ancient History.}

BARNES'S BRIEF HISTORY OF ANCIENT PEOPLES. $12 \mathrm{mo}, 340 \mathrm{pp}$. Cloth

In this work the political history is condensed to the salient and essential facts in order to give room for a clear outline of the literature, religion, architecture, character, habits, etc., of each nation.

FISHER'S ANCIENT HISTORY.

8 vo, 200 pp. Cloth. . . . . . \$1.00

Comprising Part I. of Outlines of Universal History. Designed as a textbook and for private reading. Divided into five periods, from the beginning of authentic history to the migrations of the Teutonic tribes.

THALHEIMER'S ANCIENT HISTORY.

$8 \mathrm{vo}, 365 \mathrm{pp}$. Cloth, illustrated

From the earliest times to the fall of the Western Empire, A.D. ${ }_{476}$. This $^{\mathrm{i}}$ work aims to place the leading characters and events of antiquity in a clear light. THALHEIMER'S EASTERN MONARCHIES.

$8 \mathrm{vo}$, IO3 pp. Cloth

Part I. of ancient history. This embraces the pre-classical period 80 cents of Persian ascendency.

BARNES'S BRIEF HISTORY OF ROME.

I2 mo, $300 \mathrm{pp}$. Cloth, illustrated

$\$ 1.00$

With select readings from standard authors on the plan of "Brief History of Greece." It affords a very good idea of the history of the great Roman Empire. CREIGHTON'S HISTORY OF ROME. (History Primer Series.) I $8 \mathrm{mo}$, I27 pp. Flexible cloth. . 35 cents

A brief epitome of Roman History, for use as a text-book or for reference. THALHEIMER'S HISTORY OF ROME.

$8 \mathrm{vo}, 365 \mathrm{pp}$. Cloth . . 80 cents

Part III. of Ancient History. The history of Rome as kingdom, republic, and empire. Illustrations and colored maps.

TIGHE'S ROMAN CONSTITUTION. (History Primer Series.)

I8mo, I3I pp. Cloth . 35 cents

A brief and compact work on the history of Rome. Valuable as a text-book where but little time can be devoted to the subject, or as a book of reference. BARNES'S BRIEF HISTORY OF GREECE.

I2mo, $204 \mathrm{pp}$. Cloth, illustrated

This contains the chapters on the Pollti. . 75 cents in Barnes's Brief Histor. of Ancient Peoples, tor and Civilion of Greece selections.

FYFFE'S HISTORY OF GREECE. (History Primer Series.)

$18 \mathrm{mo}$, $127 \mathrm{pp}$. Flexible cloth . . 35 cents

A short and compact epitome of Grecian History. Designed either for us $\epsilon$ as a text-book or as a book of rcference.

MAHAFFY'S OLD GREEK LIFE. (History Primer Series.)

I8mo, roI pp. Flexible cloth. .35 cents

This book contains chapters on the general featur $\epsilon$ s of the Greek nation. the men and their property; tlee Greek at home; public life of the Greek citizen, and Greek religion and law.

THALHEIMER'S HISTORY OF GREECE.

$8 \mathrm{VO}, 243 \mathrm{pp}$. Cloth 80 cents

Part II. of Ancient History. This embraces Greece and the Macedonian Empires. Illustrations, colored maps, etc.

Copies of these or any of the publications of the A merican Book Company for the use of teachers or school officers, or for examination with a view to intro. duction, will be sent by mail, postpaid, on receipt of the list or introduction price.

\section{AMERICAN BOOK COMPANY,}

NEW YORK $\therefore$ CINCINNATI $\therefore$ CHICAGO. 


\title{
P R I M E R S
}

\section{IN SCIENCE, HISTORY, AND LITERATURE.}

\author{
Flexible cloth, $18 \mathrm{mo} .35$ cents each.
}

\section{SCIENCE PRIMERS.}

Edited by Professors IUXLEY, ROSCOE, and BALFOUR STEWART.

Introductory. Prof. T. H. HuXI.ex, F.li.s.

Chemistry. Prof. H. E. Roscoe, F.R.S.

Phvsics. Prof. Balfodr Stewart, F.li.s.

Physical Geography. Prof. A. GeIKIE, F.R.S.

Geology. Prof. A. Geinie, F.R.S.

Natural Resources of the United States. J. H. PATTuN, A.M.
Physiology. M. Foster, M. D., F.R.S. Hygiene. R. S.'TRACY. Astronomy. J. N. LoCKYER, F.R.S. Botany. SIr J. D. HonkE. F.R.s. Logic. Prof. W. S. JeVons, F.R.S. Inventional Geometry. W. G. SPENCER.

Pianoforte. Frankin TaYlor.

Political Economy. Prof. W. S. JEvoss, F.R.S.

\section{HISTORY PRIMERS.}

Edited by J. R. GREEN, M.A., Anthor of "A Slort History of the English People," etc.

Greece. C. A. Frffe, M.A.

Rome. M. Creighton, M.A.

Europe. E. A. FREEMAN, D.C.L.

Old Greek Life. J. P. MaHAFFr, M.A.

Roman Antiquities. Prof. A. S. iliLins.
Geography. GEORGE GHOVE, F.R.G.S.

France. Chariotte M. Yunge.

Mediæral Civilization. Prof. G. B. ADA ME:

Roman Constitution. Aмвrose Tighe.

\section{Egypt. F. C. H. Wendel, A.M, Ph.D.}

\section{LITERATURE PRIMERS.}

American Literature. Milmed CABELL WaTKINS.

Enulish Literature. Rev. STopFORD A. BRoKE, M.A.

Classical Geography. M. F. Tozkis.

Shakspere. Prof. E. Downex.

Studies in Bryant. J. Ai.Dex.

Greek Literature. Prof. R. C. JEBB.
English Grammar. R. Morris, LI..W.

English Grammar Exescises. R. Morilis, LL.D., and H. C. BuTEN, M.A.

Philology. J. Peile, M.A.

Homer. Right Hon. W. E. (ilaD-TONF.

English Composition. Prof. J. IICHoL.

The object of these primers is to convey instruction in such a manner as to make it both intelligible and interesting to very young pupils, and so to discipline their minds as to incite them to more systematic after-studres.

AMERICAN BOOK COMPANY, Publishers, 


\section{ENGLISH LITERATURE.}

\section{Brooke's English Literature.}

By Rev. STOPford BROOKE, M.A.

Flexiole cloth, 18mo. 226 pages, . . . . . . . . . \$o.35

New edition, revised and corrected. A complete, condensed handbook of English Literature, with an appendix on American Literature.

\section{Cleveland's Literature Series.}

By Charles Dexter Cleveland.

Compendium of English Literature. Cloth, 12mo. 800 pages, . . . \$1.75

Enylish Literature of the roth Century. Cloth, 12mo. 800 pages, . . 1.75

Compendim of American Literature. Cloth, 12mo. 784 pages, . - $\quad$ r.75

\section{Gilman's First Steps in English Literature.}

By Arthur Gilman, M.A.

Cloth, 18mo. 233 pages, . . . . . . . . . . . \$u.60

\section{Gilmore's English Larguage and Its Early Literature.}

By J. H. Gilmore, M.A.

Cluth, izmo. 133 pages, . . . . . . . . . . . \$o.6o

It contains a topical abstract of the English Language and its Early Literature, with a brief summary of American Literature.

\section{Smith's Literature Series.}

By M. W. SMITH, M.A.

Elements of English. Cloth, r2mo. 232 pages, . . . . . . \$o.6o Studies in English Literature. Cloth, 12mo. 427 pages, . . . . 1.20

The first book of this Series is preparatory and treats of the Fnglish Language as a whole and of the features which constitute good literature. The second contains a history of English literature from the earliest times, with complete selections from the works of the five great founders of English Literature: Chaucer, Spenser, Shakespeare, Bacon, and X!ilton.

\section{Watkins's American Literature.}

By Mildrei Cabeli Watkins.

Fle rible cloth, r8mo. 224 pares, . . . . . . . . . \$ \$ . . . . . . 35

A simple, practical text-book on original lines for the study of American Literature in schools.

\section{SUPPLEMENTARY BOOKS FOR THE STUDY OF LITERATURE.}

Alden's Studies in Bryant. Flexible cloth, i2mo. 127 pages, . . . \$0.35

Cathcart's Literary Reader. Cloth, 12mo. 541 pages, . . . . I.15

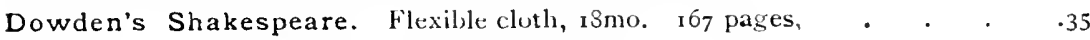

Gladstone's Homer. Flexible cluth, ismo. 153 pages, . . . . $\quad .35$

Guerber's Myths of Greece and Rome. Cloth, I2mo. $43^{8}$ pages. Illustrated, 1.50

Jebb's Greek Literature. Flexible cloth, 18mo. 166 pages, . . • $\quad 35$

McGuffey's Literary Reader. Revised edition. Cloth, 12mo. 479 pages, .85

Shepherd's Historical Readings. Cloth, 12mo. 424 pages, . . . 1.00

Skinner's Readings in Folklore. Cloth, 12mo. 448 pages, . . . $1 . \infty$

Skinner's Schoolmaster in Literature. With an Introduction by Edward

Eysleston. Cloth, 12mo. Go8 pages, . . . . . . . . 1.40

Copies of any of the above-named books will be sent, prepaid, to any address on receipt of price by the Publishers.

New York $\quad$ Cincinnati $\quad$ Chicago




\section{Eclectic English Classics for Schools.}

This series is intended to provide selected gems of English Literature for school use at the least possible price. The texts have been carefully edited, and are accompanied by adequate explanatory notes. They are well printed from new, clear type, and are uniformly bound in boards. The series now includes the following works:

Arnold's (Natthew) Sohrab and Rustum . . . . \$o.20

Burke's Speech on Conciliation . . . . . . . - -

Coleridge $\mathrm{s}$ Rime of the Ancient Mariner . . . . . . -

Defoe's History of the Plague in London . . . . . .40

DeQuincey's Revolt of the Tartars . . . . . . . . $\quad .20$

Emerson's American Scholar, Self-Reliance, and Compensation . $\quad .20$

George Eliot's Silas Marner . . . . . . . . . 30

Goldsmith's Vicar of Wakefield . . . . . . . . 35

Irvin ’'s Sketch Book-Selections . . . . . . . . . . . . . .

Tales of a Traveler . . . . . . . . . 50

Macaulay's Second Essay on Chatham . . . . . . . .20

Essay on Milton. . . . . . . . . .20

Essay on Addison . . . . . . . . . . 20

Life of Johnson . . . . . . . . . . . . -

Milton's L'Allegro, Il Penseroso, Comus, and Lycidas . . .20

l'aradise Lost-Books I. and II. . . . . . . .20

Pope's Homer's Iliad, Books I., VI., XXII. and XXIV. . . -

Scott's Ivanhoe . . . . . . . . . . . . .50

Marmion . . . . . . . . . . . . . . . . . . .

Lady of the Lake . . . . . . . . . . . . . . . . . .

The Abbot . . . . . . . . . . . . . . . . . . . .

Woodstock . . . . . . . . . . . . . . . . . . . .

Shakespeare’s Julius Ciesar . . . . . . . . . . . . . .

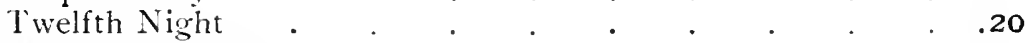

Merchant of Venice . . . . . . . . . . . . . . . . . . . .

Midsummer-Night's Dream . $. \quad . \quad . \quad . \quad$. $\quad . \quad$. 20

As You Like It . . . . . . . . . . . . . . . . .

Macbeth . . . . . . . . . . . . . . . . .

Hamlet . . . . . . . . . -

Sir Roger de Coverley Papers (The Spectator) . . . . $\quad .20$

Southey's Life of Nelson . . . . . . . . . . -

Tennyson's Princess . . . . . . . . . . . . -

Webster's Bunker Hill Orations . . . . . . . . .20

Copies of any of the Eclectic English Classics will be sent, prepaid, to any address on receipt of the price by the Publishers:

\section{American Book Company \\ New York - Cincinnati • Chicago}


$\Rightarrow$ 
- 

